\title{
Injury risk in downhill skiing : results from an etiological case-control study conducted among Dutch skiers
}

Citation for published version (APA):

Bouter, L. M. (1988). Injury risk in downhill skiing : results from an etiological case-control study conducted among Dutch skiers. [Doctoral Thesis, Maastricht University]. De Vrieseborch.

https://doi.org/10.26481/dis.19880909lb

Document status and date:

Published: 01/01/1988

DOI:

10.26481/dis.19880909lb

Document Version:

Publisher's PDF, also known as Version of record

Please check the document version of this publication:

- A submitted manuscript is the version of the article upon submission and before peer-review. There can be important differences between the submitted version and the official published version of record.

People interested in the research are advised to contact the author for the final version of the publication, or visit the DOI to the publisher's website.

- The final author version and the galley proof are versions of the publication after peer review.

- The final published version features the final layout of the paper including the volume, issue and page numbers.

Link to publication

\footnotetext{
General rights rights.

- You may freely distribute the URL identifying the publication in the public portal. please follow below link for the End User Agreement:

www.umlib.nl/taverne-license

Take down policy

If you believe that this document breaches copyright please contact us at:

repository@maastrichtuniversity.nl

providing details and we will investigate your claim.
}

Copyright and moral rights for the publications made accessible in the public portal are retained by the authors and/or other copyright owners and it is a condition of accessing publications that users recognise and abide by the legal requirements associated with these

- Users may download and print one copy of any publication from the public portal for the purpose of private study or research.

- You may not further distribute the material or use it for any profit-making activity or commercial gain

If the publication is distributed under the terms of Article $25 \mathrm{fa}$ of the Dutch Copyright Act, indicated by the "Taverne" license above, 
Sportwetenschappelijke Onderzoekingen 14 Injury risk in downhill skiing

Uitgeverij De Vrieseborch - Haarlem 


\section{Injury risk in downhill skiing}

results from an etiological case-control study conducted among Dutch skiers

\section{proefschrift}

ter verkrijging van de graad van doctor aan de Rijksuniversiteit Limburg te Maastricht, op gezag van de Rector Magnificus, Prof. Dr. F.l.M. Bonke, volgens het besluit van het College van Dekanen, in het openbaar te verdedigen op vrijdag 9 september 1988 om 14.00 uur

door

Lex Marius Bouter geboren te Rotterdam in 1956 
Promotor: prof. dr. P.G. Knipschild

Beoordelingscommissie:

prof. dr. H. Philipsen

prof. dr. F. ten Hoor

prof. dr. H.C.G. Kemper

prof. dr. G.J. Kok

dr. F.T.J. Verstappen 
De publikatie van dit proefschrift werd mede mogelijk gemaakt door een bijdrage van de Nederlandse Ski Vereniging

CIP.GEGEVENS KONINKLIJKE BIBLIOTHEEK, DEN HAAG

Bouter, Lex Marius

Injury risk in downhill skiing: results from an etiological case-control study conducted among Dutch skiers / Lex Marius Bouter. - Haarlem : De Vrieseborch. III. - (Sportwetenschappelijke onderzoekingen ; 14)

Proefschrift Maastricht. - Met lit. opg.

ISBN 90-6076-272-X

SISO 618.12 UDC [614.8;796.92](043.3) NUGI 468

Trefw: ski-ongelukken; onderzoek.

(C) 1988 L.M. Bouter

Omslagontwerp: Jan Eggen - Maastricht

No part of this book may be reproduced in any form, by print, photoprint, microfilm or any other means, without written permission from

Uitgeverij De Vrieseborch

Jacobiinestraat 5

2011 TG Haarlem

the Netherlands

ISBN $906076272 x$ 

Chapter 2: Risk factors for ski injuries: a crash course of epidemiologic methods with emphasis on conparability in experiments and case-control studies

Chapter 3: Ability and physical condition in relation to injury risk in downhill skiting

Chapter 4: Characteristics of ski and binding in relation to injury risk in downhill skiling

Chapter 5: Personal and envirommental factors in relation to injury risk in downhill skiling

Chapter 6: Alcohol consumption and injury risk in downill skiing

Chapter 7: Sensation seeking and injury risk in downhi1 ski ing

Chapter 8: The etiology of injury in downill sking: reviev of the literature

Chapter 9: Discussion

Summary

Samenvatting

Woord van dank 
CHAPTER 1

INTRODUCTION

The central subject of this dissertation is the etiology of injury in downill sking. Although the relevance of this subject to the prevention of ski injuries is self-evident, the main interest is in the determinants of injury risk themselves. Consequently this dissertation does not end with a number of guidelines for legislation and health education, although some hints for future prevention are given along the way. The principal aim of the research project described in the following chapters is the dissection of the causal network. Special attention will be given to methodological considerations comnected to epidemiological studies into the etiology of injury in general.

As often, the starting point of the study was rather trivial. Being an enthusiastic skier, but not exactly fond of helicopter flights to an emergency ward, the author, as a brand-new epidemiologist, started wondering during the summer of 1984 what was really known about the risks of downhill skilng. Under the influence of animated discussions with the other members of the Department of Epidemialogy of our university, this question gradually became more pressing. The former victims of a ski injury among our acquaintances appeared to have especially strong opinions on the subject.

Consultations with an expert ${ }^{1}$ in the field learned us that every year some 900,000 skiers leave the Netherlands for about 10 days to practise their winter sports somewhere in Europe, mostly in Austria, the majority of them (70\%) for downill skilng. Estimates of the incidence of injury appeared to have a wide range, but an educated guess of $5 \%$ seemed reasonable. We were surprised by these large numbers. Even more surprising was the discovery that most preventive recommendations appeared to be based on a mixture of plausibility, casuistry and prejudice. 
Empirical studies that permit conclusions with respect to the quantitative contribution of the most important risk factors were almost completely lacking. The results of the initial search of the literature vere formulated in a review published in a Dutch journa1 ${ }^{2}$.

Motivated by the lack of well-designed studies in the international literature and the fact that Dutch skiers had never been studied before, decided to conduct a case-control study among Dutch skiers during the 1984-1985 winter sports season. Practical and financial support was given immediately by the organization to which the expert ${ }^{3}$ whom we consulted at an earlier stage of the project belonged. Cases and controls were provided by an insurance company 4 associated with this organization and covering roughly one third of the Dutch market for ski insurance. It appeared that reliable information on the total population insured for the risk of skiling by this company was not avallable. Therefore the control group could not consist of a random sample of this population. Instead we formed a control group consisting of insured skiers without ski injury who claimed for other reasons (e.g. loss or theft). The methodological consequences of this choice are discussed below, especially in chapters 2 and 9. Conforming to the wish of the sponsors of our study, we published a preliminary report ${ }^{5}$ of its results with respect to downhill skiing in December 1985 . In this report ${ }^{5}$ also the questionnaire we used in our case-control study was published. Data on cross-country skilng were excluded from the analysts for the sake of homogeneity.

From January 1986 we worked on a more sophisticated analysis of the same data. This consisted essentially of a more precise estimation of the independent contribution to the injury risk of a number of separate risk factors of interest. Roughly this analysis led to the same conclusions as formulated in the preliminary report. During the summer of 1986 the majority of the respondents of our study received a second questionnaire. This new study tried to elucidate the question whether injured skiers differ from uninjured skiers in risk taking behavior. Financial 
support for this study was received from a regional institute ${ }^{6}$. In 1987 and the first half of 1988 the results of our original case-control study and the second questionnaire were presented at several international scientific conferences ${ }^{7}$. During the same period a number of articles on the subject appeared in Dutch sclentific journals 8 .

Yet the bulk of our data has been presented in articles submitted to international journals ${ }^{9}$. These articles are reproduced as chapter 2 to 8 of this dissertation. One of these (chapter 7) has already been printed, three of them (chapter 2,3 and 4 ) have been accepted for publication, and the others (chapter 5, 6 and B) have been submitted for publication. Before our study a review of the relevant 1 terature was witten and published in a Dutch journal ${ }^{10}$. In this dissertation the available empirical data on risk factors for ski injury is reviewed in the chapters dealing with separate categories of risk factors (chapters 3, 4, 5, 6, 7). At the end of the research project the earlier owerall review of the etlology of injury in downhill skiing was rewritten, including the results of recent studies done by others and of our own study. This article is included in this dissertation as chapter 8.

Some overlap between the chapters is unavoidable. For instance, the section on material and methods and some of the remarks on the validity of the study are repeated several tines. This has the advantage that the chapters can be read separately without consulting other parts of the dissertation. A disadvantage is that readers of the integral text might become slightly bored in some instances.

Chapter 2 deals with the methological considerations when designing an epidemiological study on the risk factors for ski infury. Chapter 3 presents our results on ability and physical condition as risk factors. Chapter 4 deals with the risks associated with several characteristics of ski and binding. In chapter 5 the putative personal and environmental risk factors we studied are presented in detail. Chapter 6 presents our data on 
alcohol consumption. Furthermore, this chapter 11 lustrates by means of statistical modelling the potential biases in our data on alcohol consumption. Chapter 7 describes the results from our second questionnaire on risk taking behavior. Chapter 8 reviews the literature on the etiology of injury in downhill skiting, including our own results. Chapter 9 contains a discussion of our findings against the background of available empirical data. Furthermore, attention is drawn to the methodological limitations of non-experimental studies of injury risk. The English part of this dissertation ends with a summary. It is followed by a summary, some acknowledgements and a curriculum vitae in Dutch. 
NorES.

1. R.E. de Groot, head of the inter sports department of the General Dutch Association of Cyclists (ANWB), nowadays primarily an organization of motorists.

2. L.M. Bouter \& P.G. Knipschild. Risicofactoren van skiletsel: een Ifteratuuroverzicht. Tijdschrift voor Sociale Gezondheldszorg 63 (1985) 846-851.

3. See note 1 .

4. Unigarant.

5. L.M. Bouter \& P.G Knipschild. Skirisico's: eerste versllag van epidemiologisch onderzoek bij Nederlandse skiërs.

Rijksuniversiteit Limburg, Maastricht, 1985.

6. Institute for Sports Medicine of Limburg (ISL).

7. - Sport for al1: Sports Injuries and their Prevention. Second meeting of the Council of Europe seminar, Arnhem, the Netherlands, 1987 .

- 7 th International Symposium on Ski Trauma and Skilng Safety. International Society for Skilng Safety, Chamonix, France, 1987.

- 8th International Conference of the International Society for Clinical Biostatistics, Gothenburg, Sweden, 1987.

- 18th Congress of the Internationale Gesellschaft für SkiTraumatologie und Wintersportmedizin, Courmayeur, Italy, 1988.

B. - L.M. Bouter \& P.G. Knipschild. Skirisuco"s. Tijdschrift voor Sociale Gezondheidszorg, 64 (1986) 273.

- L.M. Bouter. Spanningsbehoefte en ongevalsrisico bij sportbeoefening. Geneeskunde en sport 19 (1986) 205-208.

- L.M. Bouter \& P.G. Knipschild. Spanningsbehoefte en ongevalsrisico bij skiers. Tijdschrift voor Sociale Gezondheldszorg 65 (1987) 187 .

- L.M. Bouter, P.G. Knlpschild \& A. Volovics. Risicofactoren voor skiletsel samenhangend met ski en binding. Tijdschrift voor Sociale Gezondheidszorg 66 (1988) 4: WEON XIV p. $28-29$. 
9. - P.G. Knipschild \& L.M. Bouter. Risk factors for ski injury: a crash course of epidemiological methods with emphasis on comparability in experiments and case-control studies. Accepted for publication in: R.J. Johnson \& C.D. Mote (eds.), Skiing trauma and safety, Philadelphia, ASTM.

- L.M. Bouter, P.G. Knipschild \& A. Volovics. Ability and physical condition in relation to injury risk in downhill skiting. Accepted for publication in: R.J. Johnson \& C.D. Mote (eds.), Skiling trauma and safety, Philadelphia, ASTH.

- L.M. Bouter, P.G. Knipschild \& A. Volovics. Characteristics of ski and binding in relation to injury risk in downhil skiing. Accepted for publication in the American Journal of Sports Medicine*

- L.M. Bouter, P.G. Knipschild \& A. Volovics. Personal and environmental factors in relation to injury risk in downhill skilng. Submitted for publication.

- L.M. Bouter, A. Volovics and P.G. Knipschild. Alcohol consumption and injury risk in downhill skiling. Submitted for publication.

- L.M. Bouter, P.G. Knïpschild, J.A. Feij \& A. Volovics. Sensation seeking and injury risk in downill skiling. Personality and Individual Differences 9 (1988) 667-673.

- L.M. Bouter \& P.G. Knipschild. The etiology of injury in downhill sking: review of the literature. Subaitted for publication.

10. See note 2 . 
CHAPTER 2

\section{RISK FACTORS FOR SKI INJURIES}

A Crash Counse of Epidemiologic Methods with Emphasis on Comparability in Experiments and Case-Control Studies*

Paul G. Knipschild \& Lex M. Bouter

* Accepted for publication in R.J. Johnson \& C.D. Mote (eds.) Skling Trauma and Safety. Philadelphia, ASTM. 


\section{ABSTRACT}

The incidence rate of ski injuries should be studied as a function of its risk factors. Epidemiologic studies into this matter are very complicated. Central issues are comparability of baselime prognosis, comparability of measurements (effects in cohort studies and risk factors in case-control studies), and comparability of external circumstances. In experimental studies this may be achieved by randomisation, blinding and placebo intervention. The main tools in non-experimental studies to prevent incomparability are deliberate selection and multivariate analysis: An outline is given of the design of experimental studies with increased efficiency. As for case-control studies, special attention is paid to the definition of the source population and possible ways to reduce measurement incomparability. The text provides many examples related to putative ski injury risk factors. 
Epidemlology is not restricted to epidemics of infectious diseases. The present scope is much broader. Mowadays epidemiology deals with the occurrence of all sorts of defects and diseases, such as congenital malformations, cancers, dementia and also injuries, including ski injuries. Studying the mere occurrence of these injuries is rather boring. often, it is more exciting to study the occurrence of ski injuries as a function of its determinants .

This contribution deals with epidemiologic methods to study the etiology, 1.e. risk factors of ski injuries. Special attention will be paid to the theoretical background of useful study designs. It may be seen as a crash course, because it is impossible to discuss in one paper what other epidemiologists have devoted whole books to.

Firstly, some remarks are made on the definition of a ski injury and the difference between prevalence and incidence. Secondly, the rationale behind epidemiologic studies into the determinants of ski injury incidence is given. Thirdly, the concept of comparability is explained, starting from the conventional randomised double-blind placebo-controlled experiment, and suggestions are given to increase its efficiency. Fourthly, because experimental studies are not feasible in many situations, an introduction is given to the design of non-experimental studies, with the same emphasis on comparability special attention is paid to the design of case-control studies. Finally, the problems of incomparability of measurements in case-control studies are discussed.

\section{OCCURRENCE}

It is surprising to see how often the occurrence of ski injuries is discussed without any clear definition. It $\mathbb{1} s$ time, therefore, for ski injuries to be defined in a way that is logical, understandable and acceptable to all people who are interested in the epidemiology of these injuries. 
our description would be the following: It must evidently concern an injury that is received during skiling. It is impossible to sustain a ski injury in a hotel, even when one slips on the door-mat during a ski holiday. The consequences of an accident on the way to or back from the ski run cannot contribute to the occurrence as well. Slipping in a ski lift or being hit by a skier on the ski run are included in the determinants of ski injuries. It makes sense to list all potential ski injury situations and then see how much agreement there is among experts.

It is also necessary to be specific on what is called an injury. If the definition of an injury is too broad, including every scratch or haematoma, then no skier escapes injury. A statement that ski injuries occur in $100 \%$ of all skiers has no value. Our description of an injury would be stricter: all fractures and luxations, and those other injuries which require medical control. The latter include many ligament injuries, such as "ski thumb" and "ski knee", but also concussion of the brain and significant lacerations (i.e. those requiring sutures). Again, it makes sense to list all ski injuries which need to be seen by a health care professional and then study the degree of agreement among experts. We are not very happy with a definition which is used quite often in the literature, namely that a ski injury must restrict the victim's activities for a certain period (for instance, a day or more). When ski injuries are counted, of course it remains useful to distinguish subcategories according to location, severity and so on.

To sum up, ski injuries are recelved during skilng and medical control is necessary. Registration of ski injuries at the medical centre in a ski resort leads to underreporting. Not all necessary medical control takes place, whereas some control takes place elsewhere. Investigators of the occurrence of ski injuries should complete their registration ith the help of additional questionnaires. This calls for studies into the validity of these questionnaires in terms of sensitivity (underreporting, once again) and specificity (owerreporting). 
When a person has more than one ski injury, he or she is preferably counted as one injured person. Counting the number of injured persoris is rather meaningless when there is no knowledge of the reference population. It is better to study the occurrence as a fraction ith a numerator and a denominator: the number of (persons whit) ski injuries in a certain population. This opens the possibility to compare the occurrence rate between groups of skiers, for instance at different times, between areas and among groups ith different characteristics.

So far, the word "occurrence" has been used in this paper. It has two time-related meanings and so it is necessary to distinguish between prewalence and incidence. Prevalence concerns the number of existing ski injuries at a certain point in time. For example, one may wonder how many skiers have a weak ankle due to a ski injury in the past. When the occurrence of ski injuries is discussed, nearly always incidence is meant: the number of new ski injurtes in a certain period of time. Strictly speaking, incidence can only be studied in a population which has a $0 \%$ prevalence of (that) ski injury. It is the rate (speed) with wich ski injuries arise in a population at risk. This incidence rate is best expressed as injurles per hour of skilng. Then the assumption is made, however, that the incidence is constant over the first, second and later hours. A measure used quite often in the literature is the number of (new) ski injuries per 1000 ski person days. Comparisons between groups are still valid now if it may be assumed that the number of ski hours per day is the same between these groups, at least on the average (e.g. 5 hours per day).

To be less abstract, it is perhaps desirable to translate the incidence rate for a group of skiers into the risk for an Individual skier. For instance, if the incidence rate of ski injuries is 3 per 1000 ski person days in a certain population, this implies a $3 \%$ risk when the holiday consists of 10 days of skiling. People on a ski holiday for one week run a $2 \%$ risk and those who go for a fortnight of ski pleasure expose themselves to a $4 \%$ risk of a ski injury. This, again, is an average among 
members of a group of skiers. Hithin that group, there may be large differences between subgroups with certain risk factor levels .

\section{RISK FACTORS}

There is no single disease which is determined monocausally. of course, some diseases occur only when a certain risk factor is present (e.g. tuberculosis), but even then other factors play a very important role. As to ski injuries, the situation probably is very complicated. Potential risk factors can be subdivided into many categories, such as skill, physical condition, social habits, psychological profile, ski equipment and the ski run enviromment. Within the latter category, for example, it is useful to distinguish between degree of difficulty, crowdedness, sight, temperature, snow conditions, etc. The many potential risk factors are, moreover, interrelated. This implies that studying the separate contribution of a certain risk factor to the level of the ski injury incidence is far from easy, even more so if the study is after the attributable risk in a quantitative sense. It is questionable whether this puzzle can ever be solved completely.

Untroubled by this complicatedness some so-called experts pour out a large number of recommendations concerning the skier. These are often based on a mixture of plausibility, casuistry and prejudice. Sometimes a quasi-empirical reasoning is giwen to stress the importance of certain preventiwe measures. For instance, suppose the "bad" habits of 100 persons wh a ski injury are scored at the medical centre of a ski resort, and it appears that one in three has enjoyed a very pleasant evening the day before, including a more than moderate alcohol consumption; this, of course, does not mean that one in every three ski injuries is caused by alcohol. It is possible that one in every three skiers ho has received no injury also had a party the night before. A second relatively frequent fallacy is the following: Differences in the ski injury jncidence at an 
aggregated level are translated too easily to the individual level. For example, the incidence of ski injuries appears to have decreased in the seventies. In the same period an increasing number of educational brochures and booklets has been published. This does not necessarily mean that education has reduced the incidence. The improvement of ski equipment and of the ski run envitronment during the same period might be a better explanation.

Unravelling the causes of ski injuries is only possible with good empirical studies. Partly, these may be performed in the comfort of a laboratory, but in the end the answer is in the field. There, the plausibility of ideas generated in the laboratory should be tested further. If a strong association is found repeatedly, under different circumstances, between a risk factor (e.g. binding adjustment) and certain ski injuries (e.g. lower extrenity equipment-related), this not only points to causality, but also quantifies the impact of this risk factor.

At the moment, the knowledge of many putative risk factors for ski injuries is sparse. In performing epidemiologic studies two ways are open: experimental and non-experimental studies.

\section{EXPERIMENTAL STUDIES}

Characteristic of experimental studies is that the investigator interwenes in one (or more) putative risk factor(s) and then observes whether and to what extent this intervention changes the incidence. To measure a change, the incidence needs to be known in the situation where the manipulated risk factor is in fact not a risk factor - to put it differently, the incidence "under the null hypothesis". To measure this baseline incidence, one might observe the incidence twice in a group of the same persons who are subsequently exposed and not exposed to the intervention under study. For ski injury research this is not feasible, partly because an injury in the first study period makes sikiers unsuitable to participate in the second study period. A solution to this problem is to observe two groups at the same time: an 
intervention group and a control group; the latter not being manipulated or manipulated in a different way. It is very important now to have comparability of baseline prognosis. The groups who are to be contrasted should only differ prognostically as far as the intervention changes the incidence. Suppose, for instance, one wants to study the effect of ski lessons on the incidence of ski injuries; it is likely that ski lessons are more often taken by skiers with less experience, and that people with little experience run an increased injury risk. It is not valid now to compare the incidence of ski injuries in a group of people who have ski lessons, but who are also less experienced, with the incidence in a group of people who do not have ski lessons, but who also are more experienced. If the study goal is to see whether ski lessons prevent injuries, then the level of ski experience (and of all other risk factors) needs to be the same in both groups.

Analogously to a therapeutic experiment, a simple procedure to pursue this is randomisation. First, a "cohort" of skiers is defined and then subdivided into two (or more) subcohorts purely by chance. Next, one of the subcohorts is exposed to ski lessons and the other is not. Random allocation is performed to remove any judgement by the investigators or participants as to who will have ski lessons. By following this procedure it is hoped that the subcohorts are prognostically comparable with respect to the ski injury incidence, before the intervention takes place. When the subcohorts are large enough, it may be assumed that the level. of all unknown risk factors is the same as well as the distribution of known risk factors such as ski experience. An additional way to make the intervention and control group prognostically comparable is restriction. An epidemiologic study about ski lessons in relation to ski injuries might be restricted meaningfully to people without much ski experience.

A second point of attention is the comparability of (effect) measurements. Measuring the incidence in the intervention and the control group "by two standards" will invalidate the results. Of course, all effects of interest must be measured with the utmost 
precision, but there is limit to everything. In practice, sonetimes compromises are necessary for feasibility reasons, and one must be content ith only rough information about the effects. Then it is important that the efforts to discower effects are equally stenuous in both groups. It is better to have equally rough measurements in both than measurements which are, for instance, more precise in the control group than in the intervention group. Otherwise, incidence differences might be found which are related purely to differences in registration, whlle the intervention studied has no causal meaning in reality. As an example, take an investigation which is started to see whether people with badly adjusted ski bindings run an increased injury risk. Two groups with the same baseline prognosis are observed, one with badly adjusted and the other with well adjusted ski bindings. The design looks good, but investigators do have their prejudices. They may note a less serious injury more readily when it concerns a person with badly adjusted ski bindings, or they may consider an injury not new, but already existing, when it concerns a person with well adjusted ski bindings.

Analogously to a therapeutic experiment, this problem can be solved best by blinding. The investigator who gathers the information about the effects must be unaware whether it concerns a person with or without the putative risk factor, in this example with badly or well adjusted ski bindings. This can be achleved by having the effect measurements taken by someone who is not the main investigator. The former does not even need to know the specific study goal. A selfmevident supplement to blinding concerns the assessment, beforehand, of precise effect criteria. It must be stated in the study protocol how intensively the participating skiers are to be examined as to the presence of new ski injurles and which injuries are to be counted as such. When the participants need to be interviewed to complete the ski injury registration, it is desirable to blind them as well. In that case, the study is called double-blind. 
Comparability of baseline prognosis and of (effect) measurements makes the study internally valid. There still is, however, a third point of attention. It is important too to consider the independent consequences of the intervention on other risk factors. With respect to this, a distinction must be made between a purely scientific and a more pragmatic intervention study. If ve restrict ourselves to the scientific question whether a putative risk factor has a causal meaning, then it is necessary to assign all extra maneuvers which accompany the intervention to the control group as wel1. The intervention may introduce a change in other risk factors which do not belong to the direct causal chain. This lack of comparability of external circumstances may confound the association between putative risk factors of interest and effects. For instance, in an experiment to study whether warming-up exercises decrease the ski injury incidence, it is easily imaginable that good warming-up, under supervision or on the advice of a ski expert, also leads to an increased attention to other putative risk factors, such as the general physical condition, night's rest, alicohol consumption, etc. The control group who is deprived of good warming-up, does not get this extra attention. It is also possible that persons in the control group take some other preventive precaution, because they are not allowed to have their warming-up.

One solution to this problem is to compare the effect of two plausible sorts of warming-up with each other. If a comparison is needed between warming-up and no warming-up, the latter should be given as a placebo intervention, i.e. a dummy warming-up which can be assumed to have no bearing on the ski injury risk. This makes the external circumstances more comparable and also provides an opportunity to blind the participants and the person who performs the effect measurements.

Now that the principles of a blinded experiment have been explained, there remains the problem of feasibility. Randomisation, blinding and placebo-intervention which are the main tools to achieve comparability, are often not easy to perform due to ethical restrictions. Moreover, there is the 
problem of numbers. Published epidemiologic studies show that of every 100 people who return from their ski holiday, only a few have a ski injury. At that low incidence rate very large numbers of particlpants are needed to detect differences between skiers with different risk factor levels. For instance, it is thought that fitness training before the ski holiday decreases the injury risk among skiers who are in a bad physical condition, perhaps by as much as 50\%. In an experiment with no less than 500 participants, half having fitness training and half placebo training, the expected incidence rates per week ( 35 hours of skiing) $\mathbf{1} \mathbb{1}$ be about $2 \%$ and $4 \%$ respectively. Unfortunately, this difference is not statistically significant at alpha $=0.05$.

There are several ways to increase the "power" of a study. The number of particlpants can be augmented further, but it is difficult and expensive to perform an experiment with many thousands of participants (even if it is a multicenter trial, which also introduces new logistic problems). However, the incidence may be increased by selection of participants. An experiment about the effect of fitness training on ski injury risk could be restricted to group with an increased risk, e.g. beginners at a ski run for more experienced skiers (just for the sake of argument 1). With $2 \times 250$ skiers, this could lead to incidence rates of $10 \%$ and $20 \%$ per week (again with a risk ratio of 0.50 ) and there we have our beloved statistical significance.

There is also a second way to increase the incidence, namely by adopting - at least in the study - less strict criterlia for the effect parameter, in this case ski injuries. Less severe injuries, which do not require medical control, could be included. Nearly always, ski injuries are the result of a fall, but not every fall leads to an injury. The number of falls may be viewed upon as an indication of the (much lower) incidence of real injuries. The validity of this procedure depends also on the risk factor at issue. With respect to binding adjustment, for instance, the number of falls will not indicate injury risk validly, because binding adjustment is assumed to modify the risk per fall. of course, if falls are chosen as an effect parameter, 
clear criteria must be given beforehand as to which falls are to be counted as such. Similarly, it is very important to achieve comparability of effect measurements, for instance through blinding. If only a limited number of skiers can participate in an experiment, it may even be considered to include all near falls.

NON-EXPERIMENTAL STUDIES

With respect to many research questions concerning the etiology of ski injuries, it is impossible or preliminary to perform epidemiologic experiments because of ethical restraints and for reasons of feasibility. In that case the position may be taken that there is nothing left but to fall back to what is plausible in addition to what is learned from laboratory experiments. The alternative is to get involved in non-experimental studies (sometimes called "observational"). We think that these can indicate whether certain putative risk factors may be umportant and which risk factors must be studied further in an experimental design. of course, non-experimental studies are only informative if they are performed reasonably well, mimicking the basic ideas of comparability of experiments. Randomisation, blinding and placebo intervention are nothing more than (very powerful !) tools to achieve comparability. The main tools in non-experimental studies to prevent incomparability are deliberate sellection and multivariate analysis.

An experiment is a cohort study in which the investigator decides (although randonly) who is and who is not exposed to the risk factor under study. In an "observational." cohort study no intervention takes place and the investigator simply stands there beside the ski run to observe what happens to groups of skiers with certain characteristics, certain habits, under certain circumstances. In its simplest form the cohort is subdivided into two groups, with and without a certain risk factor of interest, all members of the cohort having no siki injury at the start of the study. Next, the incidence of ski injuries is measured in the 
contrasted groups. The difference or the ratio of the two incidence rates indicates the quantitative meaning of this risk factor in terms of etiology. Instead of studying two subcohorts, the experience of more groups can also be compared, when the putative risk factor is not dichotomous (e.g. men or women), but nominal (e.g. morning, early and late afternoon), ordinal (e.g. blue, red and black ski run), semi-continuous (e.g. number of alcoholic drinks a day) or continuous (e.g. body mass index).

Naturally, the several subcohorts should be prognostically comparable in relation to all other (external) risk factors. Where randomisation and placebo intervention cannot be executed, deliberate selection with respect to certain external risk factors can solve this prablem (e.g. restriction to beginners). An alternative is stmatification (e.g. combined analysis for beginners and more advanced skiers). Because there are probably many risk factors involved in the etiology of ski injuries, the confounding effect of all known external risk factors can only be adjusted for in a multivariate analysis. A weak spot of this statistical solution is that complete adjustment is not possible when there are external risk factors which are still unknown or which cannot be measured precisely. There is also the danger of overadjustment. For more detailed information about multivariate analys is techniques, such as logistic regression, the reader is referred to manuals of biostatistics.

There are no major ethical restraints to these "observational" studies and the investigator is not busy manipulating the participants. Therefore, cohort studies can often be performed with very large groups. For instance, in a cohort study 5000 (instead of 500) skiers could be studied, half of whom having fitness training before the ski holiday. In the example which was given in the section on experimental studies, this would lead to 50 ski injury victims anong the skiers with fitness training (2\%) and 100 victims in the referent group $(4 \%)$.

Much of the information on the association between fitness training and the incidence of ski injuries is found in only 150 
of all 5000 participants. Of these "cases", one in every three had fitness training. In the very large group of 4850 uninjured skiers about one in every two had fitness training. To estimate the frequency of fitness training among these "controls", data collection in a sample of, for example, 300 skiers would have given the same estimate of about $50 \%$ fitness training. In that case, only 450 study participants would have done the job. This last "trick" brings us to a very efficient study design, the so-called case-control study. For a fast and remunerative orientation as to which risk factors are associated with stei injuries, performing a case-control study seems to be the obvious way.

In an experimental or non-experimental cohort study the investigator starts by defining a study population of skiers who are candidates for receiving a ski injury (step 1). Within this population the level of all putative risk factors is recorded for every participant (step 2). Next, the incidence of ski injuries is measured in subpopulations with different risk factor profiles (step 3). In conformity with the logical sequence, first the putative causes and then the effects are recorded in the study population (cohort).

Also in a case-control study the investigator starts by defining a (source) population of skiers who are candidates likely to have a ski injury (step 1). Recording the risk factors is, however, postponed. One walts until cases of ski injury emerge from the source population. When the incidence is low (such as with ski injuries), a sample of controls is taken from the source population. So, the cases and controls are recorded first (step 2). Next, the risk factor profile in both groups is measured "retrospectively", i.e. going back to a moment preceding any sk1 injury, for instance, the moment of definition of the source population (step 3). This is not in conformity with the logical sequence, but for reasons of efficiency first the effects and then the putative causes are recorded in the source population. 
The first step in case-controlling is aften not mentioned explicitly in existing publications. It is, nevertheless, important to be fully aware which source population provides the cases. These must be restricted to those persons with new ski injuries for whom a source population can be defined reasonably well. At the same time, a sample of the same source population must be draw from persons who could have received a ski injury, but who have escaped it for one reason or another (associated with their risk factor profile ?). Uninjured skiers who are members of a different source population should not be included in the study.

Next, the risk factor profile of all cases and controls (within the source population) is to be measured "retrospectively". In a cohort study, the effects should be measured as comparably as possible, preferably blinded. In a case-control study the putatiwe causes are measured. Now the comparability of risk factor measurements has the highest priority. This also indicates a puzzling problem for case-control studies, because blinding is nearly impossible. Those who have received a ski injury are already known. It may even be that the level of some risk factors is changed due to the injury. If the choice fells on cases who have been coping with their injury for a long time already (so-called prevalent cases), the information collected may be "biased". For instance, it is thinkable that, in a case-control study about body weight in relation to ski infury incidence, cases with longer lasting ski injuries gain in weight because of theit inactivity. If the cases group consists mainly of skiers with "chronic" injuries and their weight (body mass index) is compared with the weight of a control group, a spurious association between body welght and ski injuries may be demonstrated. In a case-control study information should be collected shortly after the accident leading to ski injury, i.e. among incident cases and, of course, comparable controls. Direct measurements can only be taken of putative risk factors for which it may be assumed that any injury does not change their level immediately. Of course, incomparability of the measurements should be strenuously prevented. 
Whenever risk factors cannot be measured directly, participants in a case-control study must be interviewed. The interview should concern the risk factor profile immediately before the ski injury incident. It is easy now to blind the investigator gathering the information. A simple way to do this is by not having personal, oral interviews with the cases and controls, but to send theri a postal questionnaire. Preferably, this questionnaire is as structured as possible and contains only precoded questions. This prevents measurement incomparability by the investigator preparing the data analysis for the computer. If personal interviews are necessary, it is sometimes possible to hide the main study goals from the interviewers and the participants, but in practice this does not appear to be very successful and it still may lead to invalid information about external risk factors.

Where blinding fails, there only remains structuration of validated questionnaires. Now there is the problem whether the cases (and the controls) are willing to provide answers agreeing with reality to all questions. In general, people with a ski injury will recall the circumstances of the accident and their risky behavior relatively well. Maybe even too well, worried as they are why it all happened to them. Some of them even go and study the literature on ski injury prevention ! They may give socially desirable answers to please the investigator. This all calls for cases who are as "incident" as possible. On the other hand, some cases with an excellent memory will experience a sense of shame. Afraid as they are to be laughed at or to be addressed admonitorily, these cases may conceal. their risky behavior to some extent. For instance, in a study to see whether alcohol consumption is associated with a higher ski injury risk, people with a ski injury may recall their drinking habits very well, especially if they drank too much the night before theit accident. Some of them, however, may report a lower alcohol consumption because of a sense of shame. In general, people tend to $\mathbf{f 1 1}$ in postal questionnaires more honestly compared ith answering questions in a personal interview. 
In a case-control study the comparability of risk factor measurements is all-important. If the cases are interviewed in a certain way, the controls should be intervieved in exactly the same way. So every participant recelves a postal questionnaire, for example, with a standardized introduction and the same questionnaire as to length, lay-out, wording, etc. This, however, does not prevent incomparability completely. Suppose that the cases try very hard to recall everything the investigator wants to know and that they are willing to confess every "sin". Now, comparability of measurements is only attained when the controls can be motivated to do exactly the same. It is doubtful whether a random sample of the source population can be motivated as strongly as severely injured persons.

It may "therefore, be preferable to have a non-random, but deliberately selected control group. If the cases recall their ski holiday with mixed feelings, this calls for a control group with similar mixed feelings about their ski holiday. Following this idea of comparability, the controls might be selected among the skiers from the same source population who have been the victim of loss or theft. Of course, the assumption is made now that these victims as a group have a risk factor profile for ski injuries which is not different from that of the source population and therefore is "representative" in that sense. Choosing this control group also has the advantage that both cases and controls can be interviewed on a comparable basis about their risk factor profile immediately before their "accident", and that the non-response is equally low in both groups.

There exists a tendency among investigators to pay much attention to the measurement of risk factors of interest and little or no attention to the measurement of external risk factors. This is a mistake. In a non-randomised study the profile of these risk factors may be unequal for persons with and without the risk factors under study and, thus, may confound the association. Therefore, all external risk factors must be measured as validly and precisely as possible, and adjusted for properly to ensure comparability of baseline prognosis and of external 
circumstances. Everything that has been stressed about the comparability of risk factor measurements, can be repeated for putative "confounders". There are nany external risk factors in a study of the ski injury etiology and every one of these deserves careful attention in the data collection and data analysis. The number and range of the external risk factors may, however, be restricted by deliberate selection. For example, in a case-control study concerning the effect of night's rest on ski injury risk, the decision may be taken to make the analysis less complicated, by restricting the source population experience to good snow conditions. A disadvantage of this approach is that it is not possible anymore to study the effect of too little sleep on the ski injury risk conditional on certain snow conditions (so-called effect modification). It is thinkable that skiers who did not sleep too well only run an increased risk when the snow condition makes skiing more difficult.

A special case of deliberate selection is matching. Suppose that jit $t$ is known beforehand that a group of cases will contain twice as many females as males. (of course, the source population may have equal numbers of both, if the female/male risk ratio is two.) For efficiency reasons it may be a good idea to select twice as many female controls as well. A matched design, however, calls for a matched data analysis, but that is not a big problem with present methods of case-control data analysis. When cases and controls are matched on some risk factor, it is still possible to study effect modification by this risk factor as we11. However, the contribution of the matched risk factor to the injury risk cannot be studied anymore. Because of this and because of the danger of overmatching, only matching on age and gender may be considered and nothing more.

The Achilles" heel of "retrospectuve" case-control studies is the comparability of measurements of the risk factors of interest. effect modifiers included, and of all external risk factors which may confound any association of interest. Whenever possible, independent measurements must be taken as well. For instance, it would be of interest to do extra interviews with persons related to the cases and controls. Of course, these interviews should 
concern the risk factor profile of the cases and controls themselves in an attempt to study whether any association found is changed dramatically using these possibly less precise, but more comparable data. If independent records exist about certain risk factors, an attempt may even be made to go through these records. Case-controlling seems easy enough, but the more you think of it, the more its execution appears to be as difficult as an experiment.

\section{ACKNOWLEDGEMENT}

Many of the ideas in this paper were not developed by the authors, but by 011 S. Miettinen ${ }^{1}$ (McGill University, Montreal) and by Alvan R. Feinstein ${ }^{2}$ (Yale University, New Haven). For those who want to start a non-experimental epidemiologic study, we suggest the reading of Jennifer L. Kelsey's book. "This book also gives an introduction in data analysis. More advanced statistical methods can be found in the textbook of David G. KLeinbaum. 4 


\section{REFERENCES}

1. Miettinen, a.S., Theoretical Epidemiology: Principles of Occurrence Research in Medicine, John Wiley \& Sons, New York, 1985.

2. Feinstein, A.R. * Clinical Epidemiology: The Architecture of Clinical Research, W.B. Saunders Company, Philadelphia, 1985.

3. Kelsey, J.L., Thompson, W.D. and Evans, A.S., Methods in Observational Epidemiology, Oxford University Press, New York, 1986.

4. Kleinbaum, D.G., Kupper, L.L. and Morgenstern, H., Epidemiologic Research: Principles and quantitative Methods, Lifetime Learning Publications, Belmont, 1982. 


\section{CHAPTER 3}

ABILITY AND PHYSICAL CONDITION IN RELATION TO INJURY RISK IN DOWNHILL SKIING*

Lex M. Bouter, Paul G. Knipschild \& Alexander Volovics

* Accepted for publication in R.J. Johnson \& C.D. Mote (eds.) Skilng Trauma and Safety. Philadelphía, ASTM 
ABSTRACT

A case-control study was performed by way of a postal questionnaire among Dutch downhill skiers insured by a company covering one third of the market. Cases $(\mathrm{N}=572)$ were a sample of those who claimed medical costs because of a ski-injury that prevented them from skilng or other activities for one day of longer. Controls ( $N=576)$ were a sample of uninjured skiers who claimed for non-medical reasons. Self-reported beginners appeared to have an elevated injury risk $(O R=2.1)$ compared to intermediate or advanced skiers. Among skiers with only one or two years of experience ski lessons seemed to have a protective effect. No beneficial effect on injury risk could be demonstrated in this study for training on a artificial ski run, ski gymastics, a good physical condition or sports participation. 
As in most other sport activities, downhill skilng is not without risk. The reported incidence ranges from 1 to 10 sk 1 injuries per 1000 sthier days ${ }^{1-3}$ This variation is mainly due to different definitions of Injury, different source populations, selective reporting and underreporting. " During the last few decades the injury rate has decreased substantially, probably because of improvement of ski bindings and possibly because of better maintenance of ski runs. $2,4,5$ The number of lower extremity injuries has especially decreased. ${ }^{2}$ A further substantial reduction in the incidence of ski injury might only be expected by changing the prevalence of other risk factors. Such preventive neasures should be based on controlled etiologic studies in which relevant risk factors are identified and quantified. 3

This article focusses on the contribution of the risk factors ability and physical condition. Results will be presented from a case-control study that was conducted among Dutch skiers $(N=1148)$ during the 1984/1985 season. 6 In the literature there is consensus with respect to the higher risk for beginners. $1,3,5,7,8$ This holds both for self-reported ability and for the number of seasons of ski experience. It seems reasonable to expect that formal instruction will. increase ability and thus lover the injury risk. Sound empirical evidence on this point is lacking though. Some authors ${ }^{7,9}$ report even an elevated injury risk during ski-lessons, but it can be argued that this may be due to differences in ability or number of hours of skifing between the groups of skiers compared. 5

It 1 s often suggested that good physical conditioning can prevent fatigue and thus lower injury risk, ${ }^{10-13}$ but controlled studies in which this effect is quantified are non-existent. Furthermore, at least in The Netherlands, the commonly heard advice ${ }^{14}$ to prepare for skiting by performing a course of siki gymastics or to take lessons on an artificial ski run in order to prevent accidents is not based on adequate empirical evidence.

Valid studies quantifying the effect of putative risk factors are sparse. The inclusion of a comparable control group of uninjured 
skiers is still not a common practice and adequate multivariate analysis of the data is almost never performed. Accepted measures of association (e.g. odds ratios) between risk factors and risk are usually not given and often it is impossible for the reader to calculate them. In case-control studies especially the issues of selection bias and information bias deserve more attention than they get in most articles relevant to the subject, ${ }^{15}$ which is why in our own study we have tried to avoid these flaws.

The third classical threat to validity is uncontrolled confounding. Confounded measures of association may arise when the levels of other rusk factors (e.g. ability) are unequally distributed over the different levels of the risk factor under study (e.g. taking ski lessons). Control for confounders is necessary to estimate the independent contribution to the injury risk of the separate risk factors of interest. This was achieved by means of stratification and multivariate analysis (logistic regression). Stratification indicates that weighted averages of the associations of interest are formed over strata homogeneous for one or more other risk factors (e.g. age, gender and ability). Thus an estimate of association (odds ratio) is calculated that is adjusted for the confounding by (some) ather risk factors. In multivariate analysis (logistic regression) measures of association are calculated that are simultaneously adjusted for the confounding influence of a large number of other risk factors. This is achieved by means of mathematical modelling. In the resulting logistic model also the phenomenon of (statistical) interaction is taken into account. This deals with the situation that the effect of some risk factors on injury is (partly) independent on the level of other risk factors.

MATERIAL AND METHODS

Both cases and controls during the 1984-1985 vinter season were obtained from the records of a large Dutch insurance company. Most Dutch downill skiers are insured and this company covers about one third of the market. The cases selected included skiers 
who had claimed for medical costs as a result of a ski injury that made sking or other activities impossible for more than one day. All casualties suffering a fracture, a dislocation or a ruptured ligament were selected. Furthermore, a sample was taken of less severe injuries. For every case of injury selected, an equal number of uninjured skiers were chosen by taking the next claim from an uninjured skier received by the insurance company for other reasons (e.g. loss or theft). In addition to this, some extra cases were selected who were insured elsewhere for skining. risks but who had been repatriated by the organization selling the insurance. A postal questionnaire was sent shortly after the ski holiday to the population thus defined. Reminders were sent after 10 and 20 days. The questionnaire consisted of about 80 items for the controls and 120 items for the cases. For both groups information was collected on most risk factors mentioned in scientific and popular literature (e.g. ability, prior ski experience, alcohol consumption, snow quality, weather, physical condition, equipment, adjustment of bindings and demographic data). In addition to this, cases were also questioned about the circumstances of the accident and the characteristics of the injury. This article presents only the effects of risk factors related to ability and physical condition, although confounding and effect modification by a number of other risk factors will be taken into account. The separate effects of the other risk factors investigated will be presented elsewhere.

Data analysis was performed with the aid of BMDP and GLIM statistical software. ${ }^{16,17}$ Two steps can be distinguished. First an elementary analysis was performed in which only confounding by age and gender was adjusted for. For continuous variables this was done by way of analysis of covariance. Differences between adjusted means for cases and controls were tested with student t-test. ${ }^{16}$ For discrete variables the distribution of risk factors was calculated for both cases and controls, based on direct standardization for age (three categories) and gender. Furthermore, odds ratios (OR) were calculated as a weighted average over six strata for age and gender using the MantelHaenszel method ${ }^{18}$ with the corresponding test-based confidence intervals (CI) following the method of Miettinen. 18 
The second step of data analysis concerned a more precise control for confounding and first order interaction. For this purpose a logistic model was fitted based on a selection of 25 variables. ${ }^{18}$ In the final model 20 variables remained and 12 interaction terms. were included. From the logistic regression coefficients in this model adjusted odds ratios with their approximate $95 \%$ confidence intervals ${ }^{18}$ could be calculated.

\section{RESULTS}

\section{Response}

Response was well over $80 \%$ and about the same for cases ( $84 \%$ ) and controls $(82 \%)$. Cases responded slightly faster. The majority (81\%) of the 1540 respondents had practised downhill skiing only, the rest were cross-country skiers and were excluded from the analysis. A number of skiers (103) did claim medical costs, but appeared not to have been prevented from skiing or other activities for one day or longer. These were also excluded from the analysis. Data on 1148 downhil1 skiers were analysed, including 572 cases and 576 controls. The group of cases consisted roughly of one thind fractures and another third with a ruptured $\mathbb{l}$ ilgament or a dislocation. The rest of the cases suffered other kinds of trauma. A number (130) of the cases were not insured by the insurance company which provided the source population, but had been repatriated by the organization selling the insurance.

Between cases and controls slight differences in age and a rather strong difference in sex composition was found. Mean age for the cases was 32.0 years and for the controls 32.6 years. This is similar to the mean age ( 32 years) of active skiers among a representative sample of the Dutch population. ${ }^{19}$ Forty-six percent of the cases were males compared to $67 \%$ of the controls. Among a representative sample of the Dutch population ${ }^{19}$ females appeared to go on winter sport holiday as often as males. In our opinion the figures in our study population reflect selection bias due to the way the controls have been selected. In the 
Netherlands males are probably still mentioned more often as the owner of lost or stolen objects because they are considered to be the head of the family. The consequence is that the risks associated ith age and gender cannot be estimated in our study. For the same reason every odds ratio calculated is adjusted for confounding by age and gender.

\section{Abilitity}

The skill of the skier is supposed to be an important risk factor for ski injuries. In our questionnaire it was operationalized in terms of ability, experience, number of falls and the exposure to formal instruction. Elementary analysis revealed that skiers who had classified themselves as intermediate or advanced had a lower accident risk compared to beginners (table 3-1). This association is summarized as the cross-product or odds ratio (OR).

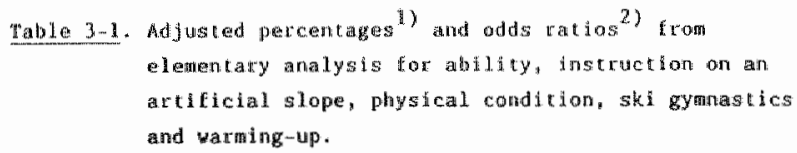

CASES CONTROLS OR MEA

\begin{tabular}{|c|c|c|c|c|}
\hline \multicolumn{5}{|l|}{ kbollity: } \\
\hline Beginuer (L) & $39 \%$ & $28 \%$ & 1.0 & \\
\hline Intermediate $(A)$ & $5.5 \%$ & $65 \%$ & 0.6 & $0.5-0.8$ \\
\hline Advanced $(S)$ & $6 \%$ & $7 \%$ & 0.6 & $0.3-1.1$ \\
\hline \multicolumn{5}{|c|}{ Instruction on artificlal silope before holiday: } \\
\hline No & $94 \%$ & $96 \%$ & 1.0 & \\
\hline Yesi & $6 \%$ & $4 x^{\prime}$ & 1.5 & $0.8-2.8$ \\
\hline \multicolumn{5}{|c|}{ Physical cond thon before nolidey: } \\
\hline Good & $71 \%$ & 648 & 1.0 & \\
\hline Intermed bo te or bad & $29 \%$ & $36 \%$ & 0.7 & $0.5-0.9$ \\
\hline \multicolumn{5}{|c|}{ Course th shy gymastixs befote hollday: } \\
\hline No & $79 \%$ & $81 \%$ & 1.0 & \\
\hline Yes & $21 \%$ & 192 & 1.1. & $0.7-1.6$ \\
\hline \multicolumn{5}{|l|}{ Watidigg-up during hollday: } \\
\hline Never & $56 \%$ & $62 \%$ & 1.0 & \\
\hline Sonet imes & 36 & $34 \%$ & 1.2 & $0.9-1.5$ \\
\hline After breaks & $8 \%$ & $4 x_{2}$ & 2.0 & $1.2-3 \cdot 4$ \\
\hline
\end{tabular}

1) after direct standardization for age and gender

2) Heighted average (Mantel-thenszel) ower 6 strata for age and gender followed by test-based $95 \%$ confidence intervals

(Hiatinea). 
Given some assumptions, the odds ratio may be interpreted as relative risk. This is the absolute risk (incidence) in the presence of a factor divided by the absolute risk in the absence of that factor. More generally, in an odds ratio two levels of a risk factor are compared. In doing this the choice of the reference level $(O R=1)$ is arbitrary. An odds ratio of 0.6 for intermediate skiers compared to beginners is equivalent to an odds ratio of $1 / 0.6=1.6$ of beginners compared to intermediate skiers. The higher risk for beginners is even more pronounced. when adjusted for a number of confounders. The logistic model shows that beginners have twice $(O R=2.0)$ the injury risk of intermediate or advanced skiers. In both the elementary analysis and the logistic regression $95 \%$ confidence intervals (CI) of the odds ratios are calculated. These are the boundaries between which the "real" value of the odds ratio is assumed with $95 \%$ confidence to lie, given the point estimate found in the study. The confidence interval gives an impression of the imprecision of the point estimate and makes further statistical testing unneccesary. A $95 \%$ confidence interval not including the null-value $(O R=1)$ is equivalent to a $p$-value smaller than 0.05 in a twosided significance test. Both table 3-1 and the confidence interval calculated from the logistic model $(1.5-2.9)$ show that the risk of being a beginner is statistically significant indeed.

It seems reasonable to expect that the skill of the skier increases with growing experience. The questionnaire included items on the total number of times the respondent had gone on winter sports holiday and on the total number of days skilng. Table 3-2 shows the adjusted means for these variables for both the cases and the controls. These figures reveal that the cases went less often on winter sports holiday and had fewer days of ski experience. The means presented in table $3-2$ are adjusted for differences in age and gender by way of analysis of cowariance.

The total number of times that the respondents went on winter sports hollday is also included in the logistic model. Overall, the effect of this variable on the injury risk seems small. Probably, this is because ability is also included in the model. 


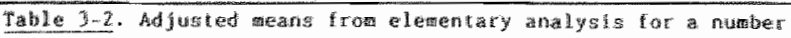
of cont intoug: watables.

ADJUSTED KEANH II

CASES CONTROLS P-VALLE ${ }^{2}$ )

\begin{tabular}{|c|c|c|c|}
\hline Number of winter sports holidays & 5.6 & 6.0 & 0.07 \\
\hline Total nuwber of days stiling & 48.4 & 55.4 & 0.03 \\
\hline Far L day during this holiday & 2. 8 & 2.6 & 0.17 \\
\hline Total number of days of ingtructuon & 19.6 & 19.8 & 0.85 \\
\hline $\begin{array}{l}\text { Wours of group instruction this } \\
\text { hold day }\end{array}$ & 5.9 & 7.7 & 0.003 \\
\hline $\begin{array}{l}\text { Hours of private instruction this } \\
\text { hollday }\end{array}$ & 0.4 & 0.4 & 0.84 \\
\hline
\end{tabular}

1) based on analystis of covariance with me and gender as covarlates

2) based or 5 thudent $t$-test for adjusted means

When ability is adjusted for, the effect of the number of winter sports holiday decreases and vice versa. This holds especially for the majority of respondents ( 359 cases and 449 controls) who knew which type of skis they had used and what the age of the bindings and the skis were. The minority of skiers who did not have this knowledge appeared to have a higher injury risk.

In figure 3-1 this (statistical) interaction is visualized. Among the skiers with inadequate knowledge of their equipment the injury risk increases in proportion to the growing number of winter sports holldays. This association, however, should be interpreted with some caution, because the number of respondents whout adequate knowledge who vent frequently on a winter sports holiday is small. In that case the confidence intervals tend to become very wide (e.g. for 10 holidays $\mathrm{OR}=4.5 ; \mathrm{CI}=1.9-10.1$.

After self-reported ability and experience, the third operationalization of skill in our study was the mean number of falls a day during this holiday. 
Pigure 3-1. Odds ratios from the logistic motel for interaction betwen the numer af unter sports holidays and knovledge about equipment.

ODDS RATIOS

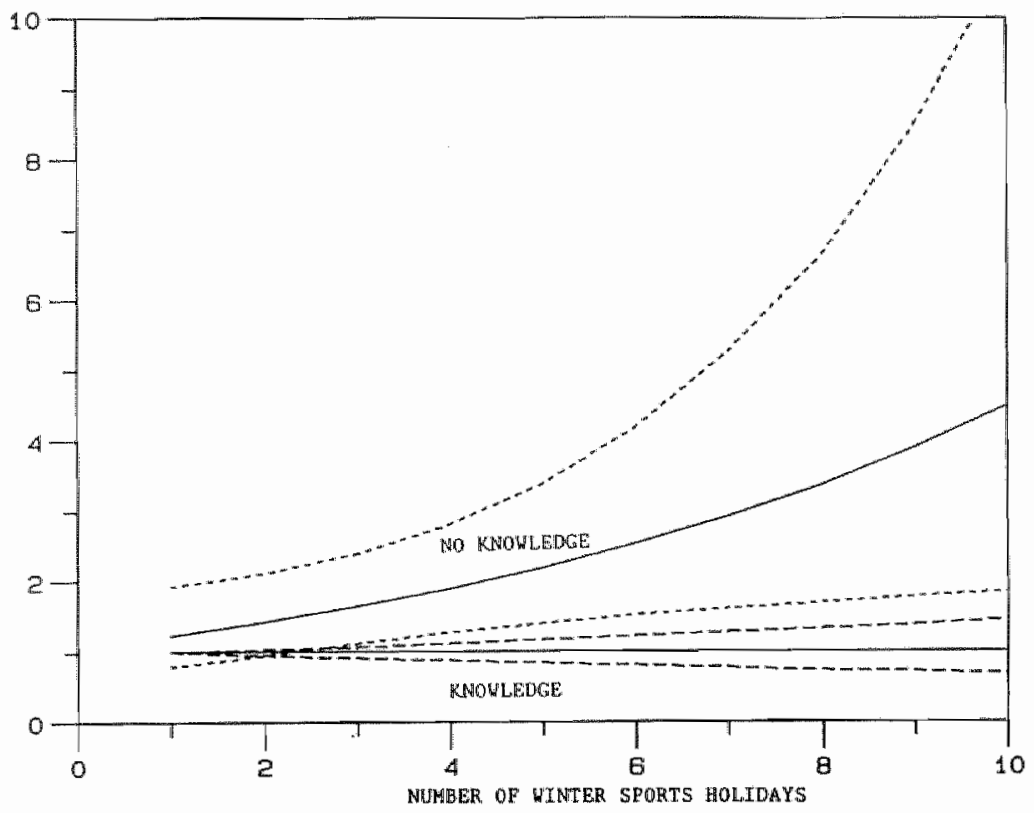

As shown in table 3-2, cases fall as of ten as controls do 2.8 . vs. 2.6), so the mean number of falls a day does not appear to be a substantial risk factor in itself.

Ski lessons are supposed to improve the skill of the skier and might thus reduce the injury r1sk. Table 3-2 indicates that there. is no apparent difference between cases and controls as far as the total number of days instruction (private or in groups) is concerned. In our data there is no evidence of any risk reduction for those who had trained on an artificial ski run before the holiday (table 3-1). However, there is a pronounced difference in the number of hours of group instruction during the holiday (table 3-2), but this is probably due to the fact that cases missed a part of their planned ski lessons because of their injury . 


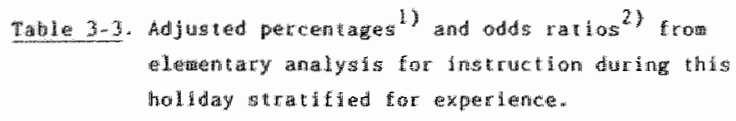

CASES COMTROLS OH $\mathrm{CI}$

1. ORR 2 THES WINTER SPOATS

(N⿴囗十) 157$)$

$\begin{array}{lllll}\text { No instruction } & 22 \% & 9 \% & 1.0 & \\ \text { Instruction } & 78 \% & 91 \% & 0.4 & 0.2-0.9\end{array}$

3 THES OR MORE $(N=366) \quad(H-4632)$

$\begin{array}{lllll}\text { Wo instruction } & 64 \% & 65 \% & 1.0 & \\ \text { Instruction } & 36 \% & 35 \% & 1.1 & 0.7-1.6\end{array}$

1) after direct standadizathon tor age and gender

2) weighted average (Nantel-Haenszel) wer 6 strata for age and gender followed by lest-baned $95 \%$ confidence interwals (CI) (Mietcinen).

To elucidate this problem, a study was made of the dichotomous answer to the question whether any formal instruction was taken during this holiday. It appeared that instruction was associated with a lower injury risk $(\mathrm{OR}=0.4)$ only among the skiers who had gone skiling far the first or second time (table 3-3). In the logistlc model the absence of an overall effect of instruction is confirmed $(O R=1.0 ; C I=0.8-1.4))$.

\section{Physical Condition}

Most skiers reported they were in a good physical condition (table 3-1). Rather surprisingly respondents who reported an intermediate or bad physical condition before their holiday appeared to have a lower injury risk $(\mathrm{OR}=0.7)$. This finding was supported by the difference in the weekly number of hours of sports participation (table $3-2$ ) between cases $(3.8 \mathrm{hr}$. ) and controls ( $3.4 \mathrm{hr}$.$) . For the majority of skiers who had refrained$ from ski gymnastics before holiday, the logistic model also showed a preventive effect of an intermediate or bad physical condition (table 3-4). 
Roughly one fifth of the respondents prepared by way of a course in ski gymnastics before their holiday. No reduction of accident risk was found for this group (table 3-1). The same holds in the logistic model (table 3-4), but there is some difficulty interpreting the statistical interaction found with the reported physical condition (table 3-4). This interaction is not very strong though and might well be a chance phenomenon in our study.

Table 3-4. Odds ratios and confudence intervals fan the logistic model for interaction between whystical condition and ski gymrastics.

\begin{tabular}{|c|c|c|c|c|}
\hline & \multicolumn{4}{|c|}{ PHYSICAL CONDITION } \\
\hline & GOOD & & IMTE & $\mathrm{HED}, / \mathrm{BAD}$ \\
\hline No ski gymasties & 1.0 & & 0.6 & $0.4 \cdots 0.8$ \\
\hline Ski gymastics & 0.7 & $0.5-1.1$ & 1.0 & $0.5-1.9$ \\
\hline
\end{tabular}

Besides sports participation and ski gymnastics, warming-up during holiday was considered as a factor with a possible influence on the physical condition. He found no evidence in favor of a preventive effect of warming-up (table 3-1). There was even a tendency in the other direction. Skiers who reported to have performed warming-up exercises sometimes or after every break seemed to have an elevated risk compared to those who refrained from this.

\section{DISCUSSION}

Before discussing the interpretation of the results, the internal. validity and reliability of our study deserves attention. Valldity can be impaired by selection bias, information blas and uncontrolled confounding. The central issue in selection blas is whether the group of cases and the group of controls are conparable with respect to the relewant factors. "This is different from representativeness. Because of the restricted nature of the source of our respondents (an insurance company associated with a organization of road-users), the skiers in our study are not a 
random sample of all Dutch alpine stiers. Furthermore, the study was biased in favor of the more severe cases, because medical. costs must have been made and repatriated cases insured elsewhere were added to the study population. "This intraduces selection bias only when there is reason to doubt that the effect of the risk factors investigated in our study population is the same as among Dutch skiers in general. We think there is no reason for such doubt.

We have already mentioned that there is probably some selection bias with respect to age and gender due to the way the controls Were selected. This bias, however, is adjusted for in the dataanalysis. There seems to be no reason to postulate other selection bias in relation to the risk factors presented in this article. The same holds for selection bias due to differential non-response. Response was high and in no observable way selective.

Information bias is concerned with the question whether the information gathered is comparable between cases and controls. An inherent limitation is that all the information gathered was based on self-assessment. Therefore, our study lacked precise and objective information on for instance physical condition and ability. Respondents were approached within three weeks after the end of their holiday to lessen the likelihood of incomplete recall of relevant facts. This, however, does not exclude bias. Our study is retrospective and as a consequence of the known outcome of the hollday the assessment of certain risk factors might be influenced. Perceived ability and physical condition especially might have been underestimated among the cases and/or overestimated among the controls for this reason. Probably less subjectlve itens, such as the total number of days skiing and the number of hours of sports participation, are less susceptible to this type of bias.

Uncontrolled confounding is the third and last issue of valldity. In the logistic regression every important confounder on which we collected information was adjusted for. This does not exclude 
bias due to unmeasured confounders nor confounding due to imprecise measurement. In general, the effects as estimated in the elementary analysis are quite simillar to those based on the logistic model.

Reliability or precision of the estimated adds ratios is a function of random measurement error in our study. The variability in the data is rather large, which might stem from the fact that the questionnaire provides rather global indicators and respondents might give imprecise answers due to incomplete recall of the relevant items. Due to the fairly large variances of most variables, interpretation of $p$-values and confidence intervals calculated becomes difficult. Also the issues of multiple testing and interdependency of the calculated confidence intervals for varlables within the logistic model must be taken into account. Taken together, it is doubtful whether a strict interpretation in terms of significance is justified.

For the interpretation of the associations between putative risk factors and injury risk we found in our data, credibility is at least as important as statistical significance. Thus the results of our study must also be interpreted in the context of earlier investigations and (biological) plausibility. The observed higher risk for beginners is both plausible and accords with earlier work. $1,3,5,7,8$ This does not exclude information bias though, because all the studies cited were also retrospective. The decreasing risk with growing experience, as expressed in the total number of days skiling and number of winter sports holidays, is also consistent with other studies. 7,8 The fact that the effect of the total number of winter sports holidays is smaller may be because not all reported holidays inwolved alpine skiling. In logistic regression the effect of experience is less pronounced, probably due to the fact that ability is adjusted for. Absence of knowledge about the equipment used was associated th a higher risk especially among experienced skiers. This has not been reported before, but certainly does not seem implausible. The same holds for the absence of any effect of training on an artificial slope. It is doubtell whether the nean dally number of 
Ealls is a valld indicator of skill. Velocity and difficulty of the pistes presumably have a strong influence on this variable. Furthermore, most falls do not lead to injury. Although cases did not report more falls, it cannot be excluded that at least some of their falls were more severe. A preventive effect of formal. instruction is found only among skiers who had gone on winter sports holiday for the first or second time. We found no evidence of the higher risk associated with the taking of ski lessons reported by some authors. $7,9,15$ The absence of an overall effect of ski lessons was confirmed in the logistic model.

No evidence could be demonstrated for a preventive effect of good physical condition. This is postulated in the literature ${ }^{10,13}$ but never adequately quantified. Our study indicates that good physical condition may even be a risk factor. This is supported by the difference in sports participation between cases and controls before holiday. However, some caution is indicated in interpetating this finding. It is difficult to imagine how a bad physical condition can protect skiers against injury. Furthermore, information bias may play some role in these findings, especially because our measures of physical condition are indirect and probably imprecise. The same holds for the observation that absence of doing warming-up exercises seems to be associated with a lower accident risk.

\section{CONCLUSTON}

It is now established beyond reasonable doubt that beginners have an elevated injury risk. For skiers with one or two years of experience, ski lessons seem to have a preventive effect. Whether ski lessons can actually lower the injury risk among inexperienced skiers who do not yet take lessons should be investigated in a preventive trial. A preventive effect of training on an artificlal slope, ski gymnastics, a good physical condition and sportparticipation could not be demonstrated. 
Again, it is stressed that our results are not yet to be interpreted causally. Further studies, preferably with a prospective design and more direct and objective measurements of putative risk factors, are first needed to replicate our findings. Final$1 y$, preventive trials should be undertaken to elucidate whether manipulating putative risk factors related to ability and physical condition actually lowers injury risk in downhill skilng. 


\section{REEREEMCES}

1. Jaffin, B. * An Epldemiologic Study of Ski Injuries: Vail, Colorato, The Hount Sinal Journal of Hedicine, Vol. 48, No. 4, July-August 1981, pp. 353-359.

2. Johnson, R.J. Ettlinger, G.F., Campbe11, R.J. and Pope, M.H., Trends in sking Injurles, The American Journal of Sports Medicine, Vol.8, No. 2, 1980, pp. 106-113.

3. Bouter, L.M. and Knipschild, P.G., Risk Factors of Ski Injury (in Dutch), Tijdschrift voor Sociale Gezondheidszorg, Vol. 63, No. 20, 1985, pp. 846-851

4. Tapper, E.A., Ski Injuries from 1939 to 1976: The Sun Valley Experience, The American Journal of Sports Medicine, Vol. 6, No. 3, 1978, pp. 114-121.

5. Shealy, J.E., Overall Analysis of MSAA/ASTM Data on Skizing Injuries for 1978 through 1981, Skiing Trauma and Safety, R.J.Johnson and C.D. Mote, Eds., ASTM, Philadelphia, 1985, pp. $302-313$.

6. Bouter, L.M. and Knipschild, P.G., Ski Risks (in Dutch), Rijksuniversiteit Limburg/ANWB, Maastricht, 1985.

7. Shealy, J.E., Leyer, L.H. and Hayder, R., Epidemiology of Ski Injuries: Effect of Method of Skill Acquisition and Release Binding Accident Rates, Human Factors, Vol. 16, No. 5, pp. $459 / 473$.

8. Young, L.R., Oman, C.M., Grane, H., Emerton, A. and Heide, R. The Etiology of ski injuries: An Eight Year Study of the Skler and his Equipment, Orthopedic Clinics of North America, Vol. 7, No. 1, January 1976, pp. 13-29.

9. Garrick, J.G. and Requa, R. The Role of Instruction in Preventing Ski. Injuries, The Physician and Sportsmedicine, Vol. 5, No. 12, December 1977, pp. 57-59.

10. Eriksson, E. Physiological Denands in Downill Skiing, The Physician and Sportsmedicine, Vol. 5, No. 12, December 1977 , pp. $28-35$.

11. Buck, P.G., Sophocles, A.M. and Beckenbaugh, R.D., Unique Aspects of Downhill Ski Injuries, Orthopedics, Wol. 5, No. 3, March $1982, p p .317-324$. 
12. Brouns, F. Saris, W.H.M. and Ten Hoor, F, Nutrition as a Factor in the Prevention of Injuries in Recreational and Competitive Downhill Skiling, The Journal of Sports Medicine, Vol. 26, 1985, pp. 85-90.

13. Nygaard, E., Andersen, P., Nilsson, P., Eriksson, E., Kjessel, T. and Saltin, B., Glycogen Depletion Pattern and Lactate Accumulating in Leg Muscles during Recreational Downhill Skiing, The European Journal of Applied Physiology. Vol. 38, 1978, pp. 261-269.

14. Luyten, J., Ski Training (in Dutch), Geneeskunde en Sport, No. 6, 1976, pp. 7-11.

15. Knipschild, P.G. and Bouter, L.M., Risk Factors for Ski Trauma. A Crash Course of Epidemiologic Methods with Special Reference to Case-Control Studies. Accepted for publication in Sking Trauma and Safety, R.J. Johnson and C.D. Mote, Eds., ASTM, Philadelphia.

16. Dixon, W.J., BMDP Statistical Software, University of California Press, Berkeley, 1983.

17. Baker, R.J. and Nelder, J.A., The Glim System. Release 3, NAG, Oxford, 1978.

18. Kleinbaum, D.G., Kupper, L.L. and Morgenstern, H., Epidemiologic Research: Principles and Quantitative Methods, Lifetime Learning Publications, Belmont, 1982.

19. CBS, Holliday Survey 1985 (in Dutch), Staatsuitgeverij/CBSpublicaties, 's Gravenhage, 1987. 
CHAPTER 4

CHARACTERISTICS OP SKI AND BINDING IN RELATION TO INJURY RISK IN DOWNHILL SKIINGK

Lex M. Bouter, Paul G. Knipschild and Alexander Volovics

* Accepted for publication in the American Journal of Sports Medicine. 


\section{ABSTRACT}

Time-trend studies suggest that the use of modern equipment and an adequate adjustment of the ski binding had a preventive effect in the recent past. The question whether a further decrease of injury figures can still be expected from better adjustment is investigated in a case-control study ( $\mathrm{N}=1148$ ) conducted among Dutch skiers. No release of both bindings directly prior to injury was associated with a higher risk $(O R=3.3)$ for lower extremity injury. Binding release prior to lower extremity injury was highest (31\%) among those for whom adjustment was performed with the use of a test devilce. The proportion of no release is highest for knee injuries. No effect on injury risk could be found for the moment of adjustment, the method of adjustment and the person performing the adjustment. Direct measurement of binding function seems indispensable. The use of rented or borrowed skis was associated with a higher risk $(0 \mathbb{R}=1.9)$ for lower extremity injury. The same holds for ignorance concerning the type of ski and the age of skis and binding. It is concluded that binding adjustment seems still to be a risk factor open to manipulation. The efficacy of an intervention aimed at better adjustment should be studied experimentally. 
Downhill skilng has gained an enormous popularity over recent decades. In common wh most other sports there is a certain risk of injury. Estimates range between 1 and 10 ski injuries per 1000 skier days. 2, 16, 18 Differences in reported incidences are partiy due to differences in the definitions of a skier and of an injury. 21 Furthermore, the method of registration will usually lead to a substantial underestimation of especially those injuries which do not immobilize the skier, e.g. injury of the thumb. ${ }^{13}$ Nowadays the incldence of serlous injury needing substantial medical treatment is generally agreed to lie in the range of $2-4$ per 1000 skier days. 14,26,33 This figure would seen to be much lower than a few decades ago. $14,28,22,26,28,33$

It is commonly agreed that the development of the modern ski equipment, especially of the release bindings, has contributed substantially to the decline in incidence of injury. $19,22,28$ Additional support for this may be seen in the changing pattern of ski injuries over the years. In thejr review of relevant studies, Hauser and Gläser ${ }^{13}$ indicate trends in the proportion of reported ski injuries for different parts of the body as weighted averages, noting the occurrence between 1960 and 1980 of a substantial decline from 80 to $55 \%$ in the proportion of lower extremity injuries, especially for the foot and ankle (45 to $10 \%)$. During the same time span the proportion of tibia fractures declined from 25 to $15 \%$, while knee injuries remained at around $20 \%$. In contrast to the relative decline of lower extremity injuries, there appeared to be an increase in upper extremity injuries from 10 to $25 \%$ between 1960 and 1980 , while the proportion of injury of head and torso doubled to $20 \%$.

Johnson and his colleagues ${ }^{17,18,19}$ introduced the concept of lower extremity equipment related (LEER) injury ".... in which the mechanism is consistent with the ski acting as a lever to bend of twist the leg' (Johnson et al ${ }^{18} \mathrm{p}$. 107). They classified $80 \%$ of the lower extremity (LE) injuries as LEER injury. Between 1972 and 1978 the LEER injury incidence rate fell by $43 \%$, while the upper body injury rate decreased only $25 \%$. The incidence of fractured tibias and sprained ankles especially declined substantially (both by more than $70 \%$ ). 
These time-trend studies suggest that the use of modern equipment and an adequate adjustment of the ski binding had a preventive effect in the recent past. Nowadays the prevallence of modern equipment is almost $100 \%$. In order to determine whether a further decrease of injury figures can be expected from a better adjustment of bindings, a case-control study was conducted among Dutch skiers during the 1984/1985 season, with the aim of examining three questions relevant to the topic. Firstly, it was hypothesised that binding release would be less frequent during accidents leading to LEER injury compared to non-LEER injury. Such a difference may be expected and is indeed reported in the literature, ${ }^{8,33}$ although it is doubtful whether an optimally adjusted ski binding will always release in time to prevent a LEER injury. The knee especially seems to be insufficiently protected by the current binding design. $11,12,17$

The second hypothesis was, that adjustment of the bindings would be better amongst uninjured skiers compared to injured skiers, especially compared to those with a LEER injury. A number of studies would seem to confirm this hypothesis to some extent. $13,18,19,23,29$ Bindings of uninjured skiers appear on average to be adjusted $50 \%$ above the recommended setting. The same holds for skiers with a non-LEER injury. The mean deviation for knee sprains is $85 \%$ and for tibia fractures even $150 \%$, according to a recent German study. ${ }^{13}$ Most observational studies of ski injury have not included the testing of bindings. As a substitute, information is often collected concerning the moment of last adjustment, the method of adjustment or the person who performed the adjustment. In this context usually information is also gathered on the age and ownership of the equipment. In most studies no clear relation between these proxy-measures of binding adjustment and injury risk could be established. $16,25,30,32$ This might be due to confounding by other risk factors (e.g. ability).

The third hypothesis was concerned with whether an intervention in the form of an adequate adjustment of the binding could prevent (LEER) injury. A randomized controlled trial has been performed in Germany, ${ }^{15}$ for this purpose. Bindings in the 
experimental group $(\mathrm{N}=460)$ were optimally adjusted by the research tean. More than $50 \%$ of these appeared to be badly adjusted beforehand. Compared to the control group $(\mathbb{N}=690$ ) the risk for LEER injuries was 3.5 times lower in the experimental group.

Our study investigates the extent to which the results of our case-control study may confirm the hypothesis that Dutch skiers could benefit substantially from a better adjustment of their bindings. Cases of Injury will be divided in a lower extremity (LE) and a non-lower extremity (non-LE) group. LE cases will be compared both to controls and non-LE cases with respect to several self-reported characteristics of ski and binding. Confounding by several other risk factors will be adjusted for by way of stratified analysis and logistic regression. Finally, the evidence from our study is discussed against the background of the relevant iterature.

MATERIAL AND METHODS

Both cases and contrals during the $1984 / 1985$ season were obtained from the records of a company covering roughly one third of the market for ski insurance in the Netherlands. Mast Dutch skiers are insured. The cases selected were skiers who had claimed for medical costs as a result of a ski linjury that made sking or other activities impossible for nore than one day. All casualties suffering a fracture, a dislocation or a ruptured ligament were sellected. Furthermore, a sample was taken af less severe injuries. In addition to this a number of cases were selected who had been repatriated by the organization selling the insurance. For every case of $\mathbb{i n j u r y}$ selected, an equal number of uninjured skiers were chosen by taking the next claim from an uninjured skifer received by the insurance company for other reasons (e.g. loss or theft). 
A postal questionnaire was sent shortly after the ski holiday to the population thus defined. Reminders were sent after 10 and 20 days. The questionnaire consisted of about 80 items for the controls and of 120 items for the cases. For both groups information was collected in a comparative way on most risk factors mentioned in scientific and popular literature. In addition to this, cases were questioned about the circumstances of the accident and the subsequent injury. This article primarily deals with the self-reported characteristics of ski and binding, al though confounding and effect modification by a number of other risk factors 111 also be taken into account. The separate effect of other categories of risk factors is presented elsewhere. $3,4,5,6,31$

Data analysis was performed with the aid of BMDP and GLIM statistical software. ${ }^{1,10}$ Two steps can be distinguished. First an elementary analysis was performed in which confounding by age and gender, and later on ability, were adjusted for. The distribution of risk factors was calculated for cases and controls based on direct standardization for age in three categories and in a number of tables for gender too. Furthermore, odds ratios (OR) were calculated as a weighted average over six strata for age and gender using the Mantel-Haenszel method with the corresponding test-based $95 \%$ confidence intervals (CI) following the method of Miettinen. ${ }^{20}$ In the instances that confounding by ability was also adjusted for, eight strata were formed in this procedure.

The second step of data analysis concerned a more complete control for confounding and first order interaction. For this purpose a logistic mode $1^{20}$ was fitted based on a selection of 25 variables. In the final model 20 variables remained and 12 interaction terms were included. From the logistic regression coefficients in this model adjusted odds ratios with their approximate $95 \%$ confidence intervals can be calculated. 20 
RESULTS

\section{Responge}

Response was well over $80 \%$ and about the same for cases (84\%) and controls ( $82 \%)$. Cases responded slightly faster. The majority (81\%) of the 1540 respondents practised downhill skitng only. The others were cross-country skiers or practised both and these were excluded from the analysis. A number of skiers (103) did claim medical costs, but appeared not to have been prevented from sking or other activities for one day or longer. These were also excluded from the analysis. Data on 1148 downhill skiers were analysed, consisting of 572 cases and 576 controls.

Between cases and controls slight differences in age and a rather strong difference in gender composition was found. Mean age for the cases was 32.0 years and for the controls 32.6 years. This is similar to the mean age (32 years) of active skiers among a representative sample of the Dutch population. ${ }^{7}$ Forty-six percent of the cases were males, compared to $67 \%$ of the controls. Among a representative sample of the Dutch population ${ }^{7}$ fenales appeared to go on winter sports holiday as often as males. In our opinion these figures reflect selection bias due to the way the controls have been selected. In the Netherlands males are probably still mentioned more often as the owner of lost or stolen objects, because they are considered to be the head of family. The consequence is that the risks assoclated with age and gender cannot be estimated from our study. For the same reason every odds ratio presented is adjusted for confounding by age and gender.

\section{Injuries}

In total 929 injuries were mentioned by our 572 cases (table 4-1), 54\% of which concerned the lower extremities. The proportion of knee injuries was $32 \%$, while tibia fractures were responsible for $6 \%$ of the total number of injuries and ankle injuries for $7 \%$. Upper extrenity injuries were responsible for $20 \%$ (thumb $8 \%$ ) and $26 \%$ of the reported injuries concerned head or torso. 


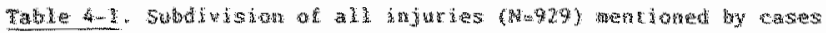
$(1-572)$. 5raticied for gater.

mTr

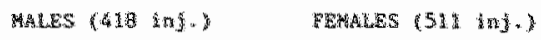

\begin{tabular}{|c|c|c|c|c|}
\hline 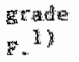 & $\begin{array}{l}\text { rade } \\
25 \\
\text { t. }\end{array}$ & $\begin{array}{l}\text { rade } \\
\text { 3y }\end{array}$ & $\begin{array}{l}\text { grate } \\
\text { i) }\end{array}$ & $\begin{array}{c}\text { grade } \\
25\end{array}$ \\
\hline
\end{tabular}

\begin{tabular}{|c|c|c|c|c|c|c|}
\hline Lawer Leg: & 22 & 1 & 16 & 35 & 4 & 18 \\
\hline Wrien: & 5 & 55 & 48 & 23 & 121 & 54 \\
\hline 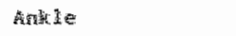 & 7 & 12 & 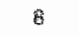 & 9 & 20 & 16 \\
\hline Gther Lover Fxt. & 10 & $x$ & 14 & 3 & 2 & 12 \\
\hline Thatrites & 7 & 19 & is & 6 & 15 & 30 \\
\hline ather bpger kxts. & 17 & 15 & 23 & 22 & 13 & 24 \\
\hline shandider & 26 & 21 & 19 & 4 & 19 & 14 \\
\hline Qther Torso & $\underline{z}$ & 5 & 22 & $y$ & 3 & 19 \\
\hline Heand ar Neck. & 6 & 0 & $27^{4}$ & 4 & 4 & $49^{5}$ \\
\hline
\end{tabular}
1) $F=$ Fract

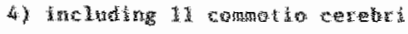

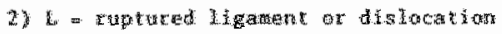
5) including 19 cantinoto cerebri

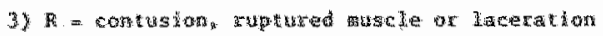

Table 4-2 shows a distinction between cases who mentioned a lower extremity injury and cases who did not. Within the groups of LE cases and non-LE cases a hierarchical subdivision is made. In table 4-2 each case is counted only once.

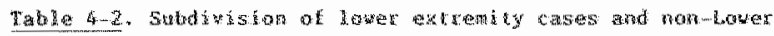
extranty cases according to most severe insury

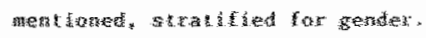

\begin{tabular}{|c|c|c|c|}
\hline $\sin x$ & GAstis & 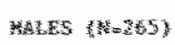 & 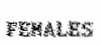 \\
\hline
\end{tabular}

\begin{tabular}{|c|c|c|c|}
\hline Lots & 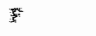 & $25+20$ & $35(1,3)$ \\
\hline 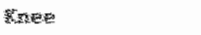 & 2 & 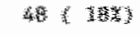 & $(x)(3)$ \\
\hline prex & w & 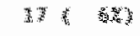 & 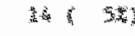 \\
\hline 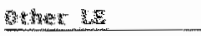 & 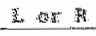 & 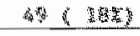 & 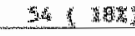 \\
\hline WGT & & 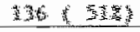 & 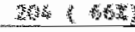 \\
\hline Strevar & war & 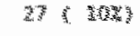 & $H<6 y$ \\
\hline 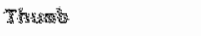 & 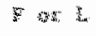 & 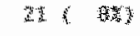 & $x^{3}$ \\
\hline 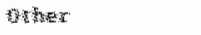 & 政 & $22 * 3$ & 2 \\
\hline 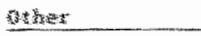 & E. & 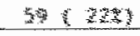 & $42 \quad(1.48$ \\
\hline nes & & 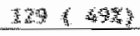 & 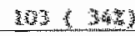 \\
\hline rovat & & 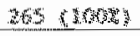 & $37 \%$ \\
\hline 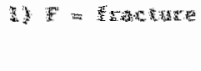 & 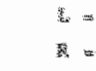 & 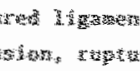 & 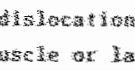 \\
\hline
\end{tabular}


Among the males $51 \%$ could be classified as LE case, while this figure was as high as 66\% for the females. This difference is almost completely the consequence of the Eunding that one third of the female cases reported injury concerning severe damage to the ligaments of the knee. Tibia fractures occurred in $8 \%$ of the wale cases and in $11 \%$ of the female cases. Among the non-LE cases severe injury of the shoulder and the thumb were the most important.

\section{Release of binding}

Among the male LE cases $30 \%$ reported a release of both bindings during the accident leading to injury (table 4-3). Anong the male non-1.E cases $50 \%$ of the accidents involved a release of both bindings. In general, the bindings of females released less often during the situations leading to injury. Only $18 \%$ of LE cases and $34 \%$ of non-LE cases reported release of both bindings. No release of binding during the accident leading to injury was associated with a higher risk for LE injury. The same holds for the release of only one binding. Among the cases of LE injury the proportion of no release was thighest for injury of the knee (males $38 \%$, females 54\%). Table $4-3$ gives the odds ratios (OR) and the corresponding confidence intervals (CI) for male and female cases separately. The owerall odds ratio for no release was 3.3 $(C I=2.1-5.3)$. For release of one binding only this was 2.3 $(\mathrm{CI}=1.4-3.8)$.

\section{Characteristics of binding}

In out study several items concerned the adjustment and Eunctioning of the bindings. To some extent all these items are probably associated wh the ability of the skier. It can be inagined, for instance, that more advanced skiers are more likely co own their skis and will have a more adequate knowledge about their equipment compared to beginners. For this reason all odds ratios and confidence intervals in this section are, in addition to adjustment for differences in age and gender, based on a stratification for ability as rell. 
Table A. 3. Retcase of binding anong lower extemity cases and non-Lower excremity cases, shatified for gender.

\begin{tabular}{|c|c|c|c|c|c|c|c|c|}
\hline & \multicolumn{4}{|c|}{ MALES $(N=265)$} & \multicolumn{4}{|c|}{ FEMALES $(N-307)$} \\
\hline & $\begin{array}{l}\text { LE } \\
\text { casest }\end{array}$ & $\begin{array}{l}\text { non-LE } \\
\text { Cases }\end{array}$ & $O R^{1)}$ & $\left(\mathbb{r}^{2)}\right.$ & $\begin{array}{l}\text { LE } \\
\text { cases }\end{array}$ & $\begin{array}{l}\text { nom-LE } \\
\text { cases }\end{array}$ & $\mathrm{OR}^{11}$ & $\mathrm{cI}^{2)}$ \\
\hline Two bindings & $30 \%$ & $50 x$ & 1.0 & & $18 \%$ & $34 \%$ & 1.0 & \\
\hline One binding & $27 \%$ & $23 \%$ & 2.1 & $(1,0-4,1)$ & $29 \%$ & $22 \%$ & 2.7 & $(1.3-5.7)$ \\
\hline Herelease & $33 \%$ & $13 \%$ & 3.2 & $(2,6-6.5)$ & $46 \%$ & $28 x$ & 3,3 & $(1.7-6.5)$ \\
\hline Unknown: & $10 \%$ & $13 \%$ & & & $7 \%$ & 178 & & \\
\hline Mumber & 136 & 129 & & & 204 & 1,03 & & \\
\hline
\end{tabular}

1) odds Ratios are given as a weighted average over 3 scralla

(15-29, 30-4.4, 45-59 year) (Hantel-Haensael)

2) $95 \%$ confidence Interwais (Mietinen)

Table 4-4 indicates the prevallence of the variables concerned among LE cases, non-LE cases and controls. Table 4-5 gives the odds ratios and confidence intervals that can be calculated for these variables.

Table 4-4. Prevalence of some self wepotted characteristics of shi and binding anomg lower extremity cases, non-bower extremity cases and controls."

\begin{tabular}{|c|c|c|c|}
\hline & $\begin{array}{l}\text { LE CASESS } \\
N=340\end{array}$ & 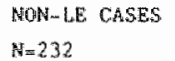 & $\begin{array}{l}\text { CONTROLS } \\
N=576\end{array}$ \\
\hline
\end{tabular}

Moment of Adfustment:

\begin{tabular}{lrrr} 
Recently & $71 \%$ & $70 \%$ & $66 \%$ \\
One yeat ago & $1.0 \%$ & $12 \%$ & $11 \%$ \\
Longrat ago & $5 \%$ & $5 \%$ & $9 \%$ \\
Unknown & $14 \%$ & $13 \%$ & $12 \%$ \\
\hline
\end{tabular}

\begin{tabular}{|c|c|c|c|}
\hline & & & \\
\hline \multicolumn{4}{|l|}{ Methad of Adjustinent: } \\
\hline Hith test apparatus & $46 \%$ & $.47 \%$ & $49 \%$ \\
\hline With intormation ondy & $3.5 \%$ & $33 \%$ & $32 \%$ \\
\hline Wi thout information & 16.8 & $14 \mathrm{x}^{\circ}$ & $14 \%$ \\
\hline Unkandus & 38 & 68 & $5 x$ \\
\hline \multicolumn{4}{|l|}{ Place of Mdfus thent: } \\
\hline Skistrog in Holland & $46 \%$ & $58 \%$ & SHA $\%$ \\
\hline Skishop in ski area & $483 \%$ & $30 \%$ & $36.8 \%$ \\
\hline Elsewhete & $4 \%$ & $8 \%$ & $\theta \%$ \\
\hline Unknian & $2 x_{0}$ & 4 & $4 \%$ \\
\hline \multicolumn{4}{|l|}{ Mwnership Slis: } \\
\hline ouned & $45 \%$ & $60 \%$ & $62 \%$ \\
\hline Ren fed or borroved & $55 \%$ & $40 \%$ & $38 \%$ \\
\hline \multicolumn{4}{|l|}{ Knowledge about Equipment: } \\
\hline abdequate & $59 \%$ & 699 & $76 \%$ \\
\hline Inadequate & 412 & $31 x$ & $24 \%$ \\
\hline \multicolumn{4}{|l|}{ Skis at Night: } \\
\hline Inside & $93 \%$ & $89 \%$ & $95 \%$ \\
\hline outside & $7 \mathrm{~g}$ & $11 \%$ & $5, \%$ \\
\hline
\end{tabular}


More than two third of the skiers in the study reported that their bindings ware recently adjusted (table 4-4). When it is assumed that the adjustment among skiers who did not know the answer to this question, was performed Ionger than one year ago, roughly $20 \%$ of the bindings were adjusted longer than one year ago. Table 4-5 shows that no relation between the moment of adjustment and accident risik could be found.

Table fo-5. Oddis ratiog and confidence lintervals for some self-epported characteristics of shi and binding. adjusted tor ability.

\begin{tabular}{|c|c|c|c|}
\hline & $\begin{array}{c}\text { CASES } \\
\text { VS } \\
\text { CONTROLS }\end{array}$ & $\begin{array}{l}\text { LE CASES } \\
\text { WS } \\
\text { CONTROLS }\end{array}$ & $\begin{array}{l}\text { LE CASES } \\
\text { WS } \\
\text { NOH-LE CASES }\end{array}$ \\
\hline \multicolumn{4}{|l|}{ Moment of Adjustotent: } \\
\hline Recently & 1.0 & 1.0 & 1.0 \\
\hline One year ago & $0.7(0.4-1.1)$ & $0.7(0.4-1.2)$ & $0.8(0.4-1.9)$ \\
\hline Longer ago & $0.6(0.4-1.2)$ & $0.7(0.3 \mathrm{~m} 1.4)$ & $1.1(a .4-2.5)$ \\
\hline \multicolumn{4}{|l|}{ Hethod of Adjus tweant: } \\
\hline b1th test apparatus & 1.0 & 1.0 & 1.0 \\
\hline Wh th information ondy & $1.1(0.8-1.5)$ & $1.1(0.7-1.7)$ & $1.0(0.6-11.5)$ \\
\hline Vi thout inforial ton & $1.1(0.7-1.8)$ & $1.2(0.7-2.1)$ & $1.2(0 .(5-2.5)$ \\
\hline \multicolumn{4}{|l|}{ Place of Adjuscment: } \\
\hline Skeshop in Holland & 1.0 & 1.0 & 1.0 \\
\hline Skx shop in ski area & $1.2(0.9-1.6)$ & $1.6(1.2-2.2)$ & $2.2(1.4-3.2)$ \\
\hline Elsegliere & $0.9(0.3 \times 3.2)$ & $0.3(0.3-2.0)$ & $0.8(0.2-2.7)$ \\
\hline \multicolumn{4}{|l|}{ ownership Skjs: } \\
\hline anned & 1.0 & 1.0 & 1.0 \\
\hline Rented or bortoned & $1.3(1.0-1.8)$ & $1.8(1.3-2.5)$ & $1.8(1.2-2.8)$ \\
\hline \multicolumn{4}{|c|}{ Knowledge about Equiphent: } \\
\hline Hdequatie & 11.0 & 1.0 & 1.0 \\
\hline Inadequate & $2.6(1.2-2.2)$ & $1.9(1.4-2.8)$ & $1.5(1.0-2.4)$ \\
\hline \multicolumn{4}{|l|}{ Skl gat ofigt: } \\
\hline Tnstue & 1.0 & 1.0 & 1.9 \\
\hline Outside & $2.0(1.2-3.4)$ & $1.5(0.7-3.1)$ & $0.6(0.3 \cdots 1 . \mathrm{j})$ \\
\hline
\end{tabular}

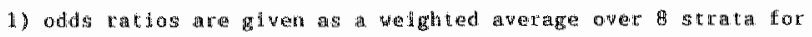
age (2), gender (2) and ablity (2) (Mantel-Hanszel) followed by a test-based 95.6 confidience interval (Mictinen).

Proper adjustment of binding is based on information concerning the skier. There are basically two methods for choosing the right setting: DIN 7881 or 'tibia method" and ISO 8061 or "weight method". "It is advocated strongly that the setting of the binding is controlled with a test device. ${ }^{24}$ Almost $50 \%$ of the skiers in our study reported this method of binding adjustment (table 4-4). One third of the skiers mentioned collection of the 
right information during the procedure, but no test device was used. About $20 \%$ of the skiers reported adjustment without the relevant information and without test device, or were ignorant of the procedure followed. No association between the method of adjustment and injury risk was found in our study (table 4-5).

The majority of bindings were adjusted in a skishop (table 4-4). Somewhat surprisingly adjustment in a skishop in the ski area (compared to a shop in the Netherlands) was associated with a higher rist for LE injury (table 4-5). This holds both for LE cases versus controls and $L E$ cases versus non-LE cases.

About $60 \%$ of the controls and of the non-LE cases owned their skis (table 4-4). The majority of LE cases used rented or borrowed skis. The latter was associated with a higher injury risk.

No relation between type of ski and age of ski and binding and injury risk was found. ${ }^{3}$ It was surprising that skiers quite of ten did not know the type $(L, A, S)$ of skis and the age of skis and binding. This was labelled as 'inadequate knowlledger in the analysis. Inadequate knowledge was associated with an elevated risk for injury in general, and even more strongly with the risk for LE injury. It can be imagined that, besides being assaciated with age, gender and ability, knowledge-status is also associated with other risk factors for injury. For this reason knowledge about equipment was included in a logistic model in which mutual confounding and first order interactions among the 20 principal. variables in our study was controlled for. In this logistic model absence of adequate knowledge appeared to be associated with an odds ratio increasing with the number of times the skier went on winter sports (figure 4-1). This first order interaction, however, should be interpreted with some caution, because the number of respondents without adequate knowledge who went frequentiy on a vinter sports holiday is small. For them the confidence interval tends to become very wide (e.g. for 10 holidays $\mathrm{OR}=4.5 ; \mathrm{CI}=1.9-10.1$. 


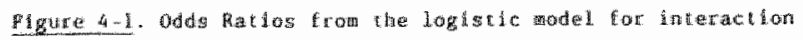
betwen knowledge about equlphent and the nuber of

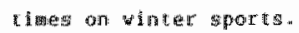

ONTS RATTOS

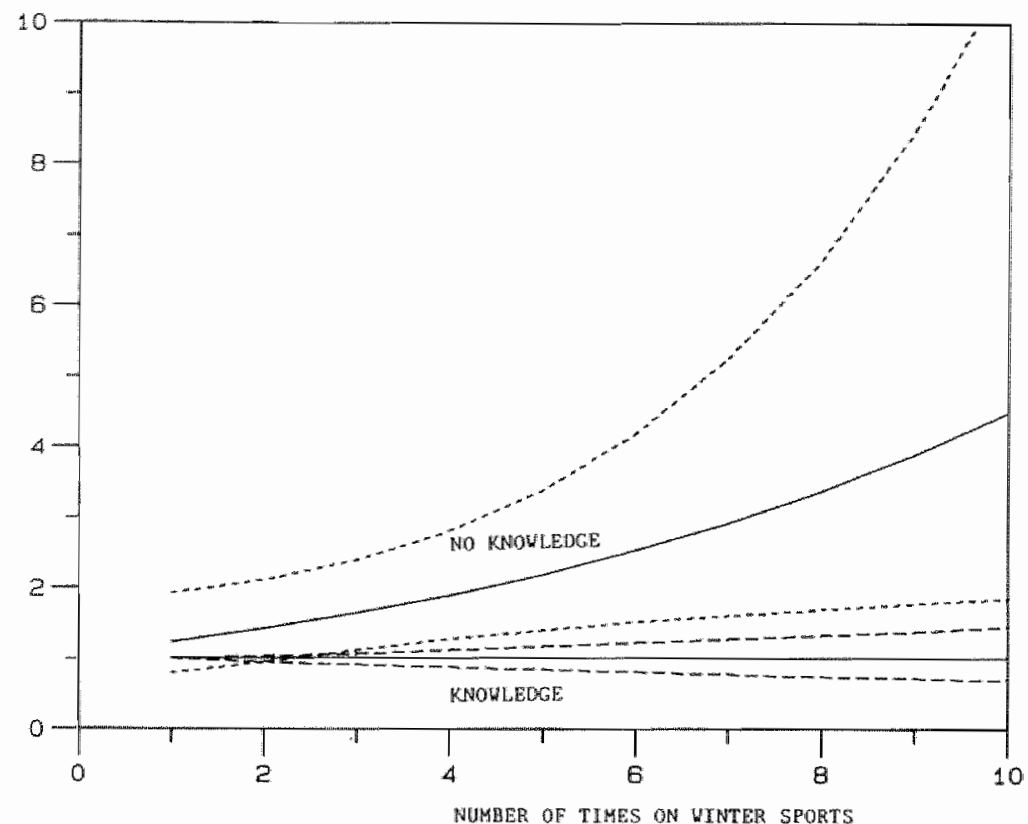

The small minority of skiers who usually leave their skis in the open air at night appeared to have a higher injury risk. Within the logistic model this effect was only found within the subgroup of skiers who did not take ski lessons. Table 4-5 leads one to infer that the risk for non-LE injury especially increases among those who leave their skis outside at night.

\section{DISCUSSION}

Despite of the fact that our study population is not a random sample of all Dutch downill skiers, the composition of the group of cases in our study is in reasonable agreement with the summary of the earlier literature provided by Hauser and Gläser, ${ }^{13}$ who refer mainly to studies in which for each case one (principal) diagnosis has been recorded by a physician. In our study, however, the diagnosis was self-reported and more than one site 
and type of injury could be mentioned. From this it can be expected that many less severe (secondary) injuries w111 be mentioned, especially contusions and minor lacerations. In table 4-2 only one diagnosis was chosen for each case. The proportion of LE-cases is similar to that of other studies. ${ }^{13}$ The same holds for the high proportion of severe knee injuries among females. $13,17,19$

It appeared that about $50 \%$ of the male and $64 \%$ of the female cases was severely limited in their activities for 10 days or longer. ${ }^{3}$ About one third of the cases was repatriated with professional support and two third of the cases mentioned further medical treatment in the Netherlands. ${ }^{3}$ From a second questionnaire that was sent to cases with a fracture, a dislocation or a ruptured ligament $12-18$ months later, ${ }^{4}$ it appeared that among those selected cases $18 \%$ of the males and $31 \%$ of the females was severely linited in their activities for 6 months or longer. About $44 \%$ of the male and $67 \%$ of the female cases with a paid job who returned this second questionnalire 4 were longer than 4 weeks absent from this job. This second questionnaire 4 also revealed that skiers tend to stick to their sport strongly. More than $70 \%$ of the controls from our study skied again during the next season. For cases with less than 3 months severe restriction of activities this was $60 \%$, for 3-6 months restriction 50\%, and for more than 6 months restriction still more than $30 \%$.

Internal validity can be impaired by selection bias, information bias and uncontrolled confounding. The central issue in selection bias is whether the group of cases and the group of controls are comparable with respect to relevant factors. We have already mentioned that there is probably some selection bias with respect to age and gender due to the way the controls were selected. This bias, however, is adjusted for in every association measure presented. There seems to be no reason to postulate other selection biases in relation to the risk factors presented here. The same holds for selection bias due to differential non-response. Response was high and in no observable way selective. 
Information bias is concerned with whether the information gathered is comparable between cases and contrals. The cholce of the control group (loss or theft) makes information bias due to selective recall less probable. Controls also had a reason to remember the details of their ski hollday. An inherent limitation of our study is that all the information we gathered was based an self-assesstent. Therefore, our study lacked precise and objective information on the injury and on the actual setting of the bindings. Furthermore, our study is retrospective and as a consequence of the known outcome (injury or no injury) the assessment of certain risk factors might be influenced. Perceived ability especially might have been underestimated among the cases and/or overestimated among the controls for this reason. Probably less subjective items, such as the circumstances of binding adjustment, as well as the comparison between $\mathrm{LE}$ cases and non-LE cases, are less susceptible to this type of bias.

Uncontrolled confounding is the thind and last issue in the assessment of internal validity. The odds ratios in table 5 are controliled for differences in ability. Furthermore, in the logistic model every important confounder on which we collected information is adjusted for. This does of course not exclude bias due to unmeasured confounders, nor confounding due to imprecise measurement.

precistion or reliability of the estimated odds ratios is a function of random measurement error in our study. The variability in the data 1 s rather large, which might sten from the fact that the questionnaire provides rather global indicators and respondents might give imprecise answers due to incomplete recall of the relevant items. Consequently variance is fairly large and confidence intervals wide for most variables. Also the issues of multiple testing and interdependency of the calculated confidence intervals within the logistic model must be taken into account. Taken together, it is doubtful whether a strict interpretation in terms of statistical significance is justified. 
For the interpretation of the associations between putative risk factors and injury risk which we did or did not find in our data, credibility is at least as important as statistical significance. Thus the results of our study must also be interpreted in the context of earlier investigations and (biological) plausibility. In this respect we return to the three questions (hypothesis) from the introduction to this article.

The first question was whether binding release was less frequent directly prior to LE injury compared to non-LE injury. He could confirm this hypothesis. No release was associated with a more than threefold risk for LE injury. We also found that release of one binding only was associated with a more than double accident risk. The fact that among the LE cases the proportion of no release was the highest for knee injuries, supports the hypothesis that the knee is insufficiently protected by the current ski binding design and/or adjustment. $11,12,17$

The second question dealt with differences in binding adjustment between controls and cases, especially LE cases. In our study, as in those of other investigators, $16,25,30,32$ no clear relation between the moment of adjustment, the method of adjustment or the person performing the adjustment on the one hand, and injury risk on the other hand could be demonstrated. Correction for confounding by self-reported ability did not influence this finding, although it cannot be excluded that uninjured skiers overestimated their ability leading to some residual blas in the estimated odds ratios. It is more probable, however, that our proxy-measures of binding adjustment were too insensitive, and possibly too biased as well, to detect the risk of badly adjusted bindings. Direct measurements of the setting of bindings of uninjured and injured skiers seems indispensable in obserwational studies. Some indirect evidence in favor of a preventive effect of the use of a test device, stems from the observation that among these skiers two bindings released directly prior to injury in $31 \%$ of the LE cases. For adjustment ith information only and adjustment without any information this happened in only $26 \%$ and $11 \%$ of the LE cases respectively. 
The fact that binding adjustment in a skishop in the ski area was associated th an elevated injury risk compared to adjustment in the Netherlands seems to confirm the widespread but poorly documented opinion that Dutch skishops perform the binding adjustment more precisely and use a test device more often. Our study could confirm the second part of this opinion. Dutch skishops (67\%) used a test device more often than the shops in the ski area $(36 \%)$. Furthermore, only $4 \%$ of the binding adjustments in Holland was performed without any relevant information. Among the skiers who had their bindings adjusted in a shop abroad, this figure was as high as $28 \%$. A further study comparing directly the quality of binding adjustment in different European countries is required, before reliable conclusions can be drawn from this abservation. Rented or borrowed skis were associated with a higher accident risk, also after correction for confounding by ability. This could be an indication of the risks of much used or low quality equipment, or maybe also of poorly performed adjustment. Our study is inconclusive on these points. Further research is indicated into these postulated risk factors, which are principally open to manipulation. The association of absence of knowledge on type of skis and age of skis and bindings with a higher risk may indicate an attitude of negligence. This interpretation is consistent with the finding that in the logistic model the effect of inadequate knowledge increased with increasing winter sport experience: to stay ignorant for many years implies a very indifferent attitude to equipment. Clearly this interpretation is mainly ad hoc and needs to be confirmed in future studies. At first glance the elevated risk for those who leave their skis outside at night would seen to point to incorrect binding function due to freezing. This, however, is inconsistent with the fact that the habit of leaving the skis outside elevates especially the risk for non-LE injury.

Furthermore, we can think of no plausible explanation for the finding that this variable increases the risk only among those who do not take ski lessons. We tend to consider the effect of leaving the skis outside coincidental within our data. 
The third and final question relevant to the topic is whether an intervention in the form of an adequate adjustment of the binding can prevent (LEER) injury. We did not investigate this crucial question, which has been the subject of only one study. ${ }^{15}$ our findings concerning the release of binding prior to injury suggests that there still is much to be done concerning timely release. Whether the solution should be sought in better technical design or in better adjustment of the bindings cannot be determined from our data. Although two third of the skiers in our study reported recent adjustment and half of our study population said that the proper methods were followed, it may still be worthwile to test in an experimental design the efficacy of optimal adjustment for Dutch skiers.

\section{CONCLUSTON}

The isk for lower extremity injury compared to non-lower extremity injury is elevated when no binding release occurs prior to the injury (OR=3.3). The proportion of no release is highest for knee injuries, suggesting that there is still much to be done concerning design and adjustment of the bindings in order to protect the knee properly.

No effect on the injury risk could be found concerning the moment of adjustment, the method of adjustment, and the person performing the adjustment. It is suggested that direct measurement of binding function is indispensable in observational. studies. Sking on rented or borrowed skis is associated with an elevated injury risk. The same holds for (persistent) ignorance on the type of skis and the age of skis and bindings. These observations seem plausible and interpretations are suggested. Further investigations should clarify these rigks.

Binding function seems still to be an important risk factor open to manipulation. Experimental studies in which the bindings of randomly chosen skiers are optimally adjusted could elucidate the current contribution of bad adjustment to injury risk in dowhill skiling. 


\section{REFERENCES}

1. Baker $R J$, Nelder $J A$ : The GLTM System. Release 3. Oxford, Numerical Algorithms Group; 1978

2. Bouter L M, Knipschild P G: Risicofactoren van skiletsel. T Soc Gez Zorg 63: 846-851, 1985

3. Bouter L M, Knipschild P G: Skirisico's. Maastricht, Rijksuniversiteit Limburg, 1985

4. Bouter L M, Knipschild P G, Feij J A, et al: Sensation seeking and injury risk in downill skitng. Pers Ind Diff 9 (1988) $667-673$

5. Bouter L M, Knipschild P G, Volovics A: Ability and physical condition in relation to injury risk in downhill skiling. Accepted for publication in sking Trauma and Safety. R J Johnson \& C D Mote (eds), Philadelphia, ASTM.

6. Bouter L M, Knipschild P G, Volovics A: Personal and envi conmental factors in relation to injury risk in downhill skiing. Submitted for publication

7. CBS: Vakantie onderzoek 1985. 's-Gravenhage, Staatsuitgeverij, 1 ?

8. Danielsson K, Eriksson E, Jonsson E, et al: Attempts to reduce the incidence of skiing injuries in Sweden. In: Skiling Trauma and Safety. R J Johnson \& C D Mote (eds), Philadelphia, ASTM, 1985

9. Delouche $G$ : Bindings' release setting in alpine skilng. In: Sking Trauma and Safety. C D Mote \& R Johnson (eds), Philadelphia, ASTM, 1987

10. DJxon U J: BMDP Statistical software, Berkeley, University of Callfornta Press 1983

11. Eriksson E, Johnson $R J$ : The etiology of downhil ski injuries * Exerc Sport Sci Rev 8:1-17, 1980

12. Ettlinger C F, R J Johnson: The state of the art in preventing equipment-related alpine sti injuries. clin in Sports Med 1: $199-207,1982$

13. Hauser $\&$ Gläser H: Alpine Skiunfälle und Verletzungen. München, 1985

14. Hauser \& Gläser H: Verletzungen beim alpinen Skilauf. Veränderungen und Trends. Deutsche Zeitschr Sportmed 38: $191-198,1987$ 
15. Hauser W: Experimental prospective sking injury study. Paper presented at the Eighth International Symposium on ski trauma and skiing safety, Chamonix, 1987

16. Jaffin B: An epidemiologic study of ski injuries: Vail Colorado. The mount Sinai $J$ of Med 48: 353-359, 1981

17. Johnson $R J$, Pope $M H$, Weisman $G$, et al: Knee injury in skiing. Am J Sports Med 7: 321-327, 1979

18. Johnson $R J$, Ettlinger $G F$, Campbell $R \mathrm{~J}$, et al: Trends in skiing injuries. Am J Sports Med 8: 106-113, 1980

19. Johnson $R$ J, Ettlinger C F: Alpine ski injuries: changes through the years. Clin in Sports Med 1: 181-196, 1982

20. Kleinbaum D G, Kupper L L, Morgenstern H: EpidemiologiC research: principles and quantitative methods. Belmont, Lifetime Learning Publications, 1982

21. Knipschild P G, Bouter L M: Risk factors for ski injuries. A crash course of epidemiologic methods ith emphasis on comparability in experiments and casemcontral studies. Accepted for publication in Skiing Trauma and Skiling Safety. R J Johnson \& C D Mote (eds), Philadelphia, ASTM

22. Kuriyama $S$, Fujimaki $E$ : Current trends in ski injuxies and their relationship to recent changes in ski equipment. In: Skiing Trauma and Safety. C D Mote \& R J Johnson (eds), Phil ladelphia, ASTM, 1987

23. Lystad H: A one-year study of alpine ski injuries in Hemsedal, Norway. In: Skiing Trauma and Safety. $\mathrm{R} J$ Johnson \& C D Mote (eds), Philadelphia, ASTM, 1985

24. Nagel A, Mösch S: Test devices for ski bindings sold in sport shops: state of the art and future development. In: Skiling Trauma and Safety. C D Mote R J Johnson (eds), Philladelphia, ASTM, 1987

25. Shealy J E, Geyer L H, Hayden R: Epidemiology of ski injuries: effect of method of skill acquisition and release binding accident rates. Human Factors 16:459-473, 1974

26. Shealy J $E$ : Overall analysis of NSAA/ASTM data on skiling injuries for 1978 through 1981. In: Skiing Trauma and Safety. R J Johnson \& C D Mote (eds) Philadelphia, ASTM, 1985 
27. Sugawara $M$, Serita $K$, Takada $Y$, et al: Analysis of sking injuries in Sapporo, Japan, during 1979 through 1984. In: Skiling Trauma and Safety. C D Hote \& $R$ J Johnson (eds), Philadelphia, ASTM, 1985

28. Tapper E D: Ski injuries from 1939 to 1976: the Sun Valley expertence. Am J Sports Med 6: 114-121, 1978

29. Ungerholm $\mathrm{s}$, Gierup $J$, Gustavsson $J$, et al: Skiling safety in children: adjustment and reliability of bindings. Int $\mathrm{J}$ Sports Med 5: $325-329,1984$

30. Ungerholm $\mathrm{S}$, Gustavsson $\mathrm{J}$ : Skilng safety in children: a prospective study of downhill injuries and their relation to the skier and his equipment. Int J Sports Med 6: 353-358, 1985

31. Volovics A, Bouter L M, Knipschild P G: Modelling injury risks for downhill skiers. Paper presented at Eighth International Conference of the International Society for Clinical Biostatistics, Gothenburg, 1987

32. Young $L \mathrm{R}$, Oman $\mathrm{C} M$, Crane $H_{\text {, }}$ et al: The etiology of ski injuries: an eight year study of the skier and his equipment. arthoped Clin of $\mathrm{N}$ Am $7: 13-29,1976$

33. Young $L R$, Crane H D: Thumbs up: the changing pattern of ski injuries. In: Skiing Trauma and Safety. R J Johnson \& C D Mote (eds), Philadelphia, ASTM, 1985 
CHAPTER 5

PERSONAL AND ENVIRONMENTAL FACTORS IN RELATION TO INJURY RISK IN DOWNHILL SKIING*

Lex M. Bouter, Paul G. Knipschild \& Alexander Volovics 


\section{ABSTRACT}

A case-control study $(N=1148)$ was conducted among Dutch downill skiers. This article presents data on the circumstances of the accident leading to injury, and on personal and environmental risk factors for both cases $(N=572)$ and controls $(N=576)$. Most accidents $(84 \%)$ happened on the pistes and ski lifts were involved in about $6 \%$ of them. Bad condition of ski run (30\%) and lost balance ( $24 \%$ ) were the direct causes most frequently mentioned. Rlsk seemed to be constant for particular days and moments of the day. Injury risk for the individual appeared to rise with increasing duration of exposure, although very small durations had an elevated risk as well. A relatively low risk was observed for skiers who reported to be only moderately rested $(O R=0.4)$ and for those who admitted a certain fear of having a ski accident $(O \mathbb{R}=0.6)$. A relatively high risk was observed for the presence of icy spots $(O R=1.4)$, while poor visibility $(O R=0.4)$, the presence of clouds $(O R=0.5)$ and perceived coldness $(O R=0.5)$ were associated with a relatively low injury risk. No recommendations for prevention can be based on these results. Most factors mentioned are not open to manipulation and further quantification should involve prospective study designs and independent measurement of relevant factors. 
Much has been written about the risks of downhil1 sking over recent decades. Most authors agree that nowadays the incidence of serious injury needing substantial medical treatment ranges between 2 and 4 per 1000 skier days. 15,26,32 Although a large number of potential risk factors are mentioned in the literature, only a small number of studies have been aimed at quantifying the effect of these factors on the injury risk of downhill skilng. 6 The inclusion of a comparable control group of uninjured skiers is still not common practice and an adequate multivariatte analysis of the data is almost never performed. 20

During the $1984 / 1985$ season a case-control study was conducted among Dutch skiers. ${ }^{7}$ In this study information was collected concerning a broad spectrum of putative risk factors. This: article focusses firstly on the circumstances directly prior to injury for which no meaningful information can be gathered from the controls. Secondly, data on several personal and environmental factors for both cases and controls will be presented, the risks of which cannot be assessed with confidence from earlier studies. Data presented on personal factors wil include smoking, sleeping, education, menstruation, fear of an accident and duration of period at risk. The section on environmental factors will include snow quality, visibility, marking of pistes, perceived temperature and cloud cover. our data on risk factors which have been already studied in some detall by others (e.g. ability, physical condition, binding adjustment) is presented elsewhere. 8,10

In a number of studies the self-reported direct causes of the accident leading to injury have been presented. Because different scales are used, it is difficult to compare the results. Some $11-20 \%$ of injuries are attributed to a collision, with $6-16 \%$ involving an object and $3-8 \%$ another skier. $14,17,24,25,27,28$ Collision injuries, moreover, tend to be rellatively serious. 14,27 It is not surprising that a fall (due to several causes) is held responsible for the majority $(70-90 \%)$ of the injuries. $3,18,24,25,28$ Premature release of the binding is mentioned as a direct cause by $2-6 \%$ of the injured cases ${ }^{14,25,28}$ and problems 
concerning the ski lift (T-bar lifts especially) by $2-9 \% *^{23}, 24,25,28$ Most accidents leading to injury (90-95\%) happen on the pistes, probably because that is where most of the sking is done. 3,30 About $15 \%$ of the cases report having a very high veloctly directly prior to the accident leading to injury, about $55 \%$ going moderately fast, about $28 \%$ sking slowly at this moment and about $2 \%$ standing sti11. 17,18 Fatal injuries occur less than once 1 in a million skier days, mostly as a consequence of collision with a tree at high velocity. $21,27,28$ In a large $s^{2}$ tudy $^{26} 90 \%$ of the cases appeared to be involved in free sking at the moment of the accident leading to injury, while $5 \%$ were taking a ski lesson and $2 \%$ were racing.

The moment of injury can be expressed as day in the week, time of the day or number of hours skied prior to the accident. Despite a fair amount of discussion, no consensus exists on the relative risks of these different moments. This is mainly due to the fact that the number of skiers at risk at the different moments is unknown. Most injuries occur during weekends, 14,31 al though Monday is also mentioned as a dangerous day. ${ }^{4,22}$ The dangers of the third day of skilng are not supported by the available data. ${ }^{4,14}$ Some authors conclude that accidents occur relatively less frequently during the morning, pointing to exhaustion as a risk factor, $3,18,22,29,31$ while others hypothesize a constant risk over the day. 14,16 on average, cases have already skied about 3 hours prior to injury. 3,31

Nowadays incidence figures are mostly expressed per 1000 skier days at risk. The individual risk can be also looked upon as a function of the duration of exposure. In a case-control study differences in planned exposure can be a confounding factor, and consequently in our study the number of skiing hours planned during the hollday has been calculated and adjusted for in the multivariate analysis. Differences in height and weight between cases and controls are usually not found or attributed to confounding by age and/or ability. 13,14,16,31 Some authors 4,22 mention a low risk for more highly educated skiers, but data on uninjured skiers is lacking. Skiers seem to sleep more than 
enough ${ }^{4}$ and no differences in duration of sleep have been reported between cases and controls. ${ }^{13}$ Different opinions with respect to the role of fear of an accident are mentioned in the literature. ${ }^{3,4} \mathrm{~A}$ possible association between accident risk and menstrual period has been mentioned by one study only. ${ }^{4}$

Snow quality is an environmental risk factor that has been investigated rather frequently. Most authors agree that icy or hard packed snow leads to a higher proportion of upper extremity and head injuries, while in wet or powder snow lower extremity injuries, tibia fractures especially, are relatively frequent. $14,18,29$ There is doubt, however, about the influence of snow quality on the incidence of injury. ${ }^{3,4,16}$ one study ${ }^{22}$ has reported double accident risk on icy surfaces. Visibility problems are mentioned by about $20 \%$ of the skiers, but no clear relation to injury risk is agreed upon. ${ }^{3,16,18}$ an elevated injury risk is reported for cloudless weather and this holds when the fact that pistes are more crowded in good weather is taken into account. ${ }^{4,22}$ Some authors ${ }^{2,5}$ attribute the relatively high risk of good skiing weather to a biological or psychological influence of high atmospheric pressure.

\section{MATERIAL AND METHODS}

Cases and controls during the 1984/1985 season were obtained from the records of a company covering roughly one third of the market for ski insurance in the Netherlands. Most Dutch skiers are insured. The cases selected were skiers who had claimed for medical costs as a result of a ski injury that made skiling or other activities impossible for more than one day. All casualties suffering a fracture, a dislocation or a ruptured ligament were selected. Furthermore, a sample was taken of less severe injuries. In addition to this, a number of cases were selected who had been repatriated by the organisation selling the insurances. For every case of injury selected, an equal number of uninjured skiers was chosen by taking the next claim from an uninjured skier received by the insurance company for other reasons (e.g. loss or theft). 
A postal questionnaire was sent shortly after the ski holiday to the population thus defined. Reninders were sent after 10 and 20 days. The questionnaire consisted of 80 items for the controls and 120 items for the cases. For both groups information was collected in a comparative way on most risk factors mentioned in scientific and popular literature. In addition to this, cases were questioned about the circumstances of the accident and the subsequent injury.

Data analysis was performed in two stages with the aid of BMDP and GLIM statistical software. ${ }^{1,12}$ Firstly an elementary analysis was performed in which confounding by age and gender was adjusted for. The distribution of categorical risk factors was calculated for cases and controls based on direct standardization for age in three categories and for gender. For these categorical variables odds ratios (OR) were calculated as a weighted average over the six strata for age and gender using the Mantel-Haenszel method ith the test-based $95 \%$ canfidence interval (CI) following the method of Miettinen. 19

The second stage of data analysis concerned a more complete control for confounding and first order interaction. For this purpose a $\log i s t$ ic mode $1^{19}$ was fitted based on a selection of 25 variables. In the final model 20 variables remained and 12 interaction terms were included. From the logistic regression coefficients in this model adjusted odds ratios with their approxinate $95 \%$ confidence intervals are calculated. 19

RESULTS

\section{Response}

Response was vell over $80 \%$ and about the same for cases (84\%) and controls $(82 \%)$. Cases responded slightly faster. The majority (81\%) of the 1540 respondents practised downil1 skiing only. The others were cross-country skiers or practised both and were excluded from the analysis. A number of skiers (103) did claim 
medical costs, but appeared not to have been prewented from sking or other activities for one day or longer. These were also excluded from analysis. Data on 1148 downhill skiers were analysed, consisting of 572 cases and 576 controls.

Between cases and controls slight differences in age and a rather strong difference in gender distribution were found. Mean age for the cases was 32.0 years and for the controls 32.6 years. This is similar to the mean age ( 32 years) of active skiers among a representative sample of the Dutch population. ${ }^{11}$ Forty-six percent of the cases were males compared to $67 \%$ of the controls. Among a representative sample of the Dutch population females appeared to go on winter sports as often as males. ${ }^{11}$ In our opinion these figures reflect selection bias due to the way the controls have been chosen. In the Netherlands males are probably still mentioned more often as the owner of lost or stolen objects, because they are considered to be the head of family. The consequence is that the risks associated with age and gender cannot be estimated from our study. For the same reason every odds ratio presented is adjusted for confounding by age and gender.

\section{Circumstances}

During their holiday the cases in our study had been sking on average for 4 days prior to the day of the accident leading to injury. Table 5-1 shows a similar distribution for males and females. Females skied on the average 2.4 hours and males 2.7 hours prior tho the accident on the same day. The accident happened on the average at about $1: 20 \mathrm{p}$.m. for both sexes. Table 1 presents the distribution of these variables for males and females.

The majority (about $85 \%$ ) of the accidents happened on the plistes (table 5-2). About one third of the cases mentioned a high or a very high welocity directly prior to the accident leading to injury, while about $7 \%$ were standing still at that moment (table $5-2)$. 
Table 5-1. Mower of the aceident leading to jnjury for ales and ferates.

\section{HALES (H-265) PEMALES (NA 307$)$}

sumber ot days shited before

aceldent dur ing this hollday:

\begin{tabular}{lll}
2 or less & $35 \%$ & $35 \%$ \\
3 or 4 & $25 \%$ & $29 \%$ \\
5 or 6 & $22 \%$ & $21 \%$ \\
7 or more & $20 \%$ & $15 \%$ \\
\hline
\end{tabular}

Nutuber of hours shled toefore accident on the same day:

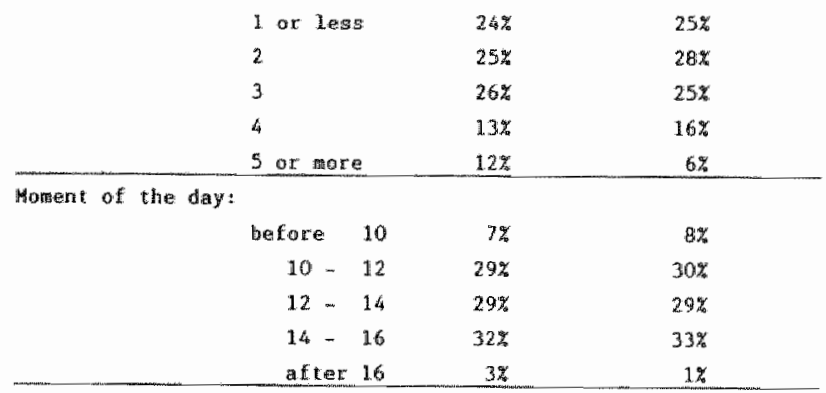

Half of the cases was descending (free sking), while $24 \%$ of the males and $16 \%$ of the females was golng straight downhill ("schuss") directly prior to the accident leading to injury (table 5-2).

A quarter of the female and one third of the male cases of injury attributed their accident to the bad condition of the ski run (table 5-3). Another quarter of the cases mentioned loss of ballance as a direct cause, while some $10 \%$ got stuck in a snow wall (table 5-3). Only $2 \%$ reported a collision with an object, but $4 \%$ of the malles and $8 \%$ of the females collided with another skier. Premature release of binding was mentioned as a direct cause by almost no one (table $5-3$ ).

\section{Personal factors}

Although cases skied daily on average 12 minutes shorter than the controls, their planned number of hours skiing during the holiday was slightly higher (53 versus 51 hours). This was due to the fact that the planned duration of the holiday of the cases was on the average a half day longer. 
Table 5-2. Circuastances directy prot to injury for ales and fenales.

\begin{tabular}{|c|c|c|}
\hline & MALES $(N-265)$ & FEMALES $(N-307)$ \\
\hline \multicolumn{3}{|l|}{ Place of accident: } \\
\hline piste & $a 7 z$ & $81 x$ \\
\hline path & $2 z$ & $\mathbb{1}$ \\
\hline off ski run & 48 & $5 \pi$ \\
\hline sid lift & 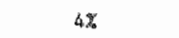 & $7 \pi$ \\
\hline not sking & 42 & $5 x$ \\
\hline \multicolumn{3}{|l|}{ Veloct ty: } \\
\hline zero & $7 x$ & 89 \\
\hline low & $23 \%$ & $30 \%$ \\
\hline moderate & 34 & $32 x$ \\
\hline fast & $27 x$ & $21 \%$ \\
\hline very fast & 90 & $9 \%$ \\
\hline \multicolumn{3}{|l|}{ Activity: } \\
\hline descending & $52 \%$ & $50 \%$ \\
\hline going straight dowhill & $24 \%$ & 168 \\
\hline ski lesson & $10 \%$ & 172 \\
\hline stand ing & $5 \%$ & 97 \\
\hline completition & $2 \%$ & $0 \%$ \\
\hline other & $7 \%$ & 82 \\
\hline
\end{tabular}

Table $5-3$. Self-reported drect cause of the accident leading to injury for males and fenales.

\begin{tabular}{|c|c|c|}
\hline & NALES $(\mathrm{N}=265)$ & FEHALES $(\mathrm{N}=307)$ \\
\hline Rat condition of ski run & $34 \%$ & $26 \%$ \\
\hline Lost balance & $23 \%$ & $25 \%$ \\
\hline cot situck in snow waIl & $10 \%$ & $9 \%$ \\
\hline Haking eyasive manoewre & $9 \%$ & $6 \%$ \\
\hline Collision wh other skier & $4 \%$ & $8 \%$ \\
\hline Slipped & $3 \%$ & $6 \%$ \\
\hline Fiall following junp & $4 \%$ & $2 \%$ \\
\hline Collistion th an object & $2 \%$ & $2 \%$ \\
\hline Premature releque of boding & $1 \mathrm{~g}$ & $a x$ \\
\hline \multirow[t]{2}{*}{ Qther } & $10 \%$ & $16 \%$ \\
\hline & $100 \%$ & $100 \%$ \\
\hline
\end{tabular}

This does not imply that the risk of injury is uniform for all levels of duration of exposure. Figure 5-1 shows the odds ratios at different levels calculated from the logistic model. As expected, risk rises with increasing duration of exposure, 
although not monotonically. The higher risk for a short duration of exposure is much more pronounced when unadjusted data are taken, probably because beginners (who have a higher risk) ski less.

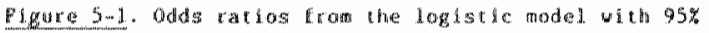
confidence invervall bounds for planned mumber of:

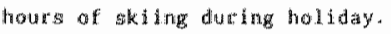

\section{ODDS RATTOS}

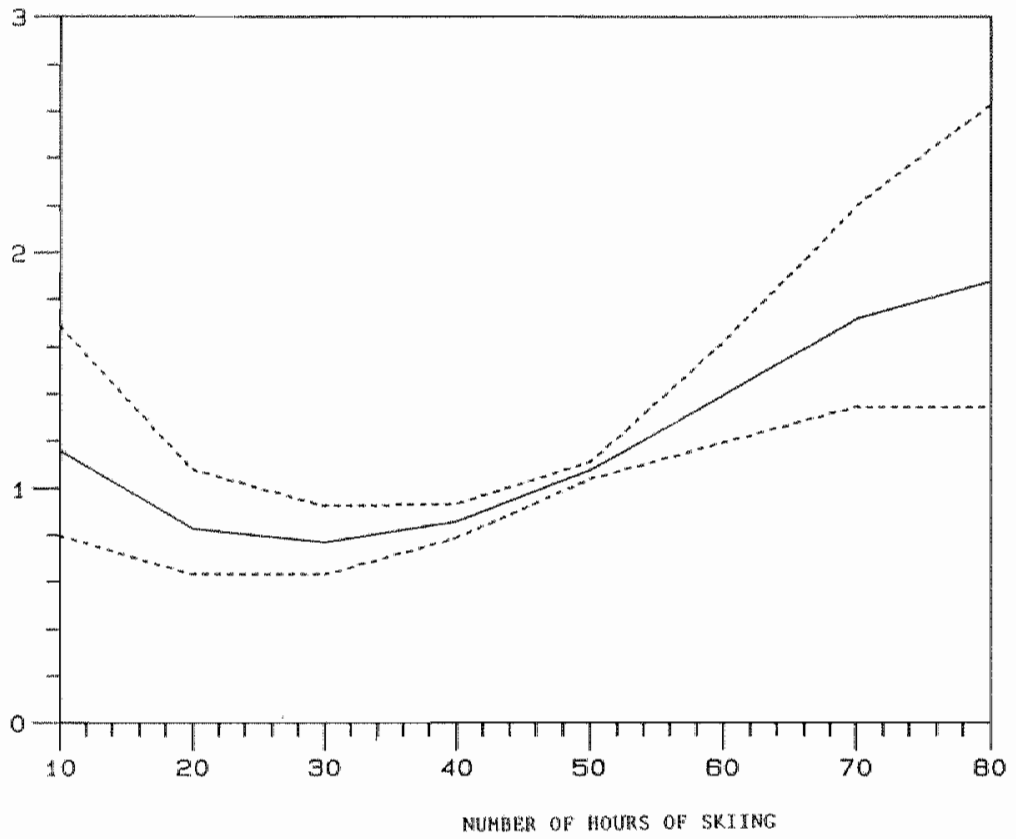

The skllers in our study were on the average $175 \mathrm{~cm}$. tall and welghed about $70 \mathrm{~kg}$. Cases were slightly smaller and $11 \mathrm{ghter}$. The average quetelet Index was similar for male (24.4) and female (23.4) skiers, although the distribution over the range showed some differences. Table 5-4 shows the Quetelet Index in three categories for males and females separately. Relatively underweight skiers (OI $\leq 20$ ) appear to have an elevated risk compared to skiers with a Quetelet Index between 20 and 27 (OR = 1.8; CI $=1.2-2.7)$. There appeared to be no effect on injury risk of relative overwelight ( $O I \geq 27$ ). These effects were also found 
in the logistic model, but appeared to be complucated by seweral first order interactions.

Table 5-4. Qwetelet Index for male and fenale cases and controls.

HALES

OI CASES CONTROLS OR (CI $)^{2)}$ CASES CONTROLS OR $(\mathrm{CT})^{2)}$

$\begin{array}{rrrlrll}\leq 20 & 10 \% & 7 \% & 1.6(0.8-3.2) & 23 \% & 14 \% & 2.0(1.1-3.3) \\ 20-27 & 81 \% & 84 \% & 1.0 & 74 \% & 82 z & 1.0 \\ \geq 27 & 9 \% & 9 \% & 0.9(0.3-3.2) & 3 \% & 4 \% & 0.8(0.1-7.7)\end{array}$

1) Quetellet Index

2) Odds Ratio as veighted average over 3 strata for age (Hantel-Haenszel) followed by a test-based $95 x$ confidence interval (Mietrinen).

Some $90 \%$ of the skiers felt rested on the day of the accident (for the cases) or on an arbitrary day (penultimate day on which one skied) (for the controls). Surprisingly, the risk of injury was lower among those who reported to be only moderately rested (table 5-5). The same effect appeared in the logistic model. This agrees with the fact that cases slept on the average 9.5 hours prior to the day of the accident, while controls slept on the average 8.6 hours prior to an arbitrary day.

No clear effect of menstruation on injury risk could be found among female skiers (table 5-5). Respondents who admitted to having been slightly afraid of an accident before their holtday appeared to have a lower injury risk compared to those who said they were not afraid (table 5-6). This effect also appears in the logistic model. More highly educated skiers tended to have lower injury risk, while smokers (on the average 13 cigarettes a day) appeared to have higher injury risk (table 5-5). The latter effect was even more pronounced in the logistic model (OR 1.7 ; $\mathrm{CI}=1 \cdot 2-2 \cdot 6$ ).

\section{Environmental factors}

Most skiers ( $86 \%$ ) had the opinion that the pistes were well marked and this did not differ between cases and controls (table 5-6). 
Table 5-5. Some protsonal risk factors for cases and controls.

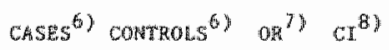

\begin{tabular}{|c|c|c|c|c|}
\hline \multicolumn{5}{|l|}{ Feeling rested: IJ } \\
\hline good & $94 \%$ & $86 \%$ & 1.0 & \\
\hline moderato & $6 \%$ & $12 \%$ & 0.4 & $0,3-0,7$ \\
\hline Had & 0 & $1 \%$ & & \\
\hline \multicolumn{5}{|l|}{ 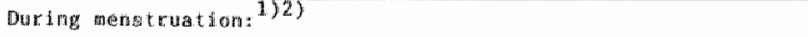 } \\
\hline no & $85 \%$ & $87 \%$ & 1.0 & \\
\hline yes & $15 \%$ & $13 x$ & 1.2 & $0.6-2.5$ \\
\hline \multicolumn{5}{|l|}{ 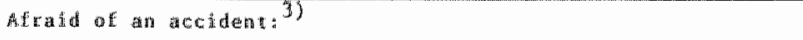 } \\
\hline not aftatid & 87 & $80 \%$ & 1.0 & \\
\hline gleghely fraid & 13 & $19 \%$ & 0.6 & $0.4-0.6$ \\
\hline very afraid & of & $-1 \%$ & & \\
\hline \multicolumn{5}{|l|}{ Education: ${ }^{4}$} \\
\hline \multicolumn{5}{|l|}{ why luerstry or higher } \\
\hline professtonal educatton & $8 \%$ & $35 \%$ & 1.0 & \\
\hline other educat ian & 728 & $65 \%$ & 1.4 & $1 \cdot 1-1 \cdot B$ \\
\hline \multicolumn{5}{|l|}{ Smoking 5$)$} \\
\hline non-smokier & $56 \%$ & 630 & 1.0 & \\
\hline gmoker & $44 \%$ & $37 \%$ & 1.4 & $1.1-1.0$ \\
\hline
\end{tabular}

1) on the day of the accident for cases and on an arbitracy day for controls

2) among women having menstrual perious only

3) before the shi hollday

4) highest educattor success fully concluded

5) during the year before the ski holiday

6) percentages based on difect stalndardization ( 6 strata) tor age and gender

7) odds ratio as velghted average over 6 strata for age and gender (Han te.-.Haenszel)

B) test-based $95 \%$ confjdence interval (Miettinen).

Items concerning the weather deal with the day of the accident leading to injury for the cases and with an arbitrary day for the controls. The presence of icy spots was associlated with an elevated injury risk. This association also shows within the logistic model. No influence of the thickness of snow could be detected. Furthermore, the risk of injury appeared to be thigher on cloudless days (table 5-6). This agrees with the observation that good visibility was associated with a higher accident risk. More than $30 \%$ of the cases called the day of the accident a (slightly) cold day, while almost half of the controls thought the same of the arbitrany day. The preventive effect of perceived coldness appeared also in the $\log$ istic model. 


\section{DISCUSSION}

Despite the fact that our group of cases is not a random sample of all injured Dutch downhill skiers, the circumstances of the accident leading to injury mentioned by our cases are in reasonable agreement with earlier studies. Elsewhere 10 it is argued that the same holds for the affected parts of the body, and the type and severity of the injury. Our data confirm that most accidents $(84 \%)$ happen on the pistes ${ }^{3,30}$ and that siki 1 ifts are involved in about $6 \%$ of the accidents leading to injury. $23,24,25,28$ In our study collisions with an object $(2 \%)$ were mentioned less often than in other studies. $14,17,24,25,27$

Premature release of binding was hardly mentioned by our respondents as a direct cause of injury.

Table 5-6. Some environmental tisk tactors for cases and controls.

$$
\text { CASES } \left.^{3)} \operatorname{CONTROLS}^{3)} \text { OF}^{4)} \mathrm{CI}^{5}\right)
$$

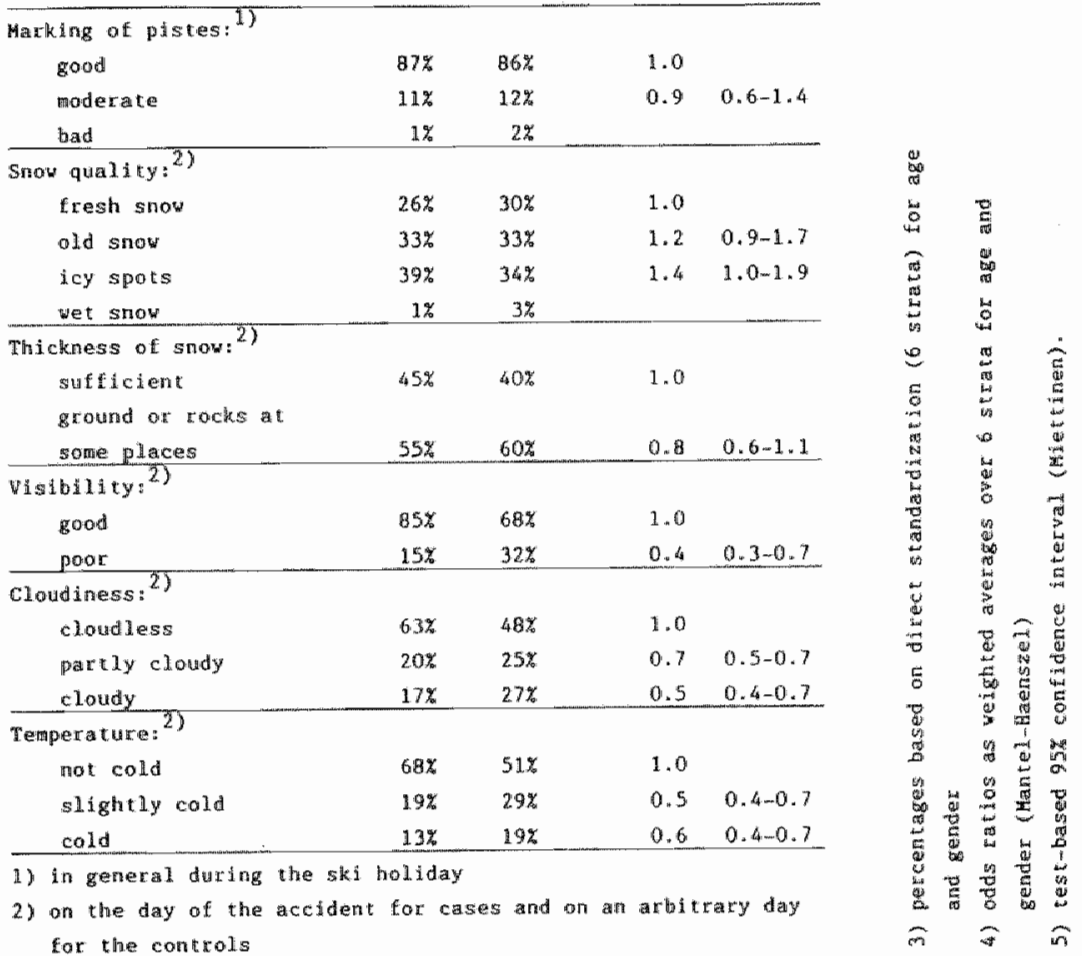


Compared to shealy $s^{26}$ study quite a lot of males (10\%) and even more females (17\%) were taking a ski lesson at the moment of the accident. This does not mean that ski lessons are dangerous. On the contrary, elsewhere ${ }^{8} i t$ is suggested from our data that ski lessons have an important protective effect, for beginners especially. Our data on the moment of the accident leading to injury seem consistent with the hypothesis that the risk is constant ower time, ${ }^{14}$, 16 although data on the population at risk over time is also lacking in our study.

Risk can only be assessed for factors for which comparable information is available for both cases and controls. The validity of this comparison can be impaired by selection bias, information bias and uncontrolled confounding. We have already mentioned that there is probably some selection bias with respect to age and gender due to the way the controls were selected. This bias, however, is adjusted for in every association measure. There seems to be no reason to postulate other selection biases in relation to the risk factors presented here. The same holds for selection bias due to differential non-response. Response was high and in no observable way selective.

Information bias is concerned with the question whether the information gathered is comparable between cases and controls. The choice of the control group (loss or theft) makes information bias due to selective recall less probable. Controls thus also had a reason to remember the detalls of their ski holiday. An inherent limitation of our study is that all the information we gathered was based on self-assessment. Consequently, the study lacks precise and objective information on weather and snow quality for example. Furthermore, data collection was retrospective and as a consequence of the known outcome (injury or no injury) the assessment of certain risk factors might be influenced. For this reason it could be expected that cases tended to mention a colder temperature, less sleep and more fear of an accident. This would lead to a bias towards the null. This means that the reported odds ratios concerning these factors would be underestimated to some extent. Probably less subjectiwe 
items, such a duration of planned exposition, smoking and education, are less susceptible to this type of bias.

Uncontrolled confounding is the third and last issue in the assessment of internal validity. All odds ratios presented are controlled for differences in age and gender. Furthermore, the logistic model adjusts for every important confounder on which we collected information. This of course does not exclude bias due to unmeasured confounders, nor confounding due to imprecise measurement. For the interpretation of the association between putative risk factors and injury risk which we did or did not find in our data, credibility is at least as important as statistical significance. Thus the results of our study must be interpreted in the context of earlier investigations and (biological) plausibility. For this we return to the results concerning personal and environmental factors from this article.

The observation that injury risk generally rose the greater number of hours of skiing planned during the holiday is certainly not implausible. The elevated risk among those who planned to ski only for a very short period can be explained by assuming a somewhat higher risk during the first hours due to the fact that the skier has to get used to skiing again. Dutch skiers are holiday skiers usually skiing only once a year. The elevated risk for skiers with a Quetelet Index of 20 or less was never reported before. This variable is difficult to interpret. Females with the same Quetelet Index have a higher percentage body fat compared to males. A possible (partial) explanation for this finding could be that relatively lightly built skiers are poorly protected by the current ski bindings ${ }^{10}$. Another (ad hoc) explanation would be that body fat protects against the consequences of a fall. Our data confirm the opinion ${ }^{4}$ that skiers sleep more than enough. The preventive effect of feeling only moderately rested has not been reported before and is difficult to interpret. This could be thought to concur with the hypothesis that relaxed skiers tend to underestimate the risks. The observation that being afrald of an accident before the holiday has a preventive effect could also be due to risk underestimation by fearless skiers. Something analog 
can be hypothesized to explain the finding that smokers and less highly educated skiers had an higher injury risk. However, elsewhere ${ }^{9}$ present data from which it is concluded that recklessness is probably not an important cause of injury in downhil skiling.

The questions concerning snow quality and weather were put twice to our respondents. The first series concerned the day of the accident for the cases and the penultimate day of skiing for the controls. The second series addressed the general situation during the ski holiday, inviting both cases and controls to generate their own average score. The items from the first series were considered to be more valid because of the focus on the circumstances on the moment of injury cor on an arbitrary moment for the controls). It can also be expected that skiers had difficulty in generalizing over their whole holiday: some respondents remarked to this effect on the questionnaire. The adds ratios based on items concerning the general situation indicated in general weaker associations in the same direction.

our data confirm the elevated injury risk, reported by Lamont, 22 when icy spots are present. We could also confirm the relatively high accldent risk during good skilng weather (cloudless, not cold and good visibility) described by others. 2,4,5,22 Because our study lacks objective meteorological information, we must be careful in drawing conclusions from this. The way these questions were put guaranteed that both cases and controls skled on the day to which these answers refer, but it cannot be excluded that skiers skied fewer hours andfor took less difficult ski runs on days of less favorable weather. Another alternative explanation would be that skiers are more careful under sub-optimal weather conditions.

Taken together the results presented in this article do not lead to firm recommendations with respect to prevention of ski injury. This is primarily due to the fact that by their own nature most of the personal and environmental risk factors discussed are not open to manipulation. Furthermore, it appears that the existing 
small empirical basis for the risks associated with some of these factors could not be confirmed by our data. Further studies should have a prospective design (for the personal factors especially) and/or should use independent objective information (for the environmental factors especially). The value of such future studies would lie in increasing our knowledge of persons and/or situations with an elevated injury risk.

\section{CONCLUSION}

Accidents leading to ski injury happen mostly on the pistes. Ski lifts are involved in $6 \%$ of the cases only. Premature release of binding and collisions with an object are rare. Injury risk is probably constant over the days of the week, the hours of the day and the number of days in the ski holiday.

Injury risk increases with increasing duration of the period at risk. Very small durations are connected to an elevated injury risk as well. A relatively low risk is observed for skiers who report to be only moderately rested, who are somewhat afraid of a ski accident, who have had a higher education and who are non-smokers. Environmental factors associated with a higher risk include the presence of lcy spots, good visibility, and the absence of clouds and coldness. 
REFERENCES

1. Baker R.J., Nelder J.A.: The GLIM System. Release 3. Oxford, Numerical Algorithms Group, 1978.

2. Bernett P., Hang W.: Skisportverletzungen und Wet terphasen. Mschr Unfallheilk 75: 485-492, 1972.

3. Bernett P., Schöffel U.: Ursache und Prophylaxe von Skiverletzungen. Münch Med Uschr 124: 178-182, 1982.

4. Biener K., Fasler S.: Sportunfälle. Bern, Verlag Hans Huber, 1978.

5. Biener K., Freihofer B., Schwarzenbach F.: Wetter und Skitunfälle. Münch Med Wschr 12: 427-430, 1979.

6. Bouter L.M., Knipschild P.G.: Risicofactoren van skiletsel. Tijdschr Soc Gez Zorg 63: 846-851, 1985.

7. Bouter L.M., Knipschild P.G.: Skirisico's. Maastricht, Rijksuniversiteit Limburg, 1985.

B. Bouter L.M., Knipschild P.G., Volovics A.: Ability and physical condition in relation to injury risk in downhill skiling. Accepted for publication in Johnson R.J., Mote C.D. (eds.) Skiing Trauma and Safety. Philadelphia, ASTM.

9. Bouter L.M., Knipschild P.G., Feij J.A., Volovics A.: Sensation seeking and injury risk in downhill skiing. Pers Indiv Diff 9: 667-673, 1988.

10. Bouter L.M., Knipschild P.G., Volovics A.: Characteristics of ski and binding in relation to injury risk in downhill skilng. Accepted for publication in the American Journal of Sports Medicine.

11. C.B.S.: Vakantie Onderzoek 1985. 's Gravenhage, Staatsuitgeverij, 1987.

12. Dixon W.J.: BMDP Statistical Software. Berkeley, University of California Press, 1983.

13. Haddon W., Ellison A.E., Carroll R.E.: Skiing injuries: Epidemiologic study. Public Health Reports 77: 975-985, 1962.

14. Hauser H., Gla"ser H.: Alpine Skiunfälle und Verletzungen. München, 1985.

15. Hauser W., Gläser $1 .:$ Verletzungen beim alpinen Skilauf. Deutsche Zeitschr sportmed 38: 191-198, 1987.

16. Jaffin B.: An epidemiologic study of ski injuries: Vail, Colorado. Mt Sinai J Med 48: 353-359, 1981. 
17. Jenkins R., Johnson R.J." Pope M.H.: Collision injuries in downhill stking. In Johnson R.J., Mote C.D. (eds.): Skilng Trauma and Safety. Philadelphia, ASTM, 1985.

18. Johnson R.J., Pope M.H.: Tibial shatt fractures in skiling. Am $J$ Sports Med 5: 49-61, 1977.

19. Kleinbaum D.G., Kupper L.L., Morgenstern H.: Epidemiologic Research: Principles and Quantitative Methods. Belmont. Lifetime Learning Publications, 1982.

20. Knipschild P.G., Bouter L.M.: Risk factors for ski injuries. A crash course of epidemiologic methods with emphasis on comparability in experiments and case-control studies. Accepted for publication in Johnson R.J., Mote C.D. (eds.) Skiing Trauma and Safety "Philadelphia, ASTM, 1988.

21. Lange J., Mong W., Hewel1 T., Maurer P.C.: Fatal and severe skiing accidents. Int Ser Sports Sci 5: 18-26, 1978.

22. Lamont M.K.: New Zealand ski injury statistics. Int Ser Sports Sci 5: $56-61,1978$.

23. Lindsjö U., Hellquist E., Engkvist 0., Balkfors B.: Injuries from T-bar ski lifts. In Johnson R.J., Mate C.D. (eds.): Skiing Truama and Safety. Philadelphia, ASTM, 1985.

24. Lystad H.: A one-year study of alpine ski injuries in Hemsedal, Norway. In Johnson R.J., Mote C.D. (eds.): Skiing Trauma and Safety. Philadelphia, ASTM, 1985.

25. 0'Malley R.: Trends in skifng injuries. Phys Sportsmed. 6: $68-76,1978$.

26. Shealy J.E.: Overall analysis of NSAA/ASTM data on skiling injuries for 1978 through 1981. In Johnson R.J., Mote C.D. (eds.): Skiing Trauma and Safety. Philadelphia, ASTM, 1985.

27. Shealy J.E.: Death in downhill skilng. In Johnson R.J., Mote C.D. (eds.): Skiling Iraura and Safety. Philadelphia, ASTM, 1985.

28. Tapper E.M.: Ski injuries from 1939 to 1976: the Sun Valdey experience. Am J Sports Med 6: 114-121, 1976.

29. Veihelmann D., Weller S., Becker V.: Skiunfälle und ihre Abhänglgkeit van äusseren Faktoren. Act Traumatologie 2: $57-62,1972$.

30. Witte B. de, Meyers B.: Epidemiologie van skiletsels: oorzaken, traumatologie, preventie. Geneeskunde en sport 19: $196-204,1986$. 
31. Young L.R., Oman C.M., Crame H., Emerton A., Heide R.: The etiology of ski injuries: an eight-year study of the skier and his equipment. orth Clin N Am 7: 13-29, 1976.

32. Young L.E., Crane H.D.: Thumbs up: the changing pattern of ski injuries. In Johnson R.J., Mote C.D. (eds.): Sking Trauma and Safety. Philadelphia, ASTM, 1985. 


\section{CHAPTER 6}

ALCOHOL CONSUMPTION AND INJURY RISR IN DONNHTLL SKITNG*

Lex M. Bouter, Alexander Volovics \& Paul G. Knipschild 
ABSTRACT

No consensus exists on the influence of a number of putative risk factors in dowhill skilng. Therefore an etiological case-control study was conducted among Dutch skiers $(N=1148)$. This article focuses on alcohol consumption as a risk factor. Although a causal role seems plausible, the sparse empirical data in the 1.1terature suggests that the prevalence of high blood levels of alcohol at the moment of the accident is very low. In our study $11 \%$ of the male and $3 \%$ of the female cases of injury report on average 1.2 consumptions almost 2 hours before the accident. Surprisingly, cases reported to drink in general less than controls. This holds for the month before the ski holiday, the average datly number of consumptions during the holiday (cases 2.4; controls 3.0) and for drinking during the breaks. There even appeared to be an inverse dose-response relationship. However, a real preventive effect of alcohol seems improbable. While controls reported a similar weekly alcohol intake one year later, cases reported on the average two consumptions a week more.

Furthermore, simulation of selective random underreporting by the cases supports the idea that the negative association of alcohol consumption and injury risk could the consequence of information bias. Our conclusion is that alcohol is probably neither a substantial risk factor, nor a protective factor for ski injury. 
Domnhili skiing has gained an enormous popularity over recent decades. A conservative estimate consists of $25-30$ million active skiers throughout the world, ${ }^{1}$ but a total number of 200 million skiers has also been mentioned. ${ }^{2}$ The incidence of serious injury meeding substantial medical treatment lies in the range of $2-4$ per 1000 skier days according to most authors. $3,4,5$ A reasonable amount of research has been done into the etiology of injury in downhill skiing, ${ }^{6}$ mostly with a case-control design. Wo consensus exists on the influence of a number of putative risk factors. This is at least partly due to the fact that measurement error and selective underreporting form a threat to the internal validitty of these case-control studies 7

This article focusses on the apparent protection against injury of alcohol consumption that was observed in our case-control study conducted among Dutch skiers. $8,9,10,11$ Firstly, earlier studies and biological plausibility with respect to this particular risk factor will be summarized. Secondly, the design of our study and the methods of data analysis are presented with special attention to the statistical modelling under reasonable assumptions of measurement error and selective underreporting we performed in order to assess the possible amount of bias in our results. Thirdily, the principal results concerning the influence of alcohol intake will be discussed, followed by the results of the statistical modelling of bias in this variable.

Several authors point to alcohol consunption as an important risk factor in dowhill skilng. Two mechanisms are mentioned in this context. Firstly, alcohol influences reaction time, the precision of movements and the perception of risks. $12,13,14$ stanley $^{15}$ supposes that this amplifies the analogous effect of hypoxia on high altitudes. Secondly, it is pointed out that alcohol of ten lowers the intake of carbohydrate, especially immediately after skiling when the glycogen resynthesis is stimulated most strongly. Consequently glycogen depletion will occur sooner on the next day of sking, increasing injury risk due to exhaustion and decreased movement control. 16 
Only a limited amount of data is available on alcohol consumption prior to injury among downill skiers. Biener and Fasler ${ }^{12}$ investigated 135 injured skiers. About 40\% reported consuming alcohol sometimes during the breaks, $24 \%$ did so on the day of the accident and in $4 \%$ of the cases of injury some alcohol could be detected in a blood sample taken about 2 hours after the accident. These authors estimate that only 2 of these 135 cases had more than 0.8 promille alcohol in their blood at the moment of injury. Similar results are presented by Matter. ${ }^{17}$ Hauser and Gläser ${ }^{18}$ also conclude that alcohol is not a significant cause of ski injury. They used a breath analyzer and found only one skier with 0.7 promille among 39 randomly selected uninjured males. Johnson ${ }^{19}$ mentions similar results. No data is available on the drinking habits of downill skiers during the evening and at night.

MATERIAL AND METHOD

Cases and controls were selected during the $1984 / 1985$ season from the records of a company which covers roughly one third of the market for ski insurance in the Netherlands. Most Dutch skiers are insured. The cases selected included skiers who had claimed medical costs as a result of a ski injury that made sking or other activities impassible for more than one day. All casualties suffering fracture, a dislocation or a ruptured ligament were selected. Furthermore, a sample was taken of less severe injuries. In addition to this a number of cases were selected who had been repatrlated by the organisation selling the insurance. For every case of injury selected, an equal number of uninjured skiers were chosen by taking the next claim from an uninjured skier received by the insurance company for other reasons (loss or thef $t$ ).

A postal questionnailre was sent shortly after the ski holiday to the population thus defined. Reminders were sent after 10 and 20 days. The questionnaire consisted of 80 items for the controls and 120 items for the cases. For both groups information was 
collected in a comparable way on most risk factors mentioned in the scientific and popular literature. In addition to this, cases were questioned about the eircumstances of the accident and the subsequent injury. A part of the study population was questioned again 12-18 months later ${ }^{28}$. For this second study all controls and all cases with a fracture, a dislocation or a ruptured ligament were selected. From this group the majority $(87 \%$ of the cases and $81 \%$ of the controls) who had earlier voliced no objection against a second study received a questionnaire 28 . From this follow-up the data on alcohol consumption are presented below.

Data analysis was performed with the aid of BMDP and GLIM statistical software. 20,21 Two steps can be distinguished. Firstly an elementary analysis was performed in which confounding by age and gender was adjusted for. The distribution of categorical risk factors was calculated for cases and controls based on direct standardization for age in three categories and for gender. For these categorical variables odds ratios (OR) were calculated as a weighted average over the six strata for age and gender, using the Mantel-Haenszel method with the test-based $95 \%$ confidence interval (CI) following the method of Miettinen. ${ }^{22}$ For continuous risk factors adjusted means were calculated by way of analysis of cowariance with age and gender as covariates. Differences between cases and controls were tested with student $t-\operatorname{tes} t .20$

The second step of data analysis was concerned with adjustment for more confounders and first order interaction. For this purpose a logistic model was fitted based on a selection of 25 variables. These were the most important risk factors in our vievt and they were selected after the elementary analysis was completted. In the final model 20 variables remained and 1 first order interaction terms were included. From the coeficients in this model adjusted odds ratios with their approximate $95 \%$ confidence intervals were calculated. 
When one or more of the risk factors is subject to random measurement error, it is well known that the estimated coefficients are biased towards zero (i.e. the odds ratios are biased towards unity). When one or more of the risk factors is subject to random underreporting, possibly by a subset af the study population, some of the coefficients will be biased downvards and some 111 be biased upwards. The problems in estimating the parameters of interest in case of random measurement errors have been addressed by several authors. $23,24,25,26$ Armstrong ${ }^{23}$ has studied the problem using a Generalized Linear Model and Quasi-Likelihood methods. We adapted this approach for risk regression modelling under the assumption that only one risk factor is subject to measurement error or selective underreporting.

Full detalls on this method and the results of the simulation of blas in more than one variable will be presented elsewhere. In this article we will only illustrate this possibility of exploring the extent of bias, given reasonable assumptions about (random) measurement error or selective (random) underreporting by the cases, using a model containing no interaction terms and only assuming measurement error or selective underreporting for the average daily alcohol consumption. For practical reasons the results of these analyses are presented as coefficients of a probit model containing the same risk factors as the logistic model. that was used to estimate the adjusted odds ratios. Random measurement error was operationalized by taking alcohol consumption contaminated by measurement ertor as equal to "true" alcohol consumption plus a random additive error term with mean zero and standard deviation equal to the standard deviation of the square root of the average daily alcohol consumption multiplied by a factor with a range from 0.125 to 1.00 . Selective (random) underreporting by the cases was operationalized by taking 'true' alcohol consumption for cases as equal to underreported alcohol consumption plus an additive underreporting component with mean equal to the square root of the average daily alcohol consumption multiplied by a factor with a range from 0.125 to 1.00 and standard deviation adapted to the chosen mean 
underreporting level in such a way as to garantee that "true" value minus underreported value should remain positive with probability practically one. Both measurement error and underreporting error were taken to have normal distribution and to be statistically independent of alcohol consumption.

\section{RESULTS}

\section{Response}

Response was well over $80 \%$ and about the same for cases (84\%) and controls $(82 \%)$. Cases responded slightly faster. The majority (81\%) of the 1540 respondents had practised downill skiling only. The rest were cross-country skiers or practised both and were excluded from the analysis. A number of skiers (103) did claim medical costs, but appeared not to have been prevented from skiling or other activities for one day or longer. These were also excluded from analysis. Data on 1148 downhil1 skiers were analysed, including 572 cases and 576 controls.

Between cases and controls slight differences in age and a rather strong difference in gender distribution was found. The average age of the cases was 32.0 years and of the controls 32.6 years. This is similar to the average age (32.1 years) of active skiers among a representative sample of the Dutch population. 27

Forty-six percent of the cases were males compared to $67 \%$ of the controls. Among a representative sample of the Dutch population females appeared to go on winter sports as often as males. ${ }^{27}$ In our opinion these figures reflect selection bias due to the way the controls have been selected. In the Netherlands males are probably still mentioned more often as the owner of lost or stolen objects because they are considered to be the head of the family. The consequence is that the risks associated with age and gender cannot be estimated from our study. For the same reason every odds ratio presented is adjusted for confounding by age and gender. 


\section{Alcohol intike}

The great majority of male $(89 \%)$ and almost all female cases (97\%) reported that they had not taken alcohol beforehand on the same day as the accident (table 6-1). Thase who did took on average 1.2 consumptions. The last one was taken on average 1.8 hour before the accident leading to injury. Almost no one in the control group reported to have taken alcohol prior to skiling on an arbitcary day (the penultimate day of the holiday during which one skied)(table 6-1). On this day $29 \%$ of the male and $16 \%$ of the female skiers among the control group took some alcohol (males 1.8 consumptions, females 1.4 consumptions) during the breaks.

Tabla 6-1. Alcolnol Intake before the accident on the same day for the fases and on an arbitrary diay for the controls.

\begin{tabular}{|c|c|c|}
\hline & MALLES & FEMALES \\
\hline CASES: & $N=2.65$ & $N-307$ \\
\hline No acohol before accident & $8.9 \%$ & $97 \%$ \\
\hline H lcothol before accident ${ }^{1}$ ) & $11 \%$ & 37 \\
\hline CONTREOLS: & $N_{*} 386$ & $N=190$ \\
\hline No alcohol befote skifing ${ }^{2}$ & $98 \%$ & $96 \%$ \\
\hline Hcohol before sking ${ }^{2 y}$ & $2 \%$ & 4. \\
\hline CONTROLS: & $N=386$ & $M=190$ \\
\hline No allcohol during breaks ${ }^{2)}$ & $71 x$ & $84 x$ \\
\hline Alcohol during breaks ${ }^{2)}$ & $29 \%$ & 168 \\
\hline
\end{tabular}

1) on the diay of the accident

2) on the pentlifuge day of the holiday during which one skied

Generally cases reported refraining from using alcohol during the breaks more often (79\%) compared to controls $(67 \%)$. An assoclation with a lower injury risk could be shown for accasional use sometimes as well as for regular use of alcohol during the breaks (table 6-2).

Both cases and controls were questioned about their drinking habits during the month prior to the ski holiday. Cases reported 
drinking less on a weekday as well as on a day in the weekend. The average weekly consumption during this month for cases of injury was almost 11 and for controls almost 13 consumptions (teetotallers included). For a part of the study population data on the average weekly alcohol consumption was again collected 12-18 months later 28 . Controls for whom data are avallable from both studies reported on average 14 consumptions a week on both accasions. Cases, however, reported 11 consumptions a week in the first study, but 13 consumptions a week 12-18 months later. Comparison of the percentages teetotallers among the cases give similar differences between the furst (males $11 \%$ and females $21 \%$ ) and the second study (males $9 \%$ and females $17 \%$ ), while the percentages teetotallers among the controls remained constant (but lower than that of the controls).

Table $6-2$. Alcohol comsumption during the breaks anomg cases and cortrols.

\begin{tabular}{|c|c|c|c|c|}
\hline & CASES $5^{1)}$ & CONTROLS $^{\mathrm{i} \text { ) }}$ & $0 \mathrm{R}_{\mathrm{ME}}{ }^{2)}$ & $\mathrm{CI}^{3 l}$ \\
\hline Never & $79 \%$ & $67 \%$ & 1,0 & \\
\hline Somet Imes & $18 \%$ & $28 \%$ & 0.6 & $0.4-0.8$ \\
\hline Every day & $3 \%$ & $6 \%$ & 0.5 & $0.3-0.9$ \\
\hline
\end{tabular}

\footnotetext{
1) percentages based on direct standmatization over 6 strata for gender and age

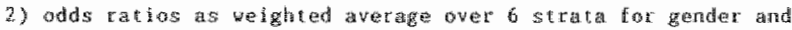
age (Mantel-maraszel)

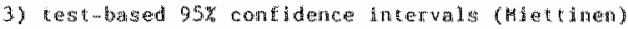

The average daily consumption during the ski hollday was for both cases ( 2.4 consumptions) and controls ( 3.0 consumptions) about the same as on a day during a weekend prior to the holiday (2.5 and 2.9 consumptions). To our surprise, injured skiers consumed less alcohol compared to controls and there appeared to be a dose-effect relationship (table 6-3). This relationship was somewhat stronger for cases with a fracture compared to cases with ligamental or other injury (table 6-4). Figure 6-1 shows the odds ratios from the logistic model in relation to the average daily number of consumptions. 
Tatle 6-3. Odds Rathos and contidence Intervils for several categories of datily alcohol consuapt tom duringe the sut holiday.

\begin{tabular}{|c|c|c|c|c|}
\hline & CASES & CONTROLS & $O R_{\text {WE }}^{2)}$ & $\mathrm{Cl}^{3}$ \\
\hline 0 cortguapt inos & $2 \pi \%$ & $22 \%$ & 1.0 & \\
\hline 1 or 2 conisumptions & 337 & $31 \%$ & 0.8 & $0.5-1.1$ \\
\hline 3 or 4 consunptions & $25 \%$ & $23 \%$ & 0.8 & $0.5-1.1$ \\
\hline 5 ot more consumptions & $15 \%$ & $23 \%$ & 0.5 & $0.3-0.7$ \\
\hline
\end{tabular}

1) percentage based an dinect standardization over 6 strata for gender and age

2) odds ratios as welgthed verage over 6 wrata for age and gender (Mant t-Hainszen)

3) test-based $95 \%$ canfidence interwals (Miettinen)

Table 6-4. Odels ratios and confldence interwals ${ }^{1)}$ for seweral categories of average dilily alcohol consumption for sone sublugroups of cases compared to controls (N=576).

\begin{tabular}{|c|c|c|c|}
\hline & $\begin{array}{l}\text { ERACTURE: } \\
\text { N.165 }\end{array}$ & $\begin{array}{l}\text { LIGAMENT } \\
\text { He } 208\end{array}$ & $\begin{array}{l}\operatorname{REST}{ }^{43} \\
N=199\end{array}$ \\
\hline 0 consumptions & 1.0 & 1.0 & 1.0 \\
\hline $1-2$ consumptions & $0.6 \cdot(0.4-1.0)$ & $0.8(0.5-1.3)$ & $0.9(0.5-1.5)$ \\
\hline $3-4$ consumptions & $0.7(0.4-1.2)$ & $1.0(0.5-1.8)$ & $0.8(0.4-1.3)$ \\
\hline 5 or more consumptions & $0.4(0.2-0.8)$ & $0.4(0.2-0.7)$ & $0.5(0.3-0.9)$ \\
\hline
\end{tabular}

1) odds ration as a welghted average over 6 strata for age and gendet: (Mantel-llatased) follawed by a lest-based $95 \%$ confldence interwal (thet inum)

2) findure as wost severe infury

3) ruptured 11 igament or dislocation as aost severe injury

4) contuston, raptured muscle or laceration as aost severe infury

The inverse dose-respons relationship between alcohol consumption and injury risk was also observed when the consumption on the day prior to that of the accident for cases and that on the antepenultimate day during which one skied for the controls were taken. The mean alcohol intake on these days appeared to be higher (cases 3.2 consumptions and controls 3.7 consumptions) than the average daily consumption during the whole holiday. 


\section{Random measurement error}

In table 6-5 the coefficients from the probit model in case of analysis of the probability model assuming randon measurement error concerning the average daily alcohol consumption are presented.

The first column provides the coefficients without adjustment for measurement exror. The second and the third column give coefficients for the assumptions of random measurement error with a standard deviation of 0.20 and 0.59 . There is no substantial change in the coefficients after modelling measurement error. only the coefficient of alcohol intake itself changes somewhat.

Plgure 6-1. Odds satios from the logistic modtel with $95 \%$ confidence intervals for average dally alcohol incake during the boliday.

ODDS RATTO

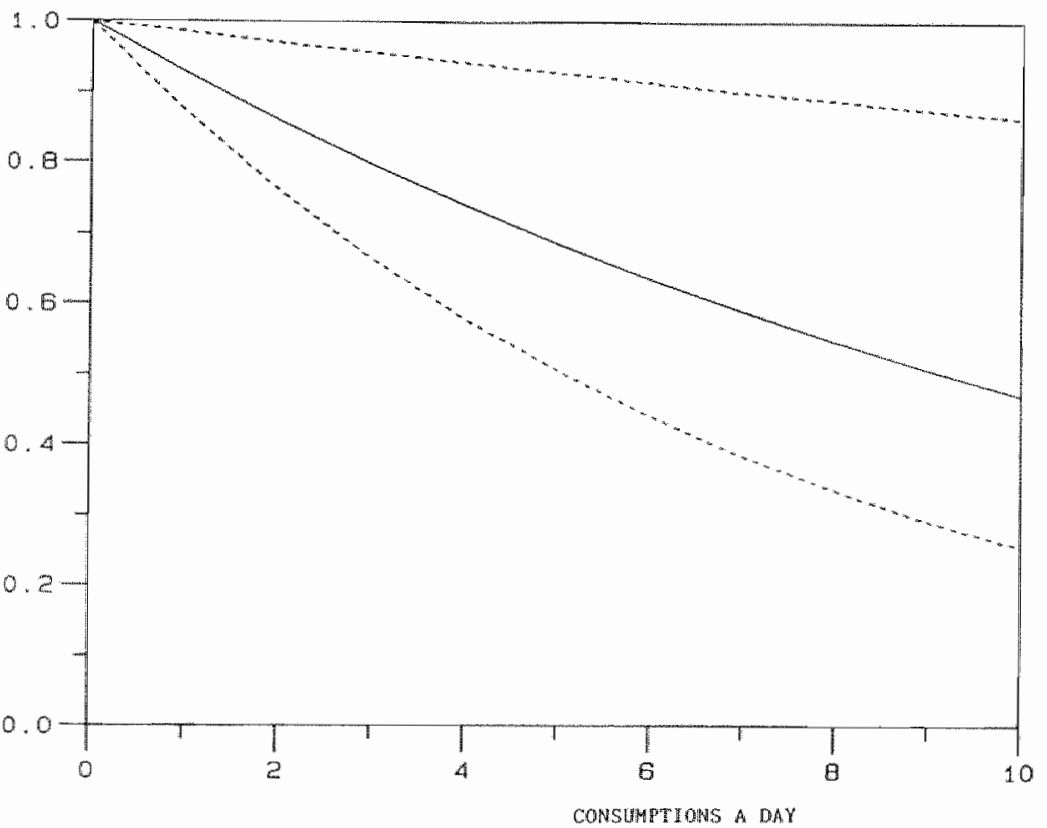

This is illustrated in figure 6-2 for the full range of standard deviations of the random measurement error we considered. Under 
our assumptions the standard deviation of the random measurement error remains just below 0.8 consumptions a day. In other words, 95\% of the reported average alcohol intake estimates will deviate under this assumption less than about 0.8 consumptions (in both directions) from their real value. It is clear from figure 6-2 that random measurement error gives the coefficient of alcohol consumption a bias towards the null.

\section{Selective underreporting}

The effect of our assumptions with respect to a possible selective (random) underreporting among the cases of their average daily alcohol consumption is shown in table 6-6.

Table 6-5. Coeffictencs from the probit model for several tisk factors ${ }^{13}$ assuming tendon measurement atror in average dally alcongl congumption.

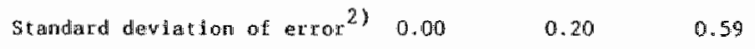

\begin{tabular}{|c|c|c|c|}
\hline Ability & 0.32 & 0.32 & 0.32 \\
\hline Condition & -0.22 & -0.22 & -0.22 \\
\hline Srtoking & 0.28 & 0.28 & 0.28 \\
\hline Sheeping & -0.55 & -0.55 & -0.55 \\
\hline Alcohol during breaks & -0.31 & -0.31 & -0.31 \\
\hline Skj gymastics & 0.19 & 0.19 & 0.19 \\
\hline knowledge & 0.32 & 0.32 & 0.32 \\
\hline skits outside at night & 0.43 & 0.43 & 0.43 \\
\hline Cender & 0.42 & 0.42 & 0.42 \\
\hline Afraid & $-0,40$ & -0.40 & -0.40 \\
\hline Sroov quald ty 1 . & -0.33 & 0.33 & -0.33 \\
\hline snow quality 2 & -0.06 & -0.06 & -0.06 \\
\hline Age & -0.07 & -0.07 & 0.07 \\
\hline Exposure & .0 .05 & -0.05 & -0.05 \\
\hline ALCOHOL. & -0.13 & -0.13 & -0.14 \\
\hline
\end{tabular}

1) bestdes alcohol nore of these risk factors are explatned in detail in this article. Specific information on thera can be fownt in references 9,10 and 11 .

2) in consumptions a day.

The table gives coefficients from the probit model for no adjustment for selective underreporting and for adjustment for an 
average selective underreporting of 0.19 and 0.56 respectively. Thus table shows that selective underreporting for daily alcohol intake can have some influence on the coefficients of other risk factors as well.

Figure 6-3 provides the coefficients for average alcohol consumption for the full range of average selective underreporting considered. From this figure it also becomes clear that our assumptions lead to a maximal average selective underreporting of less than 0.8 alcohol consumptions a day. Adjustment for the assuned relatively small selective (random) underreporting influences the coefficient of average daily alcohol consumption substantially and may even change its sign.

Figure 6-2. Coefficients from the probit fodel for awerage daily alcohol consumption in relation to the assumed standard deviation (SD) of the randomieasurement error for this variable ( $x$ ind lcates a wal calculated from the probit modely.

COEFFICTENT

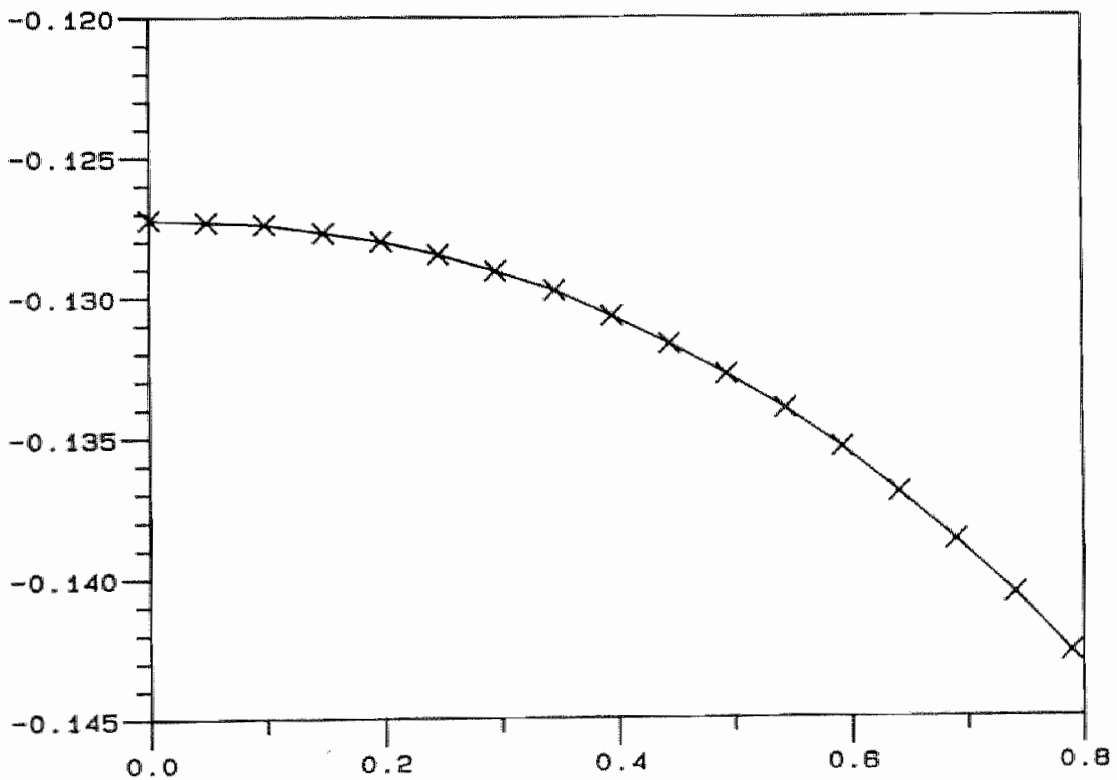

5D IN CONSUMPTIONS A DAY 
DTSCUSSION

The avaliable data in the literature suggests that alcohol consumption is not a substantial risk factor in downhlil sking. $12,17,18,19$ However, the inverse dose-effect relationship that we observed in our study was very surprising and contradicts (biological) plausibility. Yet it is by no means necessary to interpret the observed negative association between alcohol consumption and injury risk in a causal way.

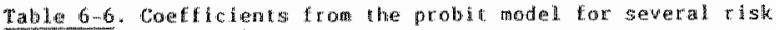 factors 1) assuming selective random underepoting by} the casses of average datily alcohol consumption.

\begin{tabular}{|c|c|}
\hline mean undermeporting ${ }^{2)}$ & 0.00 \\
\hline
\end{tabular}

\begin{tabular}{|c|c|c|c|}
\hline Ablitity & 0.32 & 0.32 & 0.32 \\
\hline Cond it it ion & -0.22 & -0.24 & -0.27 \\
\hline Strokting & 0.218 & 0.23 & 0.14 \\
\hline Sleeping & -0.55 & -0.59 & -0.68 \\
\hline Arcotol during breaks & -0.31 & -0.46 & .0 .74 \\
\hline Skl gyanastics & 0.19 & 0.19 & 0.19 \\
\hline Knowledge & 0.32 & 0.29 & 0.23 \\
\hline Skis outside at night & 0.43 & 0.43 & 0.42 \\
\hline Giender & 0.42 & 0.53 & 0.72 \\
\hline Afrald & -0.40 & -0.42 & -0.43 \\
\hline Snow quality 1 & -0.33 & -0.31 & -0.24 \\
\hline Snow quality 2 & -0.06 & -0.04 & $=0.01$ \\
\hline Age & -0.07 & -0.09 & -0.13 \\
\hline Exposut: & 0.05 & -0.05 & -0.04 \\
\hline ALCOHOLL & -0.13 & 0.14 & 0.69 \\
\hline
\end{tabular}

1) bestides alcohol none of these risk factors are explained in datall fin this article. Spectefic Information on them can be found in teforences 9,10 and 11 .

2) In consumptions a day.

Habitual abstinence from alcohol may very well be an indicator of another determinant of injury risk, possibly within the domain of personality. The relation between personality and injury risk, especially with respect to the trait "sensation seeking", is explored further elsewhere. ${ }^{28}$ However, before speculating about causality attention should focus on the internal validity and the preciston of our study. 
In a case-control study the internal validity can be inpaired by uncontrolled confounding, selection bias and information bias. The preventive effect of alcohol consumption did not disappear in the logistic model. So it is not very probable that this result can be explained by confounding, although some confounding may still be present due to factors not included in the model or due to imprecise measurement. Probably some selection bias with respect to gender and age due to the way the controls were selected was present in our data.

Eigure 6-3. Coefficients from the probit model for avesage daily alcohol consumption in relation to the assumed mean selective randon underreporting by the cases for this vartable ( $\mathrm{x}$ indicates a value calculated from the probit moded.

DOEFFTEIERT

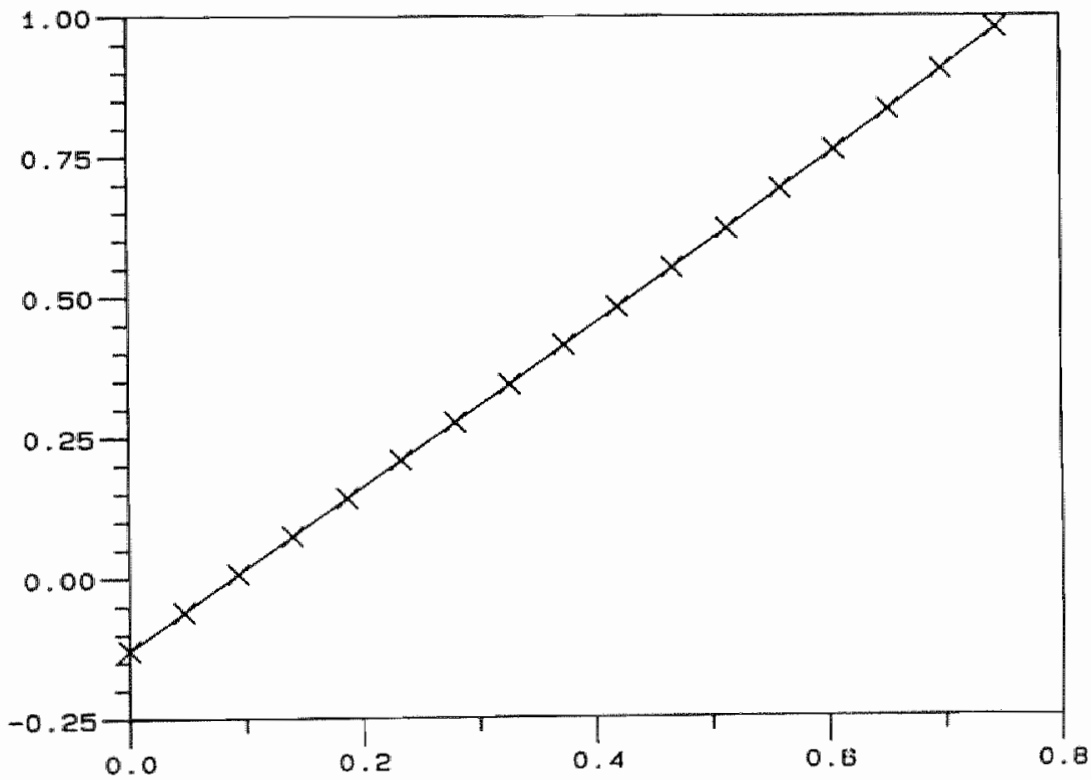

HEAN UANOERRERORTING IN CONSUMPTIONS A DAY

This bias, however, was adjusted for in every association measure presented. There seems to be no reason to postulate other selection biases in relation to drinking habits. The same holds 
Eor selection bias due to differential non-response. Response ras high and in no observable way selective.

Information blas deals with the question whether the information gathered is comparable between cases and controls. Because all information was self-reported, oux study lacks precise and objective information on alcohol consumption. We did not observe the actual alcohol intake, nor did we analyse the blood or breath levels of our respondents. The choice of the control group (loss or theft) makes information bias due to selective recall less probable. Thus controls too had a reason to remember the details of their drinking habits during the ski holiday. Our study was retrospective, and consequently the known outcome of the holiday (injury of no injury) may have influenced the assessment of certain risk factors. Consonant with the often documented general underreporting of alcohol intake in surveys, there might be selective underreporting among cases. The argument for this would be that cases underreport their intake because they are afraid that otherwise they would get no money from the insurance company. Although it was made very clear that no information would be given to the insurance company and we had the impression that the questionnaire was completed faithfully, we cannot exclude this possibility with certainty. Furthermore, it is difficult to imagine that users of alcohol among the cases would declare themselves teetotaller on a large scale. Although the percentage teetotallers differed over the situation for which information on the alcohol intake was gathered, the cases reported to be a teetotaller in every instance more frequent than the controls 8,28 .

Another argument in favor of selective underreporting by the cases came from follow-up of a part of our study population." 28 It appeared that for these respondents the weekly alcohol intake among controls 12-18 months later was similar to that in the perlod before the ski holiday. One year later cases reported two consumptions a week more. Of course, the possibility that cases really had a higher weekly alcohol intake 12-18 months later cannot be excluded. 
The consequences of imprecision in the data on average dally alcohol consumption were investigated by the statistical modelling under reasomable assumptions of random measurement error. It appears from this that such imprecision has little impact on most coefficients in the probit model and thus on the associations observed. The coefficient of average daily alcohol consumption itself will be biased towards the null value when random measurement error is present, leading to an underestimation of the actual association between average dally alcohol intake and injury risk among downhill skiers. The bias resulting from hypothetical selective (random) underreporting by the cases of the average daily alcohol intake appears to be substantial. Statistical modelling under reasonable assumptions of selective underreporting concerning this variable shows an influence on the coefficients of a number of risk factors win the probit model. For the coefficient of average daily alcohol consumption itself, a change of sign can be observed already under the assumption of a small amount of only selective (randon) underreporting by the cases. This result supports the idea that the negative association between average daily alcohol. consumption and injury risk abserved in our case-control. study could be the consequence of information bias. Of course, this does not prove that our data on alcohol consumption are biased by selective underreporting by the cases indeed. The statistical modelling only shows the consequences of the assumption that such bias is present in the data. The same modelling procedure could have been performed for other putatjve risk factors for which selective misclassification is suspected (e.g. ability). In summary, our overall conclusion is that alcohol is probably neither a substantial risk factor nor a protective factor for ski injury. 


\section{REFERENCES}

1. Zink RA, Glaser H: Incidence, morbidity and mortality of torso truama Erom skilng. In Kote $C D$, Johson $\mathbb{R J}$, editors: Shling Trauma and Safety, Philadelphia, 1987, ASTH.

2. Raas $\mathrm{E}$ : The international skiing federation contribution to safety in skiling. In Mote $C D$, Johnson RJ, editors: Philadelphia, 1987, ASTM.

3. Hauser $\forall$, Gläser $H$ : Verletzungen beim alpinen Skilauf. Deutsche Zeitschr Sportmed 38: 191-198, 1987.

4. Shealy JE: Overall analysis of NSAA/ASTM data on sking injuries for 1978 through 1981. In Johnson RJ, Mote CD editors: Skiling Trauma and Safety, Philadelphia, 1985, ASTM.

5. Young LE, Crane HD: Thumbs up: the changing pattern of ski injuries. In Johnson RJ, Mote CD, editors: Skiing Trauma and Safety, Philadelphia, 1985, ASTM.

6. Bouter LM, Knipschild PG: The etiology of injury in downhil1 sking: review of the 1iterature. Submitted for Publication.

7. Knipschild PG, Bouter LM: Risk factors for ski injuries: a crash course of epidemiological methods with emphasis on comparability in experiments and case-control studies. Accepted for Publication in Johnson RJ, Mote CD, editors: Skling Trauma and Safety, Philadelphia, ASTM.

8. Bouter LM, Knipschild PG: Skirisico's: eerste verslag van epidemiologisch onderzoek bij Nederlandse skiers. Maastricht, 1985, Rijksuntversiteit Limburg.

9. Bouter LM, Knipschild PG, Volovics A: Ability and physical condition in relation to injury risk in downill skiling. Accepted for Publication in Johnson RJ, Mote CD editors: Skilng Trauma and Safety, Philadelphia, ASTM.

10. Bouter LM, Knipschild PG, Volovics A: Characteristics of ski and binding in relation to injury risk in downhlil skiing. Accepted for Publication in the American Journal of Sports Hedicine.

11. Bouter LM, Knipschild PG, Volovics A: Personal and environmental factors in relation to injury risk in downhill skiling. Submitted for Publication.

12. Biener K, Fasler S: Sportunfälle: Epideniologie und Prävention. Bern, 1978, Verlag Hans Huber. 
13. Bernett $P$, Schöfel U: Ursache und Prophylaxe von Skiverletzungen. Münch med Wschr 124: 178-182, 1982.

14. Witte B de, Meyers G: Epidemiologie van skiletsels: oorzaken, traumatologie, preventie. Geneeskunde \& Sport 19: 196-204, 1986.

15. Stamley $J J_{*}$ : The effects of hypoxia on the endurance and coordination of skiers. Int Ser Sports Sci 5: 287-291, 1978.

16. Brouns F, Saris WHM, Hoor F ten: Nutrition as a factor in the prevention of injuries in recreational and competitive downhi11 skiing. J Sports Med 26: 85-90, 1986.

17. Matter P: Schweizerische Ski-Ausrüstungs- und Unfall-Studie 1984. Davos, 1984 .

18. Hauser $W$, Gläser $H$ : Alpine Skiunfälle und Verletzungen. Müchen, 1985, DSV.

19. Johnson RJ: Personal Communication. Chamonix, 1987.

20. Dixon WJ: BMDP Statistical Software. Berkeley, 1983, University of California Press.

21. Baker RJ, Nelder JA: The GLIM System: Release 3. Oxford, 1978, Numerical Algorithms Group.

22. Kleinbaum DG, Kupper LL, Morgenstern H: Epidemiologic Research: Principles and Quantitative Methods. Belmont, 1982, Lifetime Learning Publications.

23. Armstrong $B$ : Measurement error in the generalized Iinear model. Comm Stat Simul Comp 14: 529-544, 1985.

24. Carrol RJ, Spiegelman CH, Gordon Lan KK, Bailey KT, Abbott RD: On errors-in-variables for binary regression models. Biometrika 71: 19-25, 1984.

25. Schafer DW: Covariate measurement error in generalized linear models. Biometrika 74: 385-391, 1987.

26. Whit temore AS, Grossner S. In Moolgavkar SH, Prentice RL, editors: Modern Statistical Methods in Chronic Disease Epidemiology. New York, 1986, Wiley, pp. 19-3.4.

27. CBS: Vakantie-onderzoek 1985. 's-Gravenhage, 1987 , Staatsui tgeverij.

28. Bouter LM, Knipschild PG, Feij JA, Volovics A: Sensation seeking and injury risk in downtill sking. Pers Ind Diff 9 (1988) $667-673$. 
CHAPTER 7

SENSATION SEEKING AND INJURY RISK IN DOWNHILL SKIING*

Lex M. Bouter, Paul G. Knipschild, Jan A. Feij \& Alexander Volovics

* Published in Personality and Individual Differences 9 (1988) $667-673$. 


\section{ABSTRACT}

A validated Dutch version of Zuckerman's sensation seeking (SS) scale was sent to a population of downhill skiers. It was expected that injured skiers $(\mathrm{N}=219)$ would have higher thrill and adventure seeking (TAS) scores compared to a control group of uninjured skiers $(M=288)$. Information on other risk factors for skil injury, as measured in an earlier study among the same skiers, was included in a logistic model in order to adjust for confounding. Response (73\%) was slightly higher among females; younger skiers and higher educated persons. Skiers have a high TAS score compared to a Dutch reference population. The observed correlations between SS subscales, as well as the trends associated with age and gender are in full agreement with the literature. Surprisingly, TAS scores were lower among the cases (35.0) compared to the control group (37.3) ( $p<0.01)$. Adjustment for other risk factors for ski injury in the logistic regression does not change the effect of the TAS score substantially. It is postulated that skiers with a high TAS score could be more experienced in balancing on the limit of their individual capacities. Further research into this problem, preferable with a prospective design, is recommended. 
The popularity of downill sking has increased substantially during the last Eew decades. Ever in a small and completely flat country like the Netherlands more than 900,000 people travel abroad every year to enjoy inter sports. The majority (91\%) of them is active in downili or cross-country skiling. Like most other sports, downill sking is not without risk. The incidence of injuries can nowadays be estimated at about 5 per 1000 skier days. 2,12 This figure, however, depends heavily on the definition of a ski injury and the way the cases are collected. ${ }^{5,15}$ Most authors agree that during the last 10-15 years the incidence rate has decreased substantlally due to the introduction of modern ski bindings and possibly also because of better management of the ski runs. $13,16,17$ probably a further substantial decrease cannot be achieved by pursuing these lines. It is widely advocated that nowadays prevention strategies should be aimed at other risk factors, such as physical condition, the abstinence of alcohol intake and preparation by way of ski gymnastics. However, a sound empirical basis for these assumptions is lacking. Therefore a case-control study was conducted among Dutch skiers during the $1984 / 1985$ winter season. ${ }^{3}$ In this study the importance of certain risik factors, such as being a beginner, lack of experience and not taking ski lessons, could be confirmed and quantified. ' Some other results, however, were surprising and it was our general impression that this study lacked essential information within the behavioral domain. From these considerations the hypothesis was generated that individual differences in risk taking tendency between downhill skiers was an important risk factor for injury. 4

Theoretical support for an influence of risk taking tendency was found in the concepts of risk homeostasis and sensation seeking. In risk homeostasis 18 the central idea is that everyone has a target level of risk that is considered acceptable. A feedback mechanism is postulated in which the individual makes sure that this target level of risk is realized, taking into account all internal (emg. ability, physical condition) and external (e.g. quality of snow, difficulty of slope) circumstances. In this Iine of argument, the increased risk, because of fatigue, bad snow quality and impaired coordination due to alcohol use, can for 
instance be compensated for by a decrease in velocity and/or amount of skiing done. Assuming that the skier has an adequate perception of risk and enough ski11 to adapt his behavior by the right amount in the right direction, the individual target level would be an important determinant of the injury risk. 18,20 This target level of risk is supposed to be a function of the expected advantages and disadvantages of risky and cautious behavior alternatives. ${ }^{18}$ optimal arousal of the central nervous system seems to be an important motivation in risk taking. 21

Individual differences in optimal arousal, and thus in risk taking tendency (target level), can probably at least partly be operationalized with the personality trait sensation seeking (SS). 19 This trait has been defined as "the need for varied, novel and complex sensations and experiences and the willingness to take physical and social risks for the sake of such experience" (reference 23, page 107). The sensation seeking (SS) scale consists of four subscales: 24

1. Thrill and Adventure Seeking: TAS items indicate a desire to engage in risky and adventurous activities and sports providing unusual sensations.

2. Experience Seeking: ES items represent the seeking of stimulation through the mind and the senses, e.g. through music, art, travelling and drugs.

3. Disinhibition: DIS items describe the seeking of sensation through drinking, going to parties, gambling and sexual variety.

4. Boredom Susceptibi11ty: BS items represent an aversion to repetitive experience, whether in work or with other persons. Restlessness and boredom arise when such constancy is unavoidable.

Especially the TAS subscale seems relevant with respect to downhill skiling. Zuckerman ${ }^{25}$ places skifing in the group of high risk sports, for which it is postulated that participation will be associated with a high score on the SS scale. For some other sports in this category (e.g., mountaineering, parachuting and 
deep sea diving) this has indeed been reported and a number of studies indicate that the injured sportsmen ( $\mathrm{e} . \mathrm{g} *$, in hang-gliding and in auto-racing) had the highest SS scores among the particupants. One sma 11 cross-sectional study ${ }^{8}$ reports a higher TOTAL and TAS score for skiers $(N=47)$ compared to a group of non-skiers $(N=36)$. Among the skiers, respondents who reported an injury in the past tended to have a higher TAS, DIS and TOTAL. score compared to skiers tho had never been injured.

To investigate whether the SS (especially TAS) score is an Important risk factor in downhill skiing, a validated Dutch translation of the SS scale ${ }^{10}$ was sent to the majority of the respondents of our earlier case-control study. The central hypothesis was that SS (especially TAS) score would be higher in cases compared to controls.

\section{METHODS}

The subjects were selected from the respondents of the case-control study conducted during the 1984/1985 winter season among Dutch skiers. ${ }^{3}$ In the earlier study, cases $(N=572)$ were those who claimed medical costs because of a ski injury (that made skilng or other activities impossible for one day or longer) from a certain insurance company. This company covers roughly one third of the Dutcly downhlil skiers. For every case the next clain received from a skier for non medical reasons (e.g., loss or theft) was selected. Controls $(N=576)$ were slightly older and, more often, male gender. This probably reflects the fact that males are often considered head of the family and mentioned as owner of lost or stolen objects. As a consequence the relation of age and gender with injury risk could not be assessed. All measures of association presented in this article are adjusted for differences in these factors.

For the present study all controls and all cases with a fracture, a dislocation or a ruptured ligament were selected. From this group only those persons who had earlier voiced no objection 
against a second study received the Dutch version of the sensation seeking scale 10 12-18 months after the first questionnaire. ${ }^{3}$ Relatively few respondents of the earlier study (13\% of the cases and $19 \%$ of the controls) had objections against participation in a second study. The names and addresses of 52 persons were no longer correct. In total 290 SS forms were sent to the cases (131 had a fracture and 159 a dislocation or a ruptured Iigament) and 407 to the controls. The first reminder was sent two weeks later and the second reminder four weeks later.

Data analysis was performed with BMDP and GLIM statistical software. 1,9 Mean SS scores were calculated for males and fenales separately and group means were adjusted for differences in gender and age by means of an analysis of covariance. A number of other risk factors for the same respondents, as measured in our earlier study, were added to the analysis in order to adjust for confounding. For this purpose multivariate analysis by means of logistic regression was chosen. ${ }^{14}$ A model was fitted both with and without SS subscales, in an attempt to answer the question whether SS would explain a portion of the variance above the established risk factors. From the logistic models odds ratios (cross product ratios) with their $95 \%$ confidence intervals (CI) 14 are calculated as the appropriate measures of association.

\section{RESULTS}

\section{Response}

Information on 507 downhill skiers (290 males and 217 females) was included in the analysis. Non-response was $27 \%$ (24\% in cases and $29 \%$ in controls). Response was higher among females, younger respondents and more highly educated persons (higher professional training or university). The data are given in Table $7-1$. Among the respondents about $50 \%$ responded following the original request and $25 \%$ after the first and another $25 \%$ after the second reminder. No difference was found between cases and controls in this respect. 


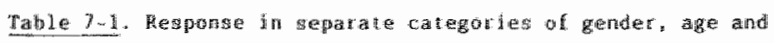
tedycation for casen and controls $(4-507)$.

\begin{tabular}{|c|c|c|}
\hline & CASES & CONTROLS \\
\hline Malles & $72 \pi \quad(91)$ & $70 \%(199)$ \\
\hline Fetelaters & $78 \%(128)$ & $72 \%(89)$ \\
\hline $15-29$ yeats & $77 \%(96)$ & $73 \%(133)$ \\
\hline $30-6 \cdot 4$ years & $76 \% \quad(87)$ & $70 \%(117)$ \\
\hline $45-59$ years & $71 \% \quad(36)$ & $66 \%$ (38) \\
\hline Higher education & $80 \% \quad(8 B)$ & $74 \%(149)$ \\
\hline Lower educallion & $70 \%(131)$ & $618 \%(139)$ \\
\hline FOTAL & $76 \%(219)$ & 71 䈐 $(288)$ \\
\hline
\end{tabular}

\section{Sensation Seeking}

Table 7-2 presents the means of sensation seeking subscores and TOTAL scores both for cases and controls. Males tended to have higher TAS and DIS scores, and consequently higher TOTAL scores, comprared to females. A trend for decreasing scores with Increasing age was found for TAS (Table 7-3), ES, BS, DIS and TOTAL scores (data not giwen).

When group means adjusted for gender and age were calculated, only the TAS score differed between cases and controls. Surprisingly, TAS scores were lower in the cases group $(35.0)$ compared to the control group (37.3). Additional adjustment for self-reported ability, the most prominent risk factor in our earlier study, could not change the calculated adjusted means substantially (cases 35.3 , controls $37.1, p=0.03$ ). 
Table 7-2. Hean Sensation Seeking subscones for cases and rom trols.

CASES (N-219) CONTEOLS (N=288) p-malue*

\begin{tabular}{|c|c|c|c|c|c|}
\hline \multirow[t]{3}{*}{ TAS } & Wales & $(\mathrm{M}=290)$ & 37.9 & 39.4 & \multirow[b]{3}{*}{$<0.01$} \\
\hline & gemales & $(\mathrm{N}=217)$ & 31.2 & 35.1 & \\
\hline & $\mathrm{H}+\mathrm{F}^{\mathrm{x} \times \hat{\mathrm{K}}}$ & $(N=507)$ & 35.0 & 37.3 & \\
\hline \multirow[t]{3}{*}{$\mathrm{s}$} & Males & & 34.2 & 34.7 & \\
\hline & Females & & 34.0 & 33.7 & \\
\hline & $M+F$ & & 34.2 & 34.3 & 0.90 \\
\hline
\end{tabular}

$\begin{array}{llll}\text { BS Males } & 40.5 & 40.2 & \\ \text { Fenalles } & 39.3 & 40.1 & \\ M+F & 40.0 & 40.1 & 0.89\end{array}$

$\begin{array}{llll}\text { Dis Hales } & 33.9 & 33.3 & \\ \text { Fenales } & 28.0 & 29.2 & \\ \mathrm{M}+\mathrm{F} & 31.3 & 31.3 & 0.98\end{array}$

$\begin{array}{llll}\text { TotAl Males } & 11.5 & 11.6 & \\ \text { Females } & 10.4 & 10.8 & \\ \text { M.F } & 11.1 & 11.2 & 0.23\end{array}$

* significance of t-Test for adjusted group means

* group neans adjusted for gendex and age by way of analysis of covariance

Table 2-3. TAS Subscale scores for difterent categorles of age and gencier.

\begin{tabular}{|c|c|c|c|c|}
\hline & & $\mathrm{N}$ & CASES & CONTROES \\
\hline \multirow[t]{3}{*}{ HALES } & $15-29$ years & 123 & 42.4 & 44.1 \\
\hline & $30-4.4$ years & 124 & 33.8 & 36.8 \\
\hline & $45-59$ years & 43 & 34.4 & 34,4 \\
\hline \multirow[t]{3}{*}{ FEMALES } & $15-29$ years & 206 & 35.4 & 35.5 \\
\hline & $30-4 \cdot 4$ years & 90 & 29.6 & 30.8 \\
\hline & $45-59$ years & 31 & 25.2 & 28.7 \\
\hline
\end{tabular}


Table 7-4 shows a comparison between the sensation seeking scores. Correlations are given for cases and controls separately. The correlation between ToTAL score and the scores on the various subscales ranged from 0.6 to 0.8 . Between subscales of the SS scale the correlation varies from 0.3 to 0.5 .

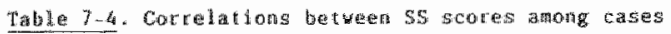
(upper-hali) and controls (lowermalsy.

\begin{tabular}{|c|c|c|c|c|c|}
\hline & $\mathrm{TAS}$ & ES & BS & ous & TOTAL \\
\hline TAS & -..- & 0.39 & 0.41 & 0.47 & 0.81 \\
\hline 85 & 0.38 & $\ldots$ & 0.33 & 0.43 & 0.70 \\
\hline $\mathrm{BS}$ & 0.28 & 0.20 & $m-$ & 0.36 & 0.69 \\
\hline DIS & 0.32 & $0.2 d_{t}$ & 0.344 & $-\cdots$ & 0.76 \\
\hline motá & 0.77 & 0.64 & 0.616 & 0.68 & $\cdots$ \\
\hline
\end{tabular}

Logistic model

To estimate the contribution of the TAS score relative to other risk factors, a logistic model was fitted both with and whout the TAS score. In such a model mutual confounding of the incorporated risk factors is adjusted for. Data on the 14 most prominent rusk factors for the respondents of the present study were retrieved from the data of our earlier study and included in a logistic model. Examples of these risk factors are ability, number of hours skiling, physlcal condition, and alcohol consumption. A second model was fitted after adding the TAS scores to this 11 st of 14 risk factors. There appears to be very little difference between the odds ratios calculated from these two models. In Table $7-5$ odds ratios for some dichotomous variables from both models are given as an illustration.

The simlarity of the two models suggests that the TAS score should be considered as a risk factor which is to a large extent independent of the other risk factors included in the madel. In figure 7-1 the contribution of the TAS score to injury risk is further quantified. 
Table 2-5. Odts tatios and gs: confidance incerwals for sone

dichoromous rish tactors from the bogistic regression.

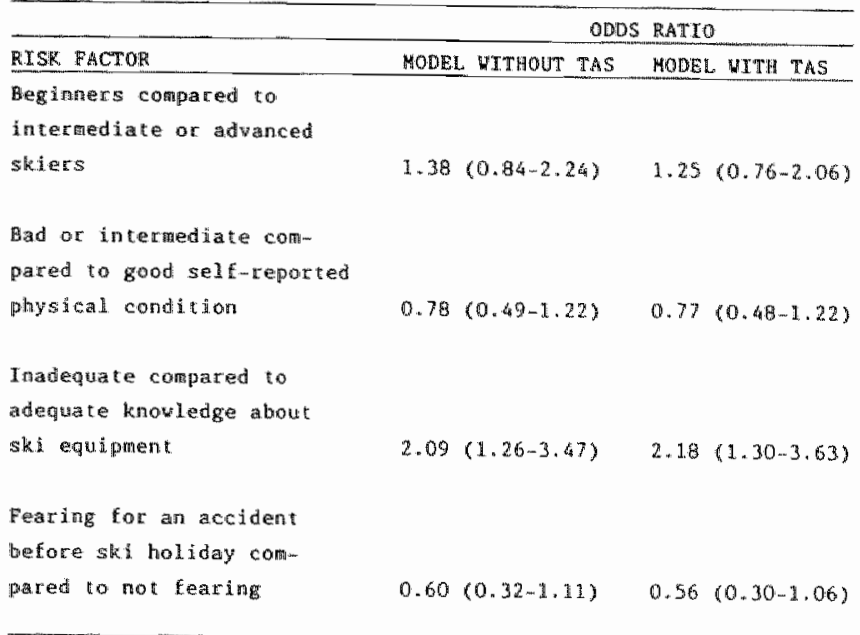

In this figure the odds ratios and $95 \%$ confidence intervals are given for different TAS scores relative to the mean TAS score of the study population (36.3).

\section{DISCUSSION}

Before discussing the results, the validity of our study deserves some attention. Validity can be impaired by selection bias, information bias and uncontrolled confounding. Selection bias deals with the question whether the cases and controls are (self) selected in a comparable way. Elsewhere ${ }^{6}$ it is argued that, besides the differences in age and gender, for which we adjusted, there is probably no selection bias in the earlier case-control study. However, not all the responders to the earlier study were actually included in the present one. Controls volunteered for further participation less often, and those who did volunteer were more likely to become non-responders in the present study compared to cases. Furthermore, response was slightly higher among females, younger skiers and more highly educated persons. This should lead to some caution when generalizating, but does not mean that within our study population the comparison between cases and controls is necessarily biased. 


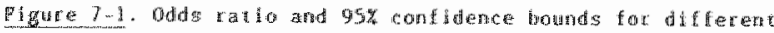
ins acones based on the logisic ic model.

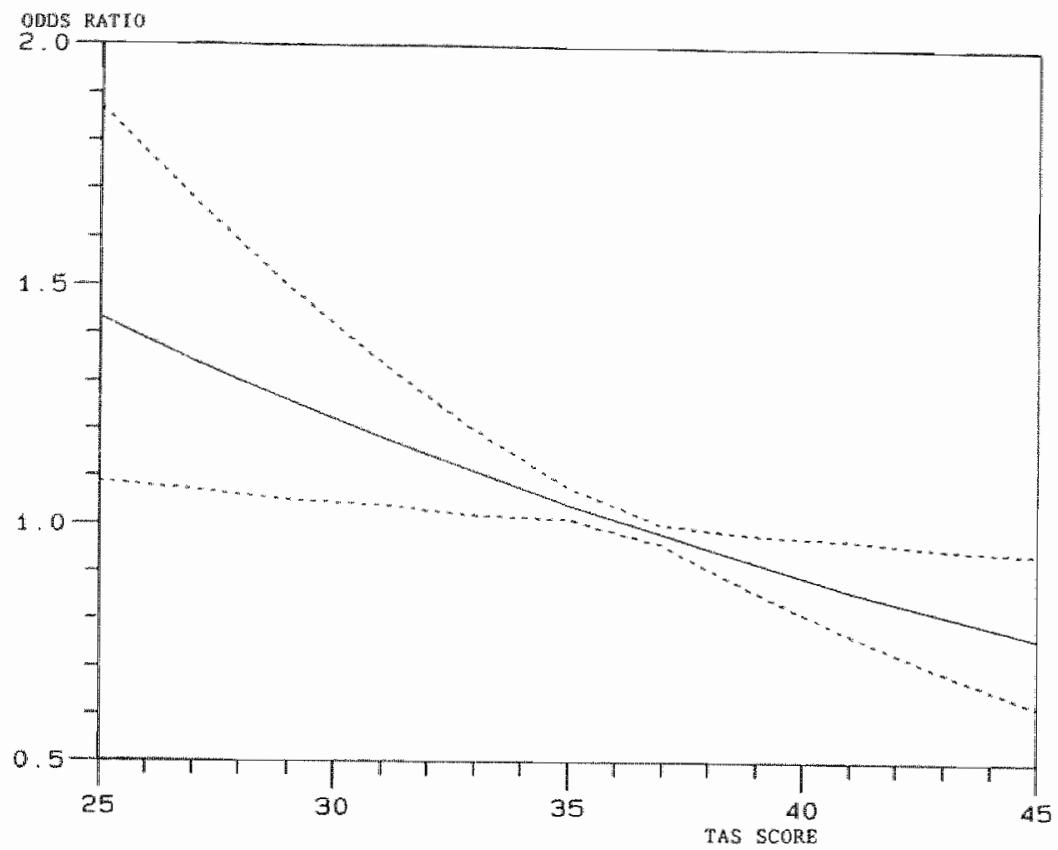

The selection af more severe injuries was introduced on purpose and served to increase the contrast between cases and controls.

The main threat to validity seems to be the "double' retrospective deslgn of our study. The earlier study was performed shortly after the winter sport episode. The present study is situated 12-18 months later. In this procedure it is assumed that SS is a trait which is reasonable constant over time within the individual and is not influenced a great deal by the experifence of getting injured (or not). Although there is some support 10,22 for these assumptions, a prospective design would have been more conclusive. Another possible source of information bias is the circumstance that all the information gathered is based on self-assessment and thus may be subject to incomplete recal1. The choice of the control group (loss or theft) made information bias due to selective recall less probable. Controls thus had also a reason to remember the detalls of their ski holiday. 
As stated above, confounding by age and gender has been controlled for. Furthermore, in the logistic model, every important confounder on which we collected information is included and subsequently adjusted for. This does of course not exclude bias due to unmeasured confounders, nor confounding due to imprecise measurement.

Compared to a Dutch reference population $(\mathbb{N}=300)$ consisting of 18-30 years old individuals registered in general practices 11 skiers in the same age group have a much higher TAS score. In this reference population the mean TAS score of males was 36.4 and of females $30.8 .^{11}$ ES and DIS scores did not differ compared to the same age group within our ski population, while BS and TOTAL scores among the skiers seemed to be slightly higher. The latter was mainly due to the higher TAS score among skiers. The trends in SS scores that we found with respect to different categories of age and gender are in full agreenent with other Dutch populations investigated. ${ }^{10}$ The same holds for the correlations found between the TOTAL score and the several. subscales. Correlation between subscales seems slightly higher in our study compared to other studies using the Dutch version of the SS scale. 10

The difference in mean TAS score between cases and controls was surprisingly the opposite to what was expected. Controls appeared to have the highest TAS scores. The protective effect of a high TAS score materialized also in the logistic model. This means that skiers who were more inclined to show a risky behawior by definition ${ }^{29}$ actually got injured less often. Our results contradict those of Conolly, ${ }^{8}$ who reported a higher TAS score among skiers reporting an injury in the past compared to skiers who had never been injured. However, the validity of this study ${ }^{8}$ should be wiewed with some caution. Skiers who did not ski again after their injury were not represented in the sample, and no adjustment is made for differences in other tisk factors between cases and controls. 
The observed difference in TAS score in our study also contradicts the idea that the individual target level of risk, as measured by the SS scale, would be higher among the cases. An alternative explanation for our findings would be that skiers with a high TAS score are better at handling the risks involved in several forms of physical exercise and therefore less prone to accidents and injury, compared to those with a relatively Iow TAS scote who may be less skilled at estimating and handling the risks of downhill sking. Following this line of argument persons with high TAS scores would be experienced in balancing on the Imit of their individual capacities, while people with low TAS scores would unknowingly take risks which are inadequate $y$ matched to their skill in handling them. of course this is an ad hoc hypothesis, which should be tested in new research preferably with a prospective design.

The confidence intervals calculated in the logistic model are rather wide. This is probably mainly due to the fact that our earlier study $(N=1148)$ consisted of more skiers compared to the present one $(\mathrm{N}=507)$. There are some differences in odds ratios calculated from the logistic model without TAS score between the present study and our earlier investigation. This again indicates that the present study population is not a random sample of the earlier study population. However, the direction of the effect of a riak factor is almost always, and the order of magnitude mastly the same within these two populations. ${ }^{5,6}$ From the comparison of the two logistic models based on the present study, it appears that including the TAS score does not change the odds ratios of the other risk factors substantially. The TAS score seems to be a risk factor ith an effect largely independent of that of the other risk factors.

\section{CONCLUSIONS}

Skiers have a relatively high TAS score when compared to non-skiers. Among skiers sensation-seeking subscales show roughiy the same inter-correlations, the same trends wh age and the 
same differences between males and females, compared to other populations. Cases and controls differed only with respect to TAS score. The protective effect of a high TAS score was not expected.

From the comparison of logistic models, it appeared that TAS is a risk factor which operates largely independently of other risk factors. Further research into this problem, preferably with a prospective design, is recommended.

The authors are grateful to the Institute for sports Medicine of Limburg (ISL) for their financial support and would like to thank Ms. M. Pereboom, Mr. E. van Rossum and Ms. M. Koekkelkoren for their help in the collection and analysis of the data. 
REPERENCES

1. Baker R.J. and Nelder J.A. (1978) The Glim System. Release 3. NAG, Oxford.

2. Bouter L.M. and Knipschild P.G. (1985) Risicofactoren wan skiletsel. Tujdschrift voor Sociale Gezondheidszorg 63 , 114-121

3. Bouter L.M. and Knipschild P.G. (1985) Skirisico's. Rijksuniversiteit Limburg, Maastricht.

4. Bouter L.M. (1986) Spanningsbehoefte en ongevalsrisico bij sportbeoefening. Geneeskunde en Sport 19, 205-208.

5. Bouter L.M. and Knipschild P.G. (1987) Accident risk in downhill skilng. Paper presented at the second meeting of the Council of Europe seminar Sport for All: Sportinjuries and their Prevention, Arnhem, The Metherlands.

6. Bouter L.M., Knipschild P.G. and Volovics A. (1987) Ability and physical condition in relation to accident risk in downh111 skiing. Accepted for publication in Skiing Trauma and Safety (Edited by R.J. Johnson and C.D. Mote) ASTM, Philadelphía.

7. C.B.S. (1987) Vakantie-onderzoek 1985. Sociaal Culturele Statistieken, C.B.S., Voorburg.

8. Conolly P.M. (1981) An exploratory study of adults engaging in the high-risk sport of skiing. Master's Thesis. Rutgers University, New Brunswick.

9. Dixon W.J. (1983) BMDP Statistical Software. University of California Press, Berkeley.

10. Feij J.A. and van Zuilen R.W. (1984) Handleiding bij de Spanmingsbehoeftelijst (SBL). Swets en Zettlinger, Lisse.

11. Felj J.A., van Kampen D. and wan den Berg P.T. (1987) De samenhang tussen onplezierige levensgebeurtenissen en klachten in relatie met persoonlijkheid, coping en sociale steun. Internal Report. Dpt * of Psychology, Free University, Ams terdam.

12. Jaffin B. (1981) An epidemiologic study of ski injuries: Vail, Colorado. The Mount Sinai Journal of Medicine 48, $353-359$. 
13. Johnson R.J., Ettlinger C.F., Campbell R.J. and Pope M.H. (1980) Trends in sking injuries. The American Journal of Sports Medicine 8, 106-113.

14. Kleinbaum D.G. Kupper L.L. and Morgenstern H. (1982) Epidemiologic Research: Principles and Quantitative Methods. Lifetime Learning Publications, Belmont, California.

15. Knipschild P.G. and Bouter L.M. (1987) Risk factors for ski injuries. A crash course of epidemiologic methods with emphasis on comparability in experiments and case control studies. Accepted for publication in Skilng Trauma and Safety (Edited by R.J. Johnson and C.D. Mote) ASTM, Philadelphia.

16. Shealy J.E. (1985) Overall analysis of NSAA/ASTM data on skiing injuries for 1978 through 1981. In Sking Trauma and Safety (Edited by R.J. Johnson and C.D. Mote) ASTM, Philadelphia.

17. Tapper E.A. (1978) Ski injuries from 1939 to 1976: The Sun Valley experience. The American Journal of Sports Medicine $6,114-121$.

18. Wilde G.J.S. (1982) The theory of risk homeostasis: implications for safety and health. Risk Analysis, 2, 209-225.

19. Wilde G.J.S., Claxon-0ldfield S.F. and Platenius P.H. (1985) Risk homeostasis in an experimental context. In Human Behavior and Traffic Safety (Edited by L. Evans and R.C. Schwing) Plenum Press, New York.

20. Wilde G.J.S. (1985) Assumptions necessary and unnecessaty to risk homeostasis. Ergonomics 28, 1531-1538.

21. Wilde G.J.S. (1986) Beyond the concept of risk homeostasis. Accident Analysis and Prevention 18, 377-401.

22. Hilde G.J.S. (1986) Personal Communication.

23. Zuckerman M. (1979) Sensation Seeking: Beyond the Optimal Level of Arousal. Erlbaum, Hillsdale, New Jersey.

24. Zuckerman M., Buchsbaum M.S. and Murphy D.L. (1980) Sensation seeking and its biological correlates. Psychological Bulletin $88,187-214$.

25. Zuckerman M. (1983) Sensation seeking and sport. Personaljty and Individual Differences $4,285-293$. 


\section{CHAPTER B}

THE ETIOLOGY OF INJURY IN DOWNHILL SKIING*

review of the literature

Lex M. Bouter \& Paul G. Knipschild 


\section{ABSTRACT}

The current state of knowledge with respect to the etiollogy of injury in downhill skiling is summarized, with, firstly, a review of the literature on the incidence and the distribution of injuries. Subsequently, attention focusses on the main cattegories of risk factors and possibilities for prevention. The incidence of serious injury ranges from 2 to 4 per 1000 skier days. In some $55 \%$ of the injuries the lower extremities are involved. Being a beginner is risky, but taking ski lessons probably lowers this to some extent. There is little doubt that adequate adjustment of the ski binding can lower the incidence of lower extremity injury further. Similarly improvements in the design of boots, bindings and ski poles can probably make skiing safer. Little is known about putative risk factors concerning behavior and the environment. Some methodological remarks are made with the aim of improving the quality of furure studies. 
Downhll sking has gained enormous populatity over recent decades. Nowadays there are at least 25-30 million active skiers over the world $d^{67}$, but some authors estimate the total number of sklers as high as 200 million. ${ }^{53}$ since the first publications on this subject appeared around the beginning of this century, ${ }^{22}$ the literature documents a substantial risk of injury. The occurrence of injury is regularly described in quantitative terms ever since Moritz ${ }^{48}$ published his local injury statistics. However, it is difficult to compare one set of injury statistics with another, because of differences in the definition of an injury and differences in the method of registration. 41 Furthermore, general underreporting and selective underreporting by specific groups of skiers (e.g. adult males) and/or for specific injuries (e.g. injury of the thumb) are mentioned in the 1 iterature. $25,31,58$ Usually the occurrence of ski injury is expressed as an incidence figure, nowadays mostly per 1000 skier days. In order to calculate this measure knowledge of the reference population in which the injuries have occurred is essential. 41,56 Such information on the reference population, and more specifically on the number of skier days 'at risk', may be based on sales of Iift companies (e.g. Blitzer ${ }^{5}$ ), on questioning a random sample of skiers (e.g. Johnson et al ${ }^{38}$ ) or a whole cohort at risk (e.g. Dowling ${ }^{18}$ ).

Effective prevention of ski injury ought to be based on an inslght into the etiology and thus should be based on knowledge concerning the quantitative contribution of the most important risk factors. For this it is mecessary to study the occurrence of ski injuries as a function of 1 ts determinants. "41 This is done most frequentiy in a case-control design, in which the same information is gathered on injured skiers and on a comparable group of uninjured skiers. Haddon et al ${ }^{29}$ were probably the first to perform such a study. Potential rask factors can be subdivided into many categories, such as demographic factors, skill, condition, behavior, equipment and environment (table 8-1). Within the latter category, for example, it is useful to distinguish weather, snow quality, visibility, difficulty of ski run, moment of the day and duration of the exposure. The many 
potential risk factors are, moreover, interrelated. This implies that studying the separate contribution of a certain risk factor to the level of ski injury incidence is far from easy.

Unconcerned by this complicatedness so-called experts pour out a large number of preventive recommendations concerning skiers. These are often based on a mixture of plausibility, casuistry and prejudice, and these claims are frequently "proven" by way of quasi-empirical reasoning from injury statistics. 41

Table 8-1. Putative atsk Factors for Injuly in Dowhill sking

\begin{tabular}{|c|c|c|}
\hline DEMOGAAPHIC FACTORS & SKILL & CONDITI I CN \\
\hline Age & Ability & Physical condtuon \\
\hline Gender & Experience & sports participation \\
\hline Helghr. & Ski lessons & ske i cymanastics \\
\hline Neight & & Natr n ing-up \\
\hline \multirow[t]{2}{*}{ Educat ion } & & Sleep \\
\hline & & Menstruation \\
\hline BEHAVIOR & EQUIPHENT & ENU IRONAESTE \\
\hline Fear & Binding adjustmen: & Snow quall ity \\
\hline Risk kakäng & Doats & Visibility \\
\hline Drtnoling & Ski poles & Weather \\
\hline Nutration & Ski brakes & \\
\hline
\end{tabular}

In this review these fallacies are avoided. A sumary will be given of the current state of knowledge with respect to the etiology of injury in downhill sking. Prior to a discussion of the main categories of risk factors, the data on the Incidence and distribution of injuries will be summarzed, as well as on the circumstances under which these injuries appear to happen. The article closes with a discussion concerning the 'state of the art" in preventing downhill ski injuries.

\section{INJURIES}

\section{Incidence}

Estimates of the incidence of injury range from 1 till $10 \mathrm{skil}$ injuries per 1000 skier days. $6,35,38$ Most authors agree that 
nowadays the incidence of serious injury needing substantial medical treatment lies in the range of $2-4$ per 1000 skier days. $32,57,65$ This measure can also be looked upon as the mean risk percentage for an individual skier during a ski holiday consisting of 10 days of skilng. This figure is probably much lower than it used to be a few decades ago. $32,42,57,65$ It is commonly agreed that the development of the modern ski equipment, especially of the release binding, has contributed substantially to this decline in the incldence of injury. $38,42,60$ The better design and maintenance of ski runs are also sometimes mentioned as factors that have contributed to this decline. 60

\section{Distribution}

The pattern of ski injuries too has changed over the years. On the basis of published data Hauser and Gläser ${ }^{31}$ present trends in the proportion of reported ski injuries for different parts of the body as weighted averages over the available studies. Between 1960 and 1980 a substantial decline was found in the proportion of lower extremity injuries from 80 to $55 \%$, especially of the foot and ankle ( 45 to $10 \%$ ). Similarly the proportion of tibia fractures declined from 25 to $15 \%$, while the proportion of knee injuries remained approximately $20 \%$. Corresponding to the decline of the proportion of lower extremity injuries, there appeared to be an increase of the proportion of upper extremity injuries from 10 to $25 \%$ between 1960 and 1980 . The proportion of injury of head and torso rose in this period from 10 to $20 \%$.

Johnson et al $37,38,40$ introduced the concept of lower extremity equipment-related (LEER) injury ' .... in which the mechanism is consistent with the ski acting as a lever to bend or twist the leg' (Johnson et al ${ }^{38}$ p. 107). They classified $80 \%$ of the lower extremity injuries as LEER injury. Between 1972 and 1978 the LEER injury incidence rate went down by $43 \%$, while the upper body injury rate decreased only by $25 \%$. The incidence of fractured tibias and sprained ankles especially declined substantially (both by more than $70 \%$ ). Several authors ${ }^{15,19,65}$ suggest that injury to the ulnar collateral ligament of the 
metacarpophalangeal joint of the thumb is currently the most frequent injury in downhill skiing (up to $20 \%$ of all injuries). It is assumed that this injury is severely underreported in most studies because it does not immobilize the skier. Besides this 'ski thumb', damage to the medial collateral ligament of the knee ('ski knee') and tibia shaft fractures ('ski fracture') are common ski injuries. ${ }^{22}$ However, the proportion of tibia shaft fractures has decreased substantially over the last few decades, probably due to a better functioning of the ski bindings. 22

Damage to the ligaments of the knee was responsible for about $20 \%$ of all ski injuries. This proportion has remained constant aver the years, indicating that modern ski equipment is less successful in protecting the skier's knee, 34,40 than it is in protecting the tibia. In table 8-2 incidence figures for several categories of ski injuries are given based on the observations at Sugarbush North, Vermont, USA. ${ }^{38}$ Hauser and Gläser ${ }^{31}$ report similar incidence figures based on a sample of more than 200,000 skier days.

Table 8-2. Incidence per 1000 skier days for several categories of ski injuries ${ }^{1}$ )

\begin{tabular}{|c|c|}
\hline CATEGORY & INCIDENCE \\
\hline Upper body & 1.6 \\
\hline Non-LEER ${ }^{2)}$ lower extremity & 0.3 \\
\hline LEER & 1.5 \\
\hline - Knee LEER & 0.9 \\
\hline - Non Wnee LEER & 0.6 \\
\hline TOTAL & 3.3 \\
\hline
\end{tabular}

1) Rased on Johnson et al, 1990

2) Lower extremity equipment-related

\section{Circumstances}

A number of studies mentioned the self-reported direct causes of the accident leading to injury. It is difficult to compare these studies, because different scales are used. Some $11-20 \%$ of the injuries are attributed to a collision, including $6-16 \%$ with an object and $3-8 \%$ with another skier. $31,36,46,50,57,60$ collision injuries tend to be relatively serious. It is not surprising that a fall (due to several causes) is held responsible for the 
majorlty (70-90\%) of injuries $2,31,39,50,60$ and problems concerning ski lifts (especially $T$-bar lifts) for $2-9 \% .45,46,50,60$ Most accidents leading to injury (90-95\%) happen on the pistes, probably because that is where most of the skilng is done. ${ }^{2,64}$ About $15 \%$ of the cases report a very high velocity directly prior to the accident leading to injury, about $55 \%$ were going moderately fast, about $28 \%$ were skilng slowly at this moment and about $2 \%$ were standing still. 36,39 Fatal injuries occur less than once in a million skier days, mostly as a consequence of a collision with a tree at high velocity. $44,57,60$

The moment of injury can be expressed as day in the week, time of the day and number of hours skied on the same day. Despite a fair amount of discussion, no consensus exists on the risks of different moments. This is mainly due to the fact that the number of sklers at risk at the different moments is unknown. Most injuries occur during the weekends, 31,66 although Monday is also mentloned as a dangerous day. ${ }^{4,43}$ The supposed dangers of the third day of skiling are not supported by the data. ${ }^{2}, 31$ Some authors conclude that accidents occur relatively less frequently during the morning, indicating that exhaustion is a risk factor, $2,39,43,63,66$ while others hypothesize a constant risk over the day. $11,31,35$ on average cases ski about 3 hours prior to injury. $2,11,66$

\section{RISK FACTORS}

\section{Demographic factors}

Children, especlally those between 11 and 13 years old, as well as adults over 40 years of age are overrepresented among injured skiers, indicating a higher risk for these age groups. $5,27,35,66$ The fact that children are less skilled at skilng seems to be at least partly responsible for this observation. Injured skiers under 15 years have a high proportion of lower extremity injuries, especilly of tibia fractures. This indicates the use of low quality equipment and/or less adequate binding adjustment for children , according to most authors. $5,27,54,61$ 
Some authors report a higher risk for females, $27,35,60$ while others report them as having the same risk as males. $18,58,66$ Furthermore, females tend to report more often to the local facilities. 25,58 Injury to the 1igaments of the knee occurs relatively often among femalles, indicating differences in anatomy and/or in efficacy of binding adjustment ${ }^{35,60}$ between males and females.

Differences in height and weight between cases and controls are not found or are attributed to confounding by age. $29,31,66$ one study ${ }^{11}$ mentions an elevated risk for skiers with a quetelet Index of 20 or less. Some authors mention a lower risk for more highly educated skiers. $4,11,43$

\section{Skil11}

There is consensus that skiers who consider themselves as a beginners have about a doubled risk compared to more advanced skiers. ${ }^{9,35,57}$ This holds also for the number of seasons of sking experience. $9,58,66$ skiing experience is highly correlated to self-rated ability, but there still remains a preventive effect of ski experience when ability is adjusted for. 9,58

It seens reasonable to expect that formal instruction will increase ability and thus lower injury risk. However, an overall effect is lacking ${ }^{9}$ and even an increased risk for those who take ski lessons is reported by some authors. ${ }^{26,58}$ The latter is probably due to the absence of adjustment for differences in ability and/or duration of period at risk. ${ }^{9,57}$ In one study the investigators adjusted for these factors in a multivariate analysis and reported a preventive effect of ski lessons during the first and second year of skiling only.

Condition

It is often suggested that a good physical condition can prevent exhaustion and thus lower accident risk. ${ }^{13,14,20,49}$ Despite the physiological plausibility of this hypothesis, empirical evidence 
is lacking. A recent study ${ }^{9}$ among Dutch skiers indicates that a self-reported good physical condition was even a risk factor. This is consistent with the higher prevalence of participation in other sports anong injured skiers. ${ }^{9}$ No empirical evidence is published that supports the advice commonly heard to prepare for the ski holiday by a course in ski gymnastics or by taking lessons on an artificial ski run. "The same holds for the assumed preventive effect of warming-up exercises. 9

Skiers seem to sleep more than enough ${ }^{4}$ and no differences are reported between cases and controls ${ }^{29}$ or cases even sleep better and longer. ${ }^{11}$ A possible association between acciden risk and $^{-}$ menstrual period is mentioned by some authors, ${ }^{4}$ but could not be confirmed by others. 11

Behavior

Skiers who report that they are somewhat afraid of having an accident before their holiday appear to have a lower injury risk in the only study dealing with this factor. ${ }^{11}$ Recklessness and risk taking behavior are often mentioned as risk factors in popular literature on downhill skiling. ${ }^{7}$ The personality trait 'sensation seeking', especially the subscale indicating a desire to engage in risky activities, seems to be relatively high indeed among downhill skiers. ${ }^{8}$ But contracy to what may be expected, injured skiers appear to have a lower score on this trait than uninjured sklers.

Several authors point to alcohol consumption as an important risk factor 1 in downill skiung. Two mechanlsms are mentioned in this respect. Firstly, alcohol influences reaction time, accuracy of movements and the perception of risks. ${ }^{2,4,64}$ stanley $^{59}$ supposes that this amplifies the effect of hypoxia on high attitudes. Secondly, it is pointed out that alcohol often lowers the intake of carbohydrate, especially immediately after skiling when the glycogen resynthesis is stimulated most strongly. Consequently glycogen depletion will occur sooner on the next day of sking, increasing injury risk due to exhaustion and decreased movement control. 13 
Only a small amount of data concerning the alcohol consumption of downhill skiers is available. Only $2 \%$ of a group of injured skiers appear to have more than 0.8 promille alcohol in their blood at the moment of injury. 4,47 Hauser \& Glaser ${ }^{31}$ could find only one skier with 0.7 promille among 39 randomly selected uninjured male skiers. Alcohol does not appear to be an important risk factor in downill sking. According to the self-reported drinking behavior, alcohol even seems to have a protective effect, but this might be caused by selective underreporting by injured skiers. 12

Glycogen depletion of muscle fibres of downhill skiers is observed at the end of a day of skiling. ${ }^{13,20,49}$ The resulting fatigue is considered to be an important risk factor. To prevent an accumulating glycogen depletion during the ski holiday, frequent small meals rich in carbohydrate are advocated. 13,23 Empirical evidence with respect to the relationship between nutrition and injury risk among skiers is lacking.

\section{Equipment}

As stated above, time-trend studies suggest an important preventive effect of the use of modern equipment and, in the recent past especially, of an adequate adjustment of the ski binding. The question is whether binding adjustment nowadays is still an important risk factor. Binding release appears to be less frequent during accidents leading to LFER injury compared to accidents leading to non-LEER injury, $10,17,65$ although it is doubtful whether an optimally adjusted ski binding will always release in time to prevent a LEER injury. The knee especially is considered insufficiently protected by the current binding design. $10,22,24$ In general, binding adjustment is more adequate among controls compared to injured skiers, especially to those with a LEER injury. $31,37,46,62$ while the bindings both of uninjured skiers and of those with a non-LEER injury are adjusted on average $50 \%$ above the recommended setting, the average deviation for knee sprains is $85 \%$ and for tibia fractures even $150 \%$, according to a recent German study. ${ }^{31}$ studies which do not 
include the testing of bindings, but collect information by questionnaire only, generally fail to show a rellation between items concerning binding adjustment and injury risk. 10,35,58,66 only skilng on rented or borrowed skis and ignorance concerning the type of skis and the age of skis and bindings, especially among experienced skiers, appear to be associated with an elevated injury risk. ${ }^{10}$ Recently a randomized controlled trial ${ }^{30}$ was performed in which it appeared that optimal adjustment could lower the risk for LEER injuries substantially.

Ski boots form a functional unity with the bindings and it is recognized that boot properties can dramatically affect release performance. ${ }^{24}$ The early models of the modern plastic ski boot (late 1960s and early 1970s) were associated with a sudden increase of isolated fractures of the fibula at the boot top level. ${ }^{22,51}$ Later on the stiffness characteristics of the boot became more appropriate, but there still seems to be room for further improvement of the ski boot design. ${ }^{24}$ No data is avaliable on the risks connected to the different current types of ski boots, although some authors ${ }^{28}$ warn that binding function may be impaired when the boot sole is made of thermoplastic rubber. This material is still used rather often in boots for children.

Several authors mention falls with the open hand on the ski pole handle as an important cause of injury to the thumb. $15,19,33,52$ To avoid this risk, it is advised not to use ski pole straps 15,19 or to use ski pole grips with a different design. ${ }^{30}$ Several authors warn against the use of safety straps around the ankle and advise the use of a ski brake ("ski stopper") instead, in order to prevent lacerations caused by the edges of the ski. 16,60

\section{Environment}

Snow quality is an environmental risk factor that is investigated rather frequently. Most authors agree that icy or hard packed snow leads to a higher proportion of upper extremity and head injuries, while in wet or powder snow lower extremity injuries, 
especially tibia fractures, are relatively frequent. $31,39,63$ There is some doubt concerning the influence of the snow quality on the overall incidence of injury, ${ }^{2,4,35}$ but some authors report a substantially elevated incident risk when icy spots are present. 11,43

Problems with visibility are mentioned by about $20 \%$ of the skiers, but no clear relation to injury risk is established. 2,35,39 An elevated injury risk is reported for cloudless weather, even when the fact that pistes are more crowded in good weather is taken into account. $4,11,43$ Some authors ${ }^{1,3}$ attribute the elevated risk of good skiling weather to a biological or psychological influence of high atmospheric pressure.

\section{DISCUSSION}

Despite the well-known problems of (selective) underreporting, a fair amount of knowledge is available on the overall incidence of ski injury and on the proportions of the most important specific injuries. The current registration systems seem sensitive enough to detect important trends. There is also consensus on the global circumstances of the accident leading to injury. Confusion arises when one tries to translate the prevalence of these circumstances to risk factors. Typically, adequate comparable information on a group of uninjured skiers is lacking. Some of these circumstances seem to call for preventive measures, for instance by removing objects from the ski run, by modifying the design of t-bar lifts or by making high velocities impossible by the design of ski runs. Before such measures are taken, it is advisable to investigate these putative risk factors in a non-experimental study (e.g. in a case-control design), preferably followed by an intervention trial in which the factor at issue is manipulated on an experimental basis.

Athough consensus exists with respect to some risk factors, there is still uncertainty about many other putative risk 
factors. Typlcally the results of these case-control studies are presented as crude frequencies of the factor at issue, without reporting appropriate measures of association (e.g. odds ratios). Although most authors agree that the risk factors mentioned are probably interrelated to some extent, stratified analysis is rare and an adequate multivariate analysis is almost never performed. Another common weak spot is the fact that these case-control studies often collect information by questionnaire, leaving much room for imprecision and bias. Future studies should try to avoid these problems and preferably focus more specifically on risk factors open to manipulation. Because of the inherent uncertainty of non-experimental (associational) studies, it is always advisable to try out a preventive measure (health educational or otherwise) in a well designed randomized trial, before introducing it on a large scale. Unfortunately, only one such a trial has been performed up to now. 30

Despite these limitations, some conclusions can be drawn ith acceptable confidence from the existing data. Being a beginner is risky, but taking ski lessons can probably lower this risk to some extent. Empirical evidence is lacking with respect to the plausible risk-reducing effect of a good physical condition. Further clarification of this point will depend on studies aiming at measuring physical condition directly (prospectively) or, even better, actively manipulating physical condition in a randomly chosen group of skiers. Sound knowledge is also virtually absent within the domain of behavior. Alcohol is probably not an important risk factor, while nutrition might be one. But the latter has never been investigated properly. A role of risk taking behavior seems evident, but its impact is uncertain and it is doubtful whether this factor is open to manipulation.

There is little doubt that adequate adjustment of the ski binding can lower the incidence of LEER injury further. Furthermore, it is plausible that a better design of boot and binding can make skiing safer, especially for children and/or with respect to knee injuries. The current design of ski poles seems to facilitate thumb injuries. Concerning the putative enviromental risk Factors little is known. 


\section{REFERENCES}

1. Bernett, P. and W. Mang. Skisportverletzungen und Vet terphasen. Mschr Unfallheilk 75: 485-492, 1972.

2. Bernett, P. and U. Schöffel. Ursache und Prophylaxe von Skiverletzungen. Münch Med Uschr 124: 178-182, 1982.

3. Biener, K., B. Freihofer and F. Schwarzenbach. Wetter und Skiunfälle. Münch Med Wschr 121:427-430, 1979.

4. Biener, $K$. and S. Fassler. Sportunfälle. Bern, Verlag Hans Huber, 1978.

5. Blitzer, C.M. , R.J. Johnson, C.F. Ettlinger and K. Aggeborn. Downhill skilng injuries in children. Am J Sports Med 12: $142-147,1984$.

6. Bouter, L.M. and P.G. Knipschild. Risicofactoren van skiletsel. Tijdschr Soc Gez Zorg 63: 846-851, 1985.

7. Bouter, L.M. Spanningsbehoefte en ongevalsrisico bij sportbeoefening. Geneeskunde en Sport 19: 205-208, 1986.

B. Bouter, L.M., P.G. Knipschild, J.A. Feij and A. Volovics. Sensation seeking and injury risk in downhill sking. Pers Ind Diff 9: $667-673,1988$.

9. Bouter, L.M., P.G. Knipschild and A. Volovics. Ability and physical condition in relation to injury risk in downhl1 skiing. Accepted for publication in: R.J. Johnson and C.D. Mote (eds) Skiing Trauma and Safety. Philadelphia, ASTM.

10. Bouter, L.M., P.G. Knipschild \& A. Volovics . Characteristics of ski and binding in relation to injury risk in downhill skilng. Accepted for Publication in the American Journal of Sports Medicine.

11. Bouter, L.M., P.G. Knipschild \& A. Volovics. Personal and environmental factors in relation to injury risk in downhill skiling. Submitted for publication.

12. Bouter, L.M., A. Yolovics and P.G. Knipschild. Modelling injury risk for downill skiers: simulation of random measurement error and selective underreporting with respect to alcohol consumption as risk factor. Submitted tor publication.

13. Brouns, F., H.H.M. Saris and $F$, ten Hoor. Nutrition as a factor in the prevention of injuries in recreational and competitive downhill skiling. J Sports Med 26: 85-90, 1986. 
14. Buck, P.G., A.M. Sophocles and R.D. Beckenbaugh. Unique aspects of downill ski injuries. Orthopedics 5: $317-324,1982$.

15. Cart, D., R.J. Johnson and M.H. Pope. Upper extremity injuries in skiing. An J Sports Med 9: 378-382, 1981 .

16. Colmey, T,G. and H.J. Rck. Sking lacerations: preventable by the use of siki brakes. JAMA 244: 1699-1700, 1980.

17. Danielsson, K., E. Eriksson, E. Johnsson, E. Lind and S. Lundkvist. Attempts to reduce the incidence of skiing injuries in Sweden. In: R.J. Johnson and C.D. Mote (eds). Skilng Trauma and Safety. Philadelphia, ASTM, 1985.

18. Dowling, P.A. Prospective study of injuries in the United States Ski Association freestyle sking: 1976-77 to 1979-80. Am J Sports Med 10: 268-275, 1982.

19. Engkvist, 0., B. Balkfors and U. Landsjö. Thumb injuries in downhill skilng. Int J Sports Med 3: 50-55, 1982.

20. Eriksson, A., P. Tersch and J. Karlsson. Fatigue during downhill skiing. Int Ser Sports Sci 5: 279-286, 1978.

21. Eriksson, E. Physiological demands in downhill skiing. Phys Sports Med 5: 28-35, 1978 .

22. Eriksson, E. and R.J. Johnson. The etiology of downhill ski injuries. Exerc Sport Sci Rev 8: 1-17, 1980.

23. Eriksson, E., E. Nygaard and B. Saltin. Physiological demands in downhil1 skiing. Phys Sports Med 4: 29-37, 1977.

24. Ettlinger, C.F. and $\mathbb{R} . J$. Johnson. The state of the art in prewenting equipment-related alpine ski injuries. Clin in Sports Med 1; 199-207, 1982.

25. Garrick, J.G. \& L.T. Kurland. The epidemiological significance of unreported ski injuries. J Saf Res 3: $182-187,1971$.

26. Garrick, J.G. and R. Requa. The role of instruction in preventing ski injuries. Phys Sports Med 5: 57-59, 1977.

27. Garrick, J.G. and R.K. Requa. Injury patterns in children and adolescent skiers. Am J Sports Med 7: 245-248, 1979.

28. Gunderson, T.M. Comparative laboratory tests of release bindings for children and young skiers with special reference to the influence of boot material and boot sole length. In: C.D. Mote and R.J. Johnson (eds). Sking Trauma and Safety. Philadelphia, ASTM, 1987. 
29. Haddon, W., A.E. Ellison and R.E. Carroll. Skiling injuries: epidemiological study. Public Health Reports 77: 975 - 985 , 1962.

30. Hauser, W. Experimental prospective skiing injury study. Paper presented at the Eighth International Symposium on Ski Trauma and Skiing Safety, Chamonix, 1987.

31. Hauser, W. and H. Gläser. Alpine Skiunfälle und Verletzungen: Häufigkeit, Risicofactoren, Ursachen. Wunchen, DSV, 1985.

32. Hauser, W. and $\mathbb{H}$. Gläser. Verletzungen belm alpinen Skilauf: Veränderungen und Trends. Deutsche Zeitschr Sportmed 38: $191-198,1987$.

33. Hollenburger, G., R. Holt and H. Dax. Der frische Skidaumen. Med Welt 33: 2: 45-47, 1982 .

34. Howe, J. and R.J. Johnson. Knee injuries in skilng, orth CIin N Am 16: 303-314, 1985.

35. Jatfin, B. An epidemiologic study of ski injuries: Vail, Colorado. Mt Sinai J Med 48: 353-359, 1981.

36. Jenkins, R., R.J. Johnson and M.H. Pope. Collision injuries in downhill skiing. In: R.J. Johnson and C.D. Mote (eds). Skiing Trauma and Safety. Philadelphia, ASTM, 1985.

37. Johnson, R.J. and C.F. Ettlinger. Alpine ski injuries: changes through the years. Clin in Sports Med 1: 181-196, 1982.

38. Johnson, R.J., C.F. Ettlinger, R.J. Campbell and M.H. Pope. Trends in skiing injuries. Arm J Sports Med 8: 106-113, 1980.

39. Johnson, R.J. and M.H. Pope. Thbual shat fractures in skiing. Am J Sports Med 5: 49 61, 1977.

40. Johnson, R.J., M.H. Pope, G. Weisman, B.F. White and C. Ettinger. Knee injury in sking. Am J Sports Med 7: $321-327,1979$.

41. Knipschild, P.G. and L.M. Bouter. Risk factors for ski injury: a crash course of eplidemiological methods with emphasis on comparability in experiments and case-control studies. Accepted for publication in: R.J. Johnson and C.D. Mote (eds). Skilng Trauma and Safety, Philadelphia, ASTM.

42. Kuriyama, $s$. and $E$. Fujimaki. Current trends in ski injuries and their relationship to recent changes in ski equipment. In: C.D. Mote and R.J. Johnson (eds). Skitng Trauma and Safety. Philadelphia, ASTM, 1987. 
43. Lamont, M.K. New Zealand ski injury statistics. Int Ser Sports Sci 5: 56-61, 1978.

44. Lange, J., Mang, T. Hewell and P.C. Maurer. Fatal and severe sking accidents. Int Ser Sparts Sci 5: 18-26, 1978.

45. Lindsjo, U., E. Hellquist, 0 . Enkvist and B. Balkfors. Injuries from T-bar ski lifts. In: R.J. Johnson and C.D. Mote (eds). Skiing Trauma and Safety. Philadelphia, ASTM, 1985.

46. Lystad, H. A one year study of alpine ski injuries in Hensedal, Norway. In: R.J. Johnson and C.D. Mote (eds). Skiling Trauma and Safety. Philadelphia, ASTM, 1985.

47. Matter, P. Schweitzerische Ski-Ausrüstungs- un Unfall-Studie 1984. Davos, 1984.

48. Moritz, J.R. Ski injuries. JAMA 121: 97-99, 1943.

49. Nygaard, E., P. Andersen, P. Nilsson, E. Eriksson, T. Kjessel and $B$. Saltin. Glycogen depletion pattern and lactate accumulating in leg muscles during recreational downhill. sking. Eur J Appl Phys 38: 261-269, 1978.

50. 0'Malley, R. Trends in skilng injuries. Phys Sportsmed 6: $68-76,1978$.

51. Pechlaner, S. and G. Philadelphy. Typical injuries caused by skiing equipment and methods to reduce them. Int Ser Sports Sci 5: 131-138, 1978.

52. Primiano, G.A. Skiers' thumb infuries associated with flared ski pole handle. Am J Sports Med 13: 425-427, 1985.

53. Raas, E. The international skifing federation contibution to safety in skilng. In: C.D. Mote and R.J. Johnson (eds). Skiing Trauma and Safety. Philadelphia, ASTM, 1987.

54. Requa, R.K. and J.G. Garrick. Sking injuries in children and adolescents. Int Ser Sports Sci 5: 5-10, 1978.

55. Shealy, J.E. Death in downhill skiling. In: R.J. Johnson and C.D. Mote (eds). Skilng Trauma and Safety. Philadelphia, ASTM, 1985.

56. Shealy, J.E. Use of statistics in identifying problems in ski injury research. In: R.J. Johnson and C.D. Mote (eds). Skiing Trauma and Safety. Philadelphia, ASTM, 1985.

57. Shealy, J.E. Overall analysis of NSAA/ASTM data on sking injuries for 1978 through 1981. In: R.J. Johnson and C.D. Mote (eds). Skiing Trauma and Safety. Philadelphia, ASTM, 1985. 
58. Shealy, J.E., L.H. Geyer and R. Hayden. Epidemiology of ski injuries: effect of method of skill acquisition and release binding accident rates. Human Factors 16: 459-473, 1974.

59. Stanley, J.J. The effects of hypoxia on the endurance and coordination of skiers. Int Ser Sports Sci 5: 287-291, 1978.

60. Tapper, E.D. Ski injuries from 1939 to 1976: the Sun Valley experience. Am J Sports Med 6: 114-121, 1978.

61. Ungerholm, S., 0. Engkvist, J. Gierup, U. Lindsjö and B. Balkfors. Skiling injuries in children and adults: a comparative study from an 8-year period. Int J Sports Med 4: $236-240,1983$.

62. Ungerholm, $S$. and $J$. Gustavsson. Skiing safety in children: a prospective study of downhil ski injuries and their relation to the skier and his equipment. Int J Sports Med 6: 353-358, 1985.

63. Veihelmann, D., S. Heller and V. Becker. Skiunfälle und ihre Abhängigkeit von äusseren Faktoren. Act Traumatologie 2: $57-62,1972$.

64. Witte, B. de and B. Meyers. Epidemiologie van skiletsels: oorzaken, traumatologie, preventie. Geneeskunde en Sport 19: $196-204,1986$.

65. Young, L.R. and H.D. Crane: Thumbs up: the changing pattern of ski injuries. In: R.J. Johnson and C.D. Mote (eds). Sikiing Trauma and Safety. Philladelphia, ASTM, 1985.

66. Young, L.R., C.M. Oman, H. Crane, A. Emerton and R. Helde. The etiology of ski injuries: an eight year study of the skier and his equipment. Orth Clin N Am 7: 13-29, 1976.

67. Zink, R.A. and H. Gläser. Incidence, morbidity and mortality of torso trauma from skiing. In: C.D. Mote and R.J. Johnson (eds). Skilng Trauma and Safety. Philadelphia, ASTM, 1987. 
CHAPTER 9

\section{DISCUSSION}

In the Elrst part of this discussion the main findings of our study will be summarized and discussed against the background of the avallable empirical data on the subject. Thus the contribution of our study to the dissection of the causal network leading to ski injury is made explicit. This answers the first part of the central question of this dissertation as stated in the introduction (chapter 1). The second part of this general discussion formulates what has been learned from the research project in a more global sense. It deals with the most important 1 Imitations of our study and formulates suggestions for future studies in order to answer the remaining questions. In this context the answer to the second central question of this dissertation, dealing with the methodological considerations connected to epidemiological studies into the etiology of injury in general, is made explicit.

RESULTS FROM THE CASE-CONTROL STUDY

The response to our questionnaire was well over $80 \%$ and it appeared that the second reminder after 20 days still elevated the response substantially (chapter 2-6). We had the overall impression that the questionnatres were completed faithfully and as accurate as possible. Relatively few respondents (13\% of the cases and $19 \%$ of the controls) had objections against particlipation in a second study. The cholce of the control group (claim for e.g. loss or theft) introduced in our opinion some selection bias with respect to age and gender. Therefore no risks associated with age and gender are calculated from our data and all odds ratios presented in this dissertation are adjusted for confounding by gender and age. There seems to be no reason to postulate other major selection biases in the original case-control study. Further consequences of the choice of the control group for the validity of our study will be discussed 
belov. In the follow-up of a part of the study population 12-18 months later (data presented in chapter 6 and 7) some additional selective non-response might be present, but this does not mean that the comparison between cases and controls within this subset of respondents is necessarily biased.

Despite the fact that our study population was not a random sample of all Dutch downhill skiers and the cases were selected towards severity, the proportion of cases with lower extremity (LE) injury $(60 \%)$ and the high proportion of severe ligamental knee injury among females (33\%) turned out to be consistent with data from other studies (chapter 4). Also the circumstances of the accident leading to injury mentioned by our cases are in reasonable agreement with earlier studies (chapter 5). Our data confirm that most accidents ( $84 \%$ ) happen on the pistes and that ski lifts are involved in about $6 \%$ of the accidents leading to injury. In our study collisions with an object (2\%) were mentioned less often than in other studies (chapter 5). Premature release of binding was hardly mentioned by our respondents as a direct cause of injury. The data on the moment of the accident leading to injury seem consistent with the hypothesis that the risk is constant over time, although in our study specific information about the population at risk over time is also lacking (chapter 5). About 50\% of our male and $64 \%$ of our female cases appeared to be severely limited in their activities for 10 days or longer. Among the more severe cases selected for the second study $44 \%$ of the males and $67 \%$ of the females with a paid job were longer than 4 weeks absent. In spite of the severity of the injury $50 \%$ of the skiers with 3-6 months restriction, and more than $30 \%$ of the skiers with a restriction of 6 months and longer, skied again during the next season (chapter 4).

\section{Ability and physical condition}

The observed higher $x$ sk for beginners $(\mathrm{OR}=2.1)$ is in accordance with earlier work (chapter 3). The same holds for the decreasing risk with growing experience. The association between absence of adequate knowledge about the equipment and injury risk, 
especially pronounced among more experienced sklers, was never reported before but certainly does not seem implausible. The same holds for the preventive effect of ski lessons $(O R=0.4)$ among skiers who had gone on winter sports holiday for the first or second time (chapter 3). Our study could not demonstrate a preventive effect of good physical condition, ski gymastics or participation in (other) sports. However, some caution is indicated in interpreting these findings. Imprecision may play some role, especially because our measures of physical condition are indirect. The same holds for our pecullar observation that absence of warming-up exercises seems to be associated with a lower accident risk (chapter 3).

\section{Ski bindings}

Binding release was less frequent directly prior to lower extremity (LE) injury compared to non-LE injury ( $O R=3.3$ for no release and $O R=2.3$ for one binding only). The fact that among the LE cases the proportion of no release (males $38 \%$ and females $54 \%$ ) was the highest for knee injuries, supports the widespread opinion that the knee is (especially among femalles) insufficiently protected by the current ski binding design and/or adjustment (chapter 4). We could not detect an effect of binding adjustment on the risk for (LE) injury in our study. Probably this was due to the fact that we did not measure the setting of the bindings of the skiers directly, but only several proxy-measures of binding adjustment from our questionnaire were available. Some indirect evidence in favor of a preventive effect of the use of a test device in the process of binding adjustment stems from the observation that use of such a device was associated with the highest prevalence of binding release directly prior to injury among the LE cases (chapter 4). The fact that binding adjustment in a skishop in the ski area was assoclated with an elevated $L E$ injury risk $(\mathrm{OR}=1.6)$ compared to adjustment in the Netherlands, seems to confirm the widespread but poorly documented opinion that Dutch skishops perform the binding adjustment more precisely and is consistent with the observation that in the Netherlands a test devise is used more 
often (67\%) than abroad (36\%). Taken together, our results confirm the hypothesis that binding function still seems to be an important risk factor open to manipulation by means of a better design and/or adjustment.

\section{Alcohol consumption}

The scarce data available in the literature suggests that alcohol is not a substantial risk factor in downhill skiing (chapter $B$ and 10). This agrees with our observation that the great majority of male ( $89 \%$ ) and almost all fenale cases (97\%) reported that they had not taken alcohol beforehand on the same day as the accident leading to injury. Those who did, took on average 1.2 consumptions of which the last one was taken on average 1.8 hour before the accident leading to injury (chapter 6). The inverse dose-response relationship between average daily alcohol consumption and injury risk in our study was very surprising and contradicts (biological) plausibility. We do not assume a causal relation, but habitual abstinence from alcohol may very well be an indicator of a yet unknown real cause of injury risk, possibly within the domain of personality. As we did not observe the actual alcohol intake, nor analyzed the blood or breath levels of our respondents, a alternative explanation could be selective underreporting by the cases of their amount of alcohol consumption. Some quantitative underreporting seems possible, but $i t$ is difficult to imagine that regular users of (some) alcohol would declare themselves teetotaller on a large scale. Although the percentages teetotallers differed ower the situation for which information on the alcohol intake was gathered, the cases reported to be a teetotaller in every instance more frequent than the controls (chapter 6).

An argument in favor of selective underreporting by the cases is that 12-18 months later the controls selected for our second study appeared to have a similar average weekly consumption, while cases reported two consumptions a week more. Statistical modelling of hypothetical selective underreporting in our data set produces a change of sign in the association between alcohol 
consumption and injury risk already under moderate assumptions (chapter 6). of course, this does not prove that our data on alcohol consumption are biased by selective underreporting indeed. The statistical modelling only shows the consequences of the assumption that such blas is present in the data. The same procedure of statistical modelling could have been performed for other putative risk factors for which selective misclassification is suspected (e.g. ability).

\section{Sensation seeking}

The main aim of the second study among a part of the respondents of the original case-control study, was to investigate whether differences in risk taking tendency between downhill skiers were an important risk factor for injury. For this purpose a validated translation of Zuckerman's Sensation Seeking scale was used (chapter 7) and the attention was focussed especially on the subscale dealing with thrill and adventure seeking (TAS). Skiers appeared to have a much higher TAS score compared to a Dutch reference population of the same age. The difference in TAS score between cases and controls was surprisingly the opposite of what was expected. It turned out that skiers who were more inclined to show risky behavior by definition actually got injured less often. An alternative explanation would be that skiers with a high TAS score are better at handling the risks of several forms of physical exercise and therefore less prone to accidents and injury, compared to those with a relatively low TAS score who may be less skilled at estimating the risks in downhill skiing. of course this is an ad hoc hypothesis, which should be tested in new studies preferably with a prospective design.

\section{other factors}

The observation that injury risk generally rose the greater number of hours of skilng planned during the holiday is certainly not implausible. The elevated risk $(O R=1.8)$ for skiers with a quetelet Index of 20 or less was never reported before (chapter 5). A possible (paxtial) explanation for this finding could be 
that relatively lightly built skiers are poorly protected by the current ski bindings. Another (ad hoc) explanation would be that body fat protects against the consequences of a fall. The observation that being afraid of an accident before the hollday has a preventive effect $(\mathrm{OR}=0.6)$ could be due to risk underestimation of fearless skiers. Our data confirm the elevated risk of the presence of icy spots $(O R=1.4)$, cloudless weather $(O R=1.7)$, the absence of cold $(O R=1.8)$ and good visibility $(O R=2.5)$ that was mentioned already by ather authors (chapter 5 and 8). An explanation for the relatively high risk during good skiing weather would be that skiers are more careful under sub-optimal weather conditions. Although all these items deal with days on which the respondents skied, it carnot be excluded that they skied fewer hours and/or took less difficult ski runs on days of less favorable weather.

\section{IMPLICATIONS FOR FUTURE STUDIES}

At the end of this dissertation it also seems appropiate to formulate what has been learned from the research project in a more general sense. Will we ever conduct a case-control study on the etiology of injury for skiing or other sports again, and can we advise others to do so? What would the design of our study look like, if we could start again with our current knowledge? Can we give some clear advice to those interested in health education with the practical purpose of lowering the incidence of ski injury? Are there any important lessons to be learned from the present study with respect to the design and conduct of research into the causes of other (sport) injuries? The purpose of this section is to formulate an opinion on questions such as these. For this reason the statements and remarks below, which are clearly outside the domain of the data we collected, should be looked upon primarily as theoretical considerations. In other words, we will try to indicate some frultul future studies and try to formulate certain methodological guidelines for these. 
Limitations

As mentioned in the discusition section of the chapters 2 to 8 , Imprecise measurement of a number of risk factors was one of the weak characteristics of our study. This was due to the fact that we measured all variables by means of a structured questionnaire. So we relled on the opinions of the skiers themselves; this also applies to factors for which different measurement procedures would have been more appropriate. Examples of these are binding adjustment and physical condition. More precise data on these variables, based on direct and more objective measurement of the phenomena at issue, would have made more precise conclusions possible with respect to these risk factors. In future studies precise measurement of the risk factors deserves considerable attention. Some of these can be measured more precisely retrospectively (e.g. binding adjustment), others more precisely only in a prospective design (e.g. physical condition), while the distribution of still other risk factars can only be known with adequate precision when they are manipulated in a experimental. design (e.g. nutrition).

The situation becomes more complicated when besides random measurement error non-random errors are also taken into account. As was shown in chapter 6 selective misclassification can lead to substantial bias in the measures of association. In case-control studies the resulting information bias can be a serious problem, particularly because blinding the respondents is almost impossible. Such bias can be expected in the measurements of variables that involve the respondent's perception possibly being colloured by the knowledge of having (or not having) a ski injury (e.g. ability and alcohol consumption). In several places of this dissertation we argued that the choice of our control group may have eliminated this type of bias to some extent, although this could have introduced some selection bias instead. The actual choice of our control group was in fact motivated by the circumstance that no random sample of the population at risk could be formed, because reliable information on the insured skiers was not available at the office of the insurance company. 
our choice (a claim for other reasons e.g. loss or theft), although possibly eliminating information bias to some extent, might have introduced some selection blas. For instance, it can be imagined that the 'thrill and adventure seeking' score (chapter 7) of our control group is higher than that of the average uninjured skier. A more radical and better solution to the issue of comparability of groups and risk factor measurement would have been to evaluate factors especially susceptible to non-random measurement errors in a prospective design.

\section{Prevention}

Ideally prevention in the form of for instance legislation or health education must be based on a sound knowledge about the etiology of the problem at issue. Furthermore, as far as health education is concerned, the quantitative contribution of behavioral risk factors under investigation ought to be substantial, and an effective manipulation of these factors must be feasible. An insight into the etiology of ski injury might stem from reasoning about plausibility, from laboratory experiments and from epidemiological studies. Examples in the first domain are the protective effect of helmets or a good physical condition. Laboratory experiments might involve for instance the adjustment of bindings and the design of ski boots. Chapter 4 for instance drew attention to the possibility of evaluating in laboratory studies the quality of binding adjustment in ski shops from different areas. Epidemiologlcal. studies might for instance clarify the role of ski lessons or the design of the ski run. Ideally these three sources of knowledge point in the same direction. Then an intervention trial, in which the factor at issue is manipulated under controlled conditions, is indicated. When the intervention appears indeed to be successful, intraduction on a large scale could be the next step.

Unfortunately, up to this moment only one intervention trial has been performed among downhill skiers ${ }^{1}$. This suggests that health education for downhill skiers on a large scale ought to be restricted to the few factors for which the causal role has been 
established beyond reasonable doubt, for instance binding adjustment and ski pole grips. In addition other factors might be considered, on the condition that health educators have a sound reason to believe that effective manipulation of these is Eeasible. In this respect consideration may be given specifically to advising beginners to take ski lessons. As far as the vast bulk of other putative risk factors is concerned, we feel that a very restrictive policy with respect to health education is appropriate. We do not agree with the habit of smothering the skiers with an avalanche of wellmeant preventive remarks. He do not think that effective prevention is possible in such a loose, aspecific way. Furthermore, we do not like the idea that some skiers might feel guilty about certain aspects of their behavior (e.g. moderate alcohol consumption) prenaturely decreed as dangerous by health educators.

\section{Intervention trials}

In epidemiology the strongest arguments for causality come from experimental studies, as was explained in chapter 2 . In a carefully chosen experimental design the groups of skiers compared differ only in their level of exposure to the risk factor at issue. For a number of practical and ethical reasons, experimental studies with respect to the etiology of ski injury are usually mot very feasible. The exception to this rule is formed by intervention trials in which a putative (behavioral) risk factor is manipulated towards (supposed) safety. As stated earlier, until now only the optimal adjustment of bindings and the use of different ski pole grips have been tested in an intervention trial the subject of a recent publication ${ }^{1}$.

Intervention trials are very expensive to conduct, mainly because of the large numbers required to reach statistical significance for effects that would be considered relevant. This is the consequence of the relatively low incidence of the outcome of interest, that is ski injury. Moreover, most preventive measures are designed to prevent only a specific class of ski injuries (e.g. injury of the thumb) for which the incidence is even lower. 
In chapter 2 a solution to this problent has been suggested in the form of creatively chosen alternative outcomes with a much higher incidence (e.g. a certain subcategory of falls). However, in such instances the investigator is still obliged to "prowe" that this alternative outcome is a valid indicator of the specific class of ski injuries at interest. Quantification of injury risk associated with the factor at issue will be especially difficult while using an alternative outcome measure.

For practical purposes intervention trials might only be considered when the risk factor at issue seems to be open to effective manipulation. Furthermore, the quantitative contribution of a factor to ski injury risk must be judged substantial by arguments originating from plausibility, laboratory studies and non-experimental epidemiological studies. Future intervention trials might involve other aspects of the equipment (e.g. new types of boots or bindings for children), skil lessons for beginners or courses in ski gymnastics. In these examples, placebo interventions are not feasible or might be considered unethical. Therefore, comparability of effect measurement and of external circumstances in these experimental studies must be ensured by other means. Furthermore, the contrast between the intervention group and the control group deserves special attention. Depending on the factor at issue, the best choice for the control group might be the situation without intervention (e.g. currently available ski boots for children) or an alternative intervention (e.g. comparing "normal" skil lessons to ski lessons th special attention to safety).

\section{Non-experimental studies}

For risk factors that are not open to manipulation in an intervention trial and for risk factors not studied before in some depth, further non-experimental studies might be considered. Case-control studies in this field can be improved by more precise measurements, adjustment for confounding in multivariate analysis and the use of more informative measures of association. 
Further improvements can be expected from the use of external sources of data (e.g. on the weather, snow quality, characteristics of the ski area). But for a number of risk factors information bias will remain a serious threat to validity of the case-control data. Therefore, follow-up studies (prospective cohort studies) are necessary in order to increase our knowledge about the tiological impact of these factors. These studies also have the advantage of providing incidence flgures. The precision of these figures can be further augmented by asking the skiers in the cohort to note their daily exposure (ski hours) in a diary. Follow-up studies are rather expensive and require a lot of administrative support. As has been explained in chapter 2, large numbers of skiers are required to reach statistical significance for the effects that would be considered relevant. The efforts can be diminished somewhat by analyzing the cohort data in a case-control format (see chapter 2).

In instances where the optimal measurement of the risk factor at issue is expensive or time consuming (e.g. physical condition), the same modifications in the outcome parameter that are adwocated above for intervention trials might be considered in follow-up studies. Other examples that seem open to investigation in a follow-up study are aspects of personality (e.g. sensation seeking), nutritional habits and alcohol consumption.

\section{Registration}

Registration projects of sports injuries provide at best only very rudimental information with respect to etiology. Actually, registration can be viewed as a case-series extended in time. ${ }^{2}$ When the corresponding population 'at risk' is known with some precision, registration systems can also provide incidence figures and detect time trends in them. Registration of sports injuries seems especially relevant in order to estimate the impact on the health care system and to assess the costs for the individual and the society. Nevertheless, we do not consider registration systems to be very useful in evaluating preventive 
measures. Ecological time trends studies are susceptible to all the types of bias mentioned in this dissertation. Furthermore, an extra opportunity for bias is created, because comparisons are made on an aggregated level and not on the level of the individual participants ('ecologic fallacy'). For etiological purposes registration seems to us to be a bad cholce, because considerable effort results in very little information. Wth respect to ski injuries, it is our opinion that the current monitoring systems ${ }^{3}$ already provide enough information on incidence and time trends (see also chapter 8).

Recently in the Netherlands a proposal was formulated for a general registration system for sports injuries. In fact this system has the design of a follow-up study. ${ }^{4}$ In the proposal a heterogeneous cohort of sportsmen and women is to be established so that it can subsequently be followed over time. A large amount of information on the participants will be gathered, partly before the start of the follow-up, partly durimg the study. Although a lot of interesting descriptive information may be collected this way, it is doubtful whether this project will increase our knowledge about the etiology of sport injuries substantially. As a consequence the clues for preventive measures from this registration project will probably also be very limited. The main reason for this is that the same questions wil be asked for all sports, for all injuries and for all situations. We do not consider it very meaningful to study the etlology of sports injury in general, and it is unclear whether this registration system wil include enough cases of a speciflc sport injury in order to make separate subgroup analyses feasible. Furthermore, it is improbable that all the relevant items for the sport at issue will be included in the questionnaire. For etiological purposes we would prefer separate studles designed with the alm of answering some specific questions with respect to (a specific class of) injury among participants of one sport. 
MOTES

1. W. Hauser. Experimental prospective skiling injury study " Paper presented at the Eight International Symposium on Ski Trauma and Skiling Safety, Chamonix, France, 1987.

2. S.D. Walter, J.R. Sutton, J.M. McIntosh \& C. Connolly. The aetiology of sport injuries: a review of methodologics. Sport Medicine 2 (1985) 47-58.

3. J.E. Shealy. Use of statistics in identifying problems in ski injury research. In: R.J. Johnson \& C.D. Mote (eds.) Skiing tratuma and safety. Philadelphila, ASTM, 1985, pp.285-292.

4. H. Schlatmann, H. Hlobil, W. van Mechelen \& H. Kemper. Naar een registratiesysteem van sportblessures in Nederland. Oosterbeek, NISGZ publicatie nr. 24, 1986. 
The introduction to this dissertation (chapter 1) states that the central subject is the etiology of injury in downhill sking and provides some background information on the origins of the study. The primary purpose of the case-control study conducted anong Dutch downhill skiers is a further dissection of the causal network leading to ski injury. In this context special attention will be given to methodological considerations in the design of the relevant experimental and non-experimental studies. Information is provided on the original presentation and publication of the material covered in this dissertation. In conclusion the structure of the dissertation is explained and an indication is given of the contents of the chapters.

Chapter 2 provides a short introduction to the methodological framework for experimental and non-experimental studies into the etlology of ski injury. It explains that for this purpose it is necessary to study the incidence rate of ski injuries as a function of its risk factors. Central issues in epidemiological studies into this matter are comparability of baseline prognosis, comparability of measurements and comparability of external circumstances. In experimental studies these may be achieved by randomization, blinding and placebo intervention. The main tools to prevent incomparability in non-experimental studies are deliberate selection and multivarlate analysis. An outline is given of the design of experimental studies that have increased efficiency. As for case-control studies, special attention is paid to the definition of the source population and possible ways to reduce measurement incomparability.

Chapter 3 presents the results from our case-control study with respect to ability and physical condition as potential risk factors. This study was performed by way of a postal questionnaire among Dutch downhill skiers insured by a company covering one third of the market. Cases $(\mathrm{M}=572)$ were a sample of those who claimed medical costs as a result of a ski injury that 
prevented them from skiling or other activities for one day or longer. Controls $(\mathrm{N}=576)$ tere a sample of uninjured skiers who claimed for non-medical reasons. Response was over $80 \%$.

self-reported beginners appeared to hawe an elevated injury risk $(O R=2.1)$ compared to intermediate or advanced skiers. Among skiers with only one or two years of experience ski lessons seemed to have a preventive effect. No beneficial effect on injury risk could be demonstrated for training on an artificial ski run, ski gymnastlcs, a good physical condition or sports participation.

Chapter 4 focusses on the characteristics of ski and binding as risk factors. Prior to this, data on the type and severity of the injuries included in our study are presented. Time-trend studies suggest that the use of modern equipment and an adequate adjustment of the ski binding had a preventive effect in the recent past. The question at issue is whether a further decrease of injury figures can still be expected from a better adjustment. No release of both bindings directly prior to injury was associated with a higher risk $(O R=3.3)$ for lower extremity injury in our study. The proportion of no release is highest for knee injuries. Binding release prior to lower extremity injury was highest (31\%) among those for whom adjustment was performed with the use of a test device. No effect on injury risk could be found for the moment of adjustment, the method of adjustment and the person performing the adjustment. Direct measurement of binding function seems indispensable. The use of rented or borrowed skis was associated with a higher risk $(\mathrm{OR}=1.9)$ for lower extremity injury. The same holds for ignorance concerning the type of ski and the age of ski and binding. It is concluded that binding adjustment still seems to be a risk factor open to manipulation.

Chapter 5 deals with personal and envirommental risk factors for ski injury. Prior to this, data on the circumstances of the accident leading to injury for the cases in our study are presented. Most accidents happened on the pistes and ski lifts were involved in about $6 \%$ of them. Bad condition of the ski run and loss of balance were the direct causes most frequently 
mentioned. Injury risk for the individual appeared to rise with increasing duration of exposure, although very short durations had an elevated risk as well. A relatively low risk was observed for skiers who reported to be only moderately rested $(0 \mathbb{R}=0.4)$ and for those who admitted to be somewhat afraid of having a ski accident $(O R=0.6)$. A relatively high risk was observed for the presence of icy spots ( $O R=1.4)$, while poor visibility $(O R=0.4)$, the presence of clouds $(O R=0.5)$ and perceived coldness $(O R=0.5)$ were associated with a relatively low injury risk. No recommendations for prevention are made on the basts of these results. Most of these factors are not open to manipulation and further quantification should involve prospective study designs and independent measurements of the relevant factors.

Chapter 6 focuses on alcohol consumption as a risk factor. Although a causal role seems plausible, the sparse empirical data in the literature suggests that the prevalence of high blood levels of alcohol at the moment of the accident is very low. In our study $11 \%$ of the male and $3 \%$ of the female cases of injury report on average 1.2 consumptions almost 2 hours before the accident. Surprisingly, cases reported to drink in general less than controls. This holds for the month before the ski holliday, the average daily number of consumptions during the hollday (cases 2.4; controls 3.0) and for drinking during the breaks. There even appeared to be an inverse dose-response relationship. However, a real preventive effect of alcohol seems improbable. While controls reported a similar weekly alcohol intake one year later, cases reported on the average two consumptions a week more. Furthermore, simulation of selective randon underreporting by the cases supports the idea that the negative association of alcohol consumption and injury risk could be the consequence of information bias. Our conclusion is that alcohol is probably neither a substantial risk factor, nor a protective factor for ski injury.

Chapter 7 presents the results from a later study conducted among a part of the population of downhill skiers selected from our original case-control study. A validated Dutch version of 
Zuckerman"s sensation seeking (SS) scale was sent to these skiers. It was expected that injured skiers $(\mathrm{N}=219)$ would have higher thrill and adventure seeking. (TAS) scores compared to the control group of uninjured skiers $(N=288)$. Information on other risk factors for injury, as measured in the earlier study among the same skiers, was included in the logistic model in order to adjust for confounding. Response (73\%) was slightly higher among females, young skjers and higher educated persons. Skiers turned out to have a high TAS score compared to a Dutch reference population. The observed correlations between SS subscales, as well as the trends associated with age and gender were in full agreement ith the 1iterature. Surprisingly, TAS scores were lower among the cases compared to the control group. Adjustment for other risk factors for ski injury in the logistic regression does not change the effect of the TAS score substantially. It is postulated that skiers with a high TAS score could be more experienced in balancing on the limit of their individual capacities. Further research into this problem, preferably with a prospective design, is recommended.

Chapter 8 summarizes the current state of knowledge with respect to the etiology of injury in downhill skiing. In this overview the results of our own studies are also taken into account. Firstly, the literature on the incidence and the distribution of injury is reviewed. Subsequently, attention focusses on the main categories of risk factors and on the possibilities for prevention. The incidence of serious ski injuries ranges from 2 to 4 per 1000 skiers days. In some $55 \%$ of the injuries the lower extremities are involved. Being a beginner is risky, but taking ski lessons probably lowers this risk to some extent. There is 1ittle doubt that adequate adjustment of the ski binding can lower the incidence of lower extremity injury further. Also improvements in the design of boots, bindings and ski poles can probably make skilng safer. Little is known about putative risk factors concerning behavior and the environment. Some methodological remarks are made with the aim of improving the quality of future studies. 
Chapter 9 provides a discussion of the material covered by this dissertation. The first part summerizes our main findings and interprets them against the background of the available data on the subject. Thus the contribution of our study to the dissection of the causal network leading to ski injury is made explicit. The second of the general discussion formulates what has been learned from the research project in a more global sense. Imprecise measurement of a number of risk factors seems to be the most prominent weakness in our study. Information bias was another important source of validity problems. Suggestions are made to avoid these flaws in future studies. It is pointed out that some risk factors can only be investigated adequately in a prospective design. Proposals are formulated for future follow-up studies and intervention trials with the aim of increasing our knowledge with respect to the etiology of injury in downhill skiing further. The opinion is given that prevention by means of legislation or health education ought to restrict itself to the small number of risk factors for which an important causal contribution is already established beyond reasonable doubt. Furthermore, it is argued that no significant contribution to our knowledge about the etiology of sports injury can be expected from registration systems. 
SAMENVATTING

Hoofdstuk 1 geeft de inlelding tot dit proefschrift. Daarin vordt gesteld dat het centrale onderwerp de etiologie van skiletsel is. Verwolgens wordt enige achtergrondinformatie over het ontstaan van het betreffende onderzoeksproject verschaft. Het patiëntcontrole onderzoek onder Nederlandse alpine skiërs werd met name verricht on een nader inzicht te krijgen in het netwerk van oorzaken dat leidt tot letsel. In deze context wordt in deze dissertatie tevens aandacht besteed aan de methodologische overwegingen die een rol spelen bij het opzetten van hiertoe relevante experimentele en niet-experimentele studies. Er wordt aangegeven war het materiaal warop dit proefschrift betrekking heeft werd gepresenteerd en gepubliceerd. Tot slot wordt de opbouw van de dissertatie toegelicht en wordt kort uitgelegd wat de Inhoud is van de verschillende hoofdstukken.

Hoofdstuk 2 biedt een korte introductie in de voor de bestudering van de etiologie van skiletsel relevante methodologische principes die gelden bij het opzetten van experimentele en niet-experimentele studies. Er wordt uitgelegd waarom de incidentie van skiletsel dient te worden bestudeerd als een functie van risicafactoren. Vergelijkbaarheid van de prognose van de groepen aan het begin van de studie, van de metingen en van de externe onstandigheden, zijn cruciaal in epideniologisch onderzoek op dit terrein. In experimenten kan deze vergelijkbaarheid worden bewerkstelligd met behulp van randomizatie, blindering en placebo interventie. De belangrijkste hulpmiddelen om vergelijkbaarheid te verkrijgen in niet-experimenteel onderzoek zifn selectie en multivariate analyse. Er wordt aangegeven op welke wijze de efficièntie van experinenteel onderzoek kan worden vergroot. Met betrekking tot patient-controle onderzoek wordt in het bijzonder aandacht besteed aan het nawweurig omschrijven van de populatie waaruit de onderzochte skiers voortkomen en aan manieren om een gebrekkige vergelijkbaarheid van de metingen te voorkómen. 
Hoofdstuk 3 presenteert de resultaten ust ons patient-controle onderzoek met betrekking tot vaardigheid en lichamelijke conditie als potentiele risicofactoren. In het onderzoek werd een schriftelijke vragenlijst verzonden aan Nederlandse skiërs die zich hadden verzekerd bij een matschappij die een derde wan de markt voor wintersport verzekeringen bestrijkt. De patiënten $(\mathrm{N}=572)$ vormden een steekproef van degenen die een claim indienden voor medische kosten die waren gemaakt tengevolge van letsel dat skiën of andere aktiviteiten voor één dag of langer onmogelijk maakte. De controlegroep $(N=576)$ bestond uit personen zonder letsel die een claim indienden om andere redenen. De respons was ruim $80 \%$. Beginners bleken een verhoogd ongewalsrisico $(O R=2.1)$ te hebben in vergelijking tot middelmatige of gevorderde skiërs. Onder skiërs met slechts éen of twee jaar ervaring bleek skiles een preventief effect te hebben. Voor training op een kunstskibaan, skigymnastiek, een goede lichamelijke conditie en deelname aan andere sporten kon geen preventief effect op het ongevalsrisico worden aangetoond.

Hoofdstuk 4 gaat in op de vraag in hoeverre bepaalde eigenschappen van ski en binding werkzaam zijn als een risicofactor. Voorafgaand hieraan wordt een overzicht gegeven van de aard en ernst van het letsel bij de patiënten uit onze studie. Tijdstrend studies maken aannemelijk dat in het recente verleden het gebruik van een moderne uitrusting en een adequate afstelling van de skibindingen een preventief effect sorteerden. Het is de vraag of een betere afstelling wan de bindingen het incldentle cijfer nog steeds verder kan terugdringen. Het niet-losgaan van de bindingen vlak voor het ontstaan van het letsel bleek in onze studie te zijn geassocieerd met een hoger risico ( $\mathrm{R}=3.3)$ voor letsel aan de onderste extremiteiten. Onder skiërs waarvan de afstelling van de bindingen was gecontroleerd met een test-apparaat, was het percentage dat open ging vlak voor het ontstaan van letsel aan de onderste extremiteiten het hoogste $(31 \%)$. De proportie niet-opengaande bindingen bleek het hoogste te zijn onder patienten met knieletsel. Van het moment van afstellen, de daarbij gehanteerde methode en van de persoon die de afstelling verrichtte, kon geen effect op het ongewalsrisico worden aangetoond. Directe meting 
van het functioneren van de bindingen lijkt onmisbaar te zijn. Het gebruik van geleende of gehuurde ski's ging samen met een hogere kans op letsel aan de onderste extremiteiten (OR=1.9). Hetzelfde gold voor onbekendheid met het type ski en de leeftijd van de ski"s en bindingen die werden gebruikt. De conclusie luidt dat het afstellen van de bindingen nog steeds een manipuleerbare risicofactor lijkt te zijn.

Hoofdstuk 5 heeft betrekking op risicofactoren die samenhangen met de persoon en met de omgeving. Voorafgaand hieraan wordt een overzicht geboden van de omstandigheden waronder het letsel ontstond bij de patiënten uit onze studie. De meeste ongevallen vinden plaats op de piste en in $6 \%$ van de gevallen is een skilift erbiy betrokken. Als directe oorzaak werden een slechte toestand van de piste en het verliezen van het evenwicht het meest frequent genoemd. Het risico bleek te stijgen bij een toenemende blootstelling, maar ook woor een extreem korte blootstelling werd een verhoogd risico gevonden. Een relatief laag risico werd wargenomen onder skiërs die verklaarden slechts matig zijn uitgeslapen $(\mathrm{OR}=0.4)$ en voor degenen die toegaven een beetje bang te zijn voor een ongeval $(O R=0.6)$. Een relatief hoog risico werd gevonden bij aanwezigheid wan ijzlge plekken $(O R=1.4)$, terwijl slecht $z i c h t(O R=0.4)$ ), bewolking ( $(O R=0.5)$ en koude ( $O R=0.5)$ juist met een relatief laag risico bleken te zijn geassocieerd. op basis van deze bevindingen worden geen preventieve aanbevelingen gedaan. De meeste van deze factoren staan niet open voor mantpulatie. Een nadere kwantificering van de invloed van deze factoren moet worden gezocht in een prospectieve opzet, zo moge$11 j k$ met behulp van onathankelijke metingen.

Hoofdstuk 6 beschouwt in hoeverre alcohol een risticofactor is. Hoewel een oorzakelijke rol plausibel is, lijkt de prevalentie van een hoge bloedsplegel op het moment van het ongeval op grond van de schaarse beschikbare literatur erg laag te zijn. Zo"n 11\% wan de mannelijke en $3 \%$ van de vrouwelijke patiënten rapporteerden gemiddeld 1,2 consumptie ongeveer 2 uur voor het ongeval. Tot onze verrassing bleek dat patiënten over het algemeen zeiden minder te drinken dan controlepersonen. Dit gold voor de maand 
voor de wintersport, de gemiddelde dagelijkse consumptie tujdens de vacantie (patienten 1,4 en controles 3,0 ), alsmede voor het alcohol gebruik tijdens pauzes. Er bleek zelfs een inverse dosisrespons relatie te bestaan. Toch 1 ijkt een werkelijk preventief effect van alcohol erg onwarschijnlijk. Hoewel controlepersonen een jaar later eenzelfde wekelijkse consumptie rapporteerden, meldden patiënten gemiddeld twee consumpties per week meer. Ook simulatie van selectieve random onderrapportage door de patienten ondersteunt de veronderstelling dat de geobserveerde negatieve associatie tussen alcoholgebruik en letsel zou kunnen berusten op informatie-bias. Onze conclusie is dat alcohol vermoedelijk geen bellangrijke risicofactor, maar ook geen beschermende factor is voor skiletsel.

Hoofdstuk 7 presenteert de resultaten van een vervolg-studie die werd gehouden onder een deel van de skiërs uit ons oorspronkel1jke patiënt-controle onderzoek. Een gevalideerde Nederlandse versie van de spanningsbehoeftelijst (SBL) van Zuckerman werd aan deze skiërs toegezonden. De verwachting was dat de patiënten $(\mathrm{N}=219)$ hoger zouden scoren dan de controlegroep $(\mathrm{N}=288)$ op de subschaal die ingaat op 'thrill and adventure seeking" (TAS). Om te corrigeren voor confounding werd ook informatie over andere risicofactoren die was verzameld in de eerdere studie opgenomen in een logistisch model. De respons (73\%) was iets hoger onder vrouwen, jongeren en hoog opgeleiden. De skiërs bleken een hoge TAS score te hebben in vergelijking tot een Nederlandse referentiepopulatie. Zowel de correlaties tussen de subschalen van de SBL, als de waargenomen trends naar leeftijd en geslacht, kwamen goed overeen met wat in de literatuur hierover werd gevonden. Tot onze verrassing bleken de TAS scores van patiênten lager te zijn dan die in de controlegroep. Correctie voor de bijjdrage van andere risicofactoren in het logistische model veranderde hier weinig aan. Tot slot wordt de veronderstelling geuit dat skiërs met een hoge TAS score wellicht meer ervaren zijn in het balanceren op de grens van hun individuele capacitelten. Nader onderzoek hiernaar, bij vorkeur met een prospectleve opzet, wordt aanbevolen. 
Hoofdstuk $B$ vat de huidige kennis met betrekking tot de etiologie van sklletzel samen. ook de resultaten van onze eigen studies worden in dit overicht betrokken. Allereerst wordt de literatuur over de incidentie en de aard van het letsel samengevat. Vervolgens wordt de aandacht gericht op de literatuur over de belangrijkste categorieën risicofactoren en de mogelijkheden voor preventie. De incidentie van serieus skiletsel ligt tussen de 2 en de 4 per 1000 skidagen. In 55\% wan de gevallen zijn de onderste extremiteiten aangedaan. Beginner zijn is riskant, maar vermoedelijk kan het nemen wan skiles dit risico enigszins verminderen. Er bestaat weinig twijfel aver dat een adequate afstelIing van de skibindingen het ongevalsrisico kan verminderen. Ook verbeteringen in het ontwerp van skischoenen en skistokken kunnen naar alle warschijnlijkheid het skien veiliger maken. $\operatorname{Er}$ is weinig bekend over de veronderstelde risicofactoren op het gebied van het gedrag en de omgeving. Tot slot worden er een aantal methodologische opmerkingen gemaakt, teneinde de kwalitelt van toekomstige studies te verhogen.

Hoofdstuk 9 bevat de discussie over de thematiek van dit proefschrift. Het eerste gedeelte vat onze voornaamste bevindingen samen en geeft een interpretatie ervan tegen de achtergrond van de bestaande empirische gegevens over het onderwerp. Daarmee wordt de bijdrage van het in deze dissertatie beschreven onderzoek aan het ontwarren van het causale netwerk dat leidt tot skfletsel expliciet gemaakt. In het tweede deel van de algemene discussie wordt getracht om lering te trekken uit ons onderzoeksproject in meer algemene $z$ in. De weinig precieze meting van een aantal risicofactoren lijkt het meest zwakke punt van onze studie te zijn. Informatie-bias was een andere belangrijke bedreiging van de validiteit. Er worden suggesties gedaan om de tekortkomingen te voorkómen in toekomstig onderzoek. Een aantal risicofactoren kan uitsluitend in een prospectief design adequaat worden onderzocht. Voorstellen voor toekomstige follow-up en interventie studies worden geformuleerd, met als doel een verdere groei van de kennis omtrent de etiologie van skiletsel. Voorts wordt gesteld dat preventie door middel van voorschriften en gezondheidsvoorlichting en -opvoeding (GVO) beperkt dient te blijuen tot de 
risicofactoren waarvan een kwantitatief relevante causale rol boven redelijke twijel is verheven. Van registratiesystemen van sportblessures wordt weinig werwacht met betrekking tot nader inzicht in de etiologie. 
WOORD VAM DANK

Omdat de academische folklore vereist dat slechts de nam van de promovendus wordt genoemd op het titelblad van een proefschrift. zou de indruk kunnen ontstaan dat een dissertatie het werk van én persoon is. Het tegendeel is waar. Velen hebben bij het opzetten, uitwoeren en analyseren wan het hier beschreven onderzoek een bellangrijke directe of indirecte roll gespeeld.

In de eerste plaats gaat mijn dank wit naar alle anonieme skiërs die bereld waren om uitvoerige vragenlijsten in te vullen. Ook zonder de medewerking van de ANWB en Unigarant was het onderzoek op deze wijze niet mogelijk geweest. Met name de enthousiaste unzet van René de Groot \# Jan Philippa en Peter Houtman werden zeer gewaardeerd. Binnen de vakgroep zijn Myra Pereboom, Ad Vissers, Eric van Rossum, Sacha van de Crommert en Monique Koekkelkoren behulpzaam geweest bij het coderen en analyseren van de gegevens. Dankzij hen kon ik me al snel concentreren op het schrijven wan artikelen. Deze werden vervolgens op professionele wijze op tekstverwerker gezet en veelvuldig aangepast door Thum Aarts, Riny Bodifée en Lia Gray. Zonder hen was thet nooit zo' $n$ mooi boekje geworden. Bijzonder waardevol waren de adviezen met betrekking tot de stijl en spelling van de engelstalige artikelen die werden gegeven door Bob Wilkinson.

In elke fase van het hier beschreven onderzoek ontwing ik meer dan adequate steun van mijn promotor. Hij was de drijvende kracht wanneer de voortgang even stokte en zette de puntjes op de "il" war nodig. Los daarvan ben ik Paul knipschild met name erkentelijk voor de wijze warop hij me enthousiast heeft genakt voor het vak. Aan zijn wetenschappelijke creativiteit en opbouwende kritjek op een groot aantal van mijn concept-artikelen heb ik veel te danken. Maar bovenal ben ik hem gaan waarderen als een eerlijk en loyaal collega.

ook de andere co-auteurs van de in deze dissertatie opgenomen artikelen hebben meer dan hun steentje bijgedragen. Van Lex Volowics heb ik veel geleerd over de statistische aspecten van 
het analyseren van onderzoeksgegevens. Hoewel ik soms wel eens mopperde op het lange wachten, hebben hij, Marion de Leeuw en Marcel Theunissen me toch veel werk uit handen genomen. Jan Feij ben ik erkentelijk voor de adequate wijze waarop hij behulpzaam was bij het meten vañ de spanningsbehoefte van de skiërs.

Martien van Dongen en Bart Koes wil ik danken voor het felt dat ze bereid waren om de hoofdzakelijk decoratieve rol van paranimf te vervullen. Met hen werk ik momenteel het meest intensief samen op het gebied van respectievelijk onderwijs en onderzoek. Het feit dat ik hen als paranimf heb gevraagd, symboliseert bowendien de stimulerende en vriendschappelijke sfeer binnen de vakgroep. Dok de hier niet met name genoemde collega's hebben er in belangrijke mate aan bijgedragen dat het werken aan dit proefschrift overwegend een genoegen was.

En op de momenten dat het dat niet was, was Mayke Arts er om me op te vrolijken met har onverwoestbare humeur. Achter de coulissen was $z i j$ op emotioneel gebied de co-auteur van dit proefschrift. Tot slot, maar zeker niet in de laatste plaats, wil ik mijn ouders danken voor hun levenslange steun en vertrouwen. zonder hen was het allemal heel anders gelopen. 


\section{LEVENSLOOP}

De auteur van dit proefschrift werd op 24 Januari 1956 te Rotterdam geboren. Aan het Christelijk Lyceum te Dordrecht werd in 1974 het Atheneum B diploma behaald. In 1982 werd de studie Medische Biologie aan de Rijksuniversiteit Utrecht, met als hoofdvak Humane Fysiologie en als bijvakken Sociale Geneeskunde en Didacthek wan de biologie, cum laude afgesloten. Tijdens de studie werd een aantal student-assistentschappen in de Anatomie en in de Psychofysiologie vervuld. Van 1982 tot en met 1984 was de auteur werkzam als docent Gezondheidskunde aan het Moller Instituut te Tllburg en de Stichting Opleiding Leraren te Utrecht. In 1984 werd hif aangesteld als universitair docent bij de vakgroep Epidemiologie/Gezondheidszorgonderzoek binnen de Faculteit der Gezondheidswetenschappen van de Rijksuniversiteit Limburg. Zijn postdoctorale scholing tot epidemioloog bestond, naast de éducation permanente binnen de eigen vakgroep, ondermeer uit deelname aan cursussen van dr. D.G. Kleinbaum en prof. dr. 0.S. Miettinen. In 1984 heeft de auteur (samen met dr. C.J.A. van Keulen) een leerboek Anatomie en Fysiologie gepubliceerd, en in 1988 is van zijn hand (samen met Ir. M.C.J.M. van Dongen) een leerboek Epidemiologile verschenen. Vanaf 1983 heeft hij artikelen gepubliceerd in diverse tijdschriften over ondermeer de gevolgen van stress, gezondheidseducatie, interventie-onderzoek, de epidemiologie van sportongevallen en de effectiviteit van fysiotherapie. 



\section{Sportwetenschappelijke Onderzoekingen}

1. Dr. M.P. van den Heuvel

Sport in de Sovjetunie

ISBN 9060760735

2. Dr. B.J. Crum

Aan sport georiënteerd bewegings. onderwijs

3. Dr. H. Kuipers

Variability of physiological respon. ses to exercise

ISBN $906076188 x$

4. Dr. H.A. Keizer

Hormonal responses in women as a function of physical exercise and training

ISBN 9060761855

5. Drs. H.H. van der Brug/H. Marseille Achtergronden van vandalisme bij voetbalwedstrijden

6. Dr. B.P.L.M. den Brinker

E.M.G..feedback bij revalidatie Het toepassen van myofeedback bij stoornissen in het bewegingsapparaat

ISBN 9060762118

7. Dr. J.W.I. Tamboer

Mensbeelden achter bewegings. beelden

Kinantropologische analyses

ISBN 9060762126

8. J.M.M. Swinkels/

D.J.W. Langenbach (eds.)

Movement analysis by computer for the explosive events in track and field

ISBN 9060762215
9. Drs. R.C. van Lummel/

M.L.M.P. Haane

Gehandikapten op het clos?

ISBN 9060762363

10. Dr. W.C.C. van Galen

Overtredingen en strafzaken in het amateurvoetbal

ISBN 9060762487

11. Dr. H.H. van der Brug

Voetbalvandalisme

Een speurtocht naar verklarende factoren

ISBN 9060762509

12. Dr. R. Verschuur

Daily physicall activity and health

Longitudinale veranderingen $t_{i j}$ dens de tienerjaren

ISBN $906076269 X$

13. Dr. J.E. Hueting e.a.

Experimenteel onderzoek naar de invloed van hormonen (ACTH en bijnierschorshormonen) op de maximale prestaties van beroepsrenners ISBN 9060762894

14. Dr. L.M. Bouter Injury risk in downhill skiing

Results from an etiological casecontrol study conducted among Dutch skiers

ISBN $906076272 X$

15. Dr. F.J.P.H. Brouns

Food and fluid related aspects in highly trained athletes ISBN 9060762916

\section{Uitgeverij De Vrieseborch - Haarlem}

